\title{
Community, Forest Carbon \& Indigeneity: A Case Study of the Loru Project in Espiritu Santo, Vanuatu
}

\author{
Bridget Hannah Payne
}

A thesis submitted to Te Herenga Waka-Victoria University of Wellington in partial fulfilment of requirements for the degree of Master of Development Studies

School of Geography, Environment and Earth Studies

Te Herenga Waka-Victoria University of Wellington 


\section{Abstract}

Forest carbon farming offers customary landowners an alternative livelihood to socially and environmentally unsustainable logging, through the sale of carbon offset credits. REDD+, the global forest carbon scheme to address deforestation in developing countries, has attracted scholarly criticism for the risks it poses to communities. Critics warn that REDD+: (1) benefits may be captured by elites, (2) threatens forest-dependent livelihoods, (3) reduces local forest governance, and (4) a results-based payments mechanism can undermine conservation. Community-owned forest carbon farming may mitigate these risks by empowering communities to manage forest resources locally. The Loru project in Vanuatu is the first of its kind, and Indigenous landowners legally own the carbon rights and manage the carbon project. This thesis examines the community ownership and the social impact of the Loru project on its Indigenous project owners, the ni-Vanuatu Ser clan. The thesis uses a 'semi'mixed-methods approach, based primarily on interviews conducted in in Espiritu Santo, Vanuatu with Indigenous landowners and supplemented with quantitative data from a monitoring exercise conducted by the author. Grounded in social constructivism, the thesis makes a genuine attempt to decolonize the research process, adopting a self-reflexive approach. The research finds that the project is leading to positive social and economic impacts at the community level. Further, the Loru project is legitimately community-owned and driven, meaning it adapts effectively to the local context. Overall, the findings suggest that implementing REDD+ through a multi-scalar institutional network and building local capacity could mitigate the risks of REDD+ to forest communities.

Keywords: REDD+, forest carbon farming, Payment for Ecosystem Services, deforestation, Indigenous peoples, forest-dependent peoples, climate change mitigation, Vanuatu, decolonizing methodologies 


\section{Acknowledgements}

Thank you to the Ministry of Foreign Affairs and Trade for the Field Research Award without which, none of this research would have been possible.

My supervisors Ralph and Warwick, thank you for the many flat whites and reading all my emails which had too many exclamation marks.

Sean and Anjali. I had hoped that I could write a thesis with real world relevance-thank you for making that happen. Your compassion and dedication break through an industry so filled with criticism and paralysis. Your ability to make real change is inspiring.

To my family: Mum, Dad, Jack, Kath and Des. For supporting me unconditionally despite not knowing how forest governance could be so complicated. Thanks for listening and brainstorming forest puns.

My colleagues and managers, Heather, Ryan Kerr, Ryan Krug, Adrienne and Timon. Thanks for your interest and flexibility despite my attention often being divided at work. Having a supportive workplace was invaluable.

To the cave dwellers of CO115: Lauren, Lizzie, Jessie, Penny, Finn, Tess, Isabella, Anna. You are my best friends and a world-class support group. I couldn't imagine a better group to write a thesis alongside.

And the rest of the SGEES whanau. Thanks for your ability to rant about thesis but also maintain rich interesting lives. I can't wait to see where you all are in a few years and the better world you will help create.

The beautiful community of Khole village. Thank you for inviting me into your lives with open arms. Thank you for sharing your homes, your kaekae and your time. Your love for your land and your family is infectious. Thank you to Serge for showing me around, Janice for your hospitality and storian, Chief Skip for your welcome, Rhonda for your sisterly support translating, Rachel for your cooking. And congratulations Diana on your new baby. Tankyu tumus long Ser famli.

The Live \& Learn Port Vila office. Thank you for your help and friendship despite my lousy volleyball. 


\section{Table of Contents}

Abstract......................................................................................................................

Acknowledgements...................................................................................................

Table of Acronyms .................................................................................................. viii

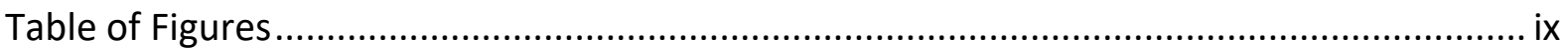

Table of Tables .............................................................................................................

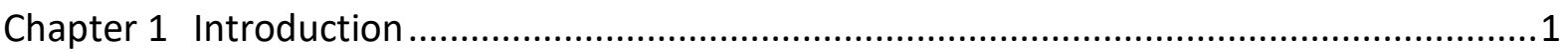

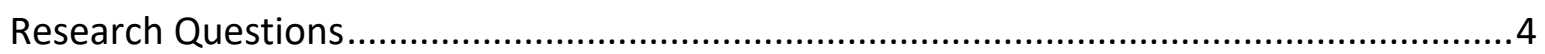

Chapter 2 Deforestation in the global South ...................................................................

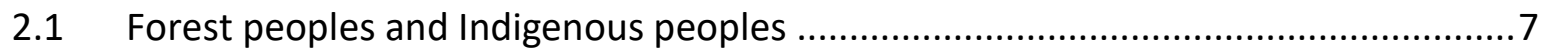

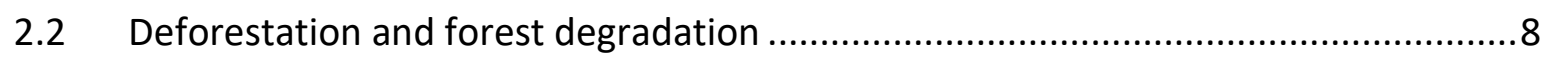

2.3 Drivers of deforestation and forest degradation ...................................................

2.3.1 Export-led deforestation and forest degradation ..........................................10

2.3.2 Deforestation and forest degradation due to shifting cultivation ....................12

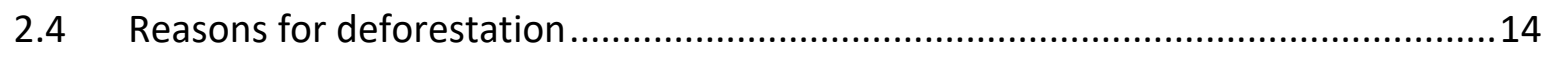

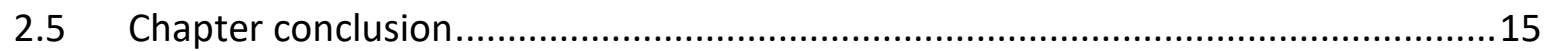

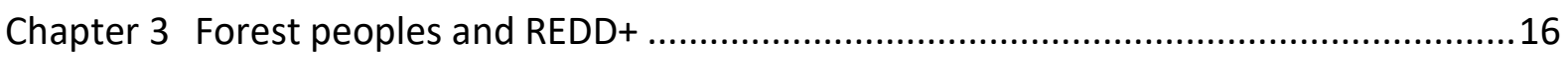

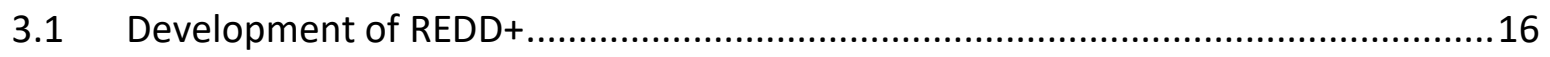

3.2 Risks of REDD+ to forest peoples ....................................................................17

3.2.1 Centralisation of forest governance ........................................................18

3.2.2 Elite capture of benefits.........................................................................19

3.2.3 PES mechanism undermines forest conservation .........................................21

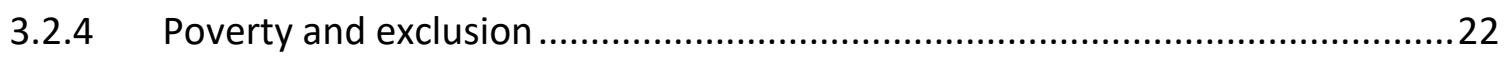

3.3 Community Forest Management and REDD+ ..................................................23

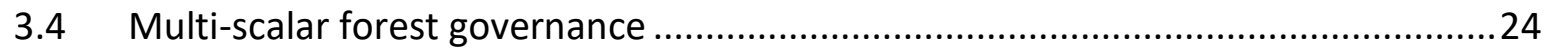

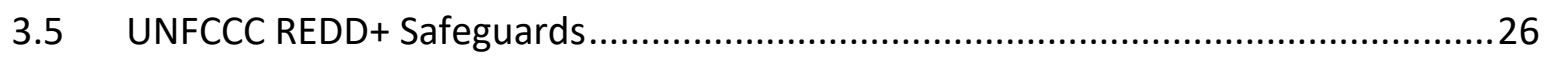

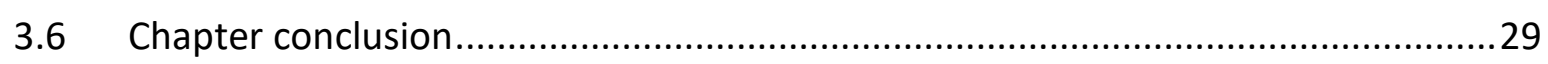

Chapter 4 Socio-historical background of Vanuatu ..............................................................30

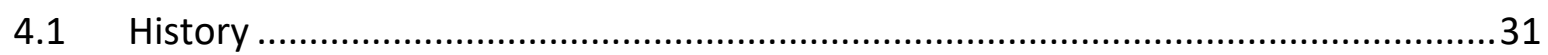

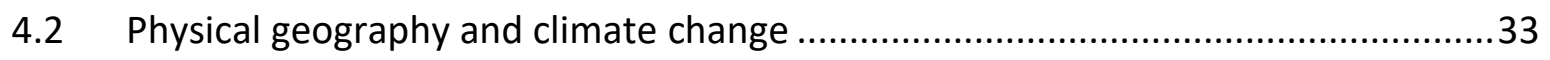

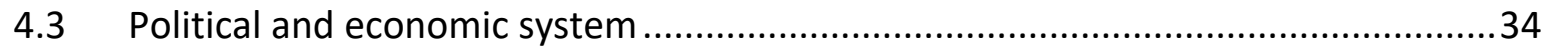

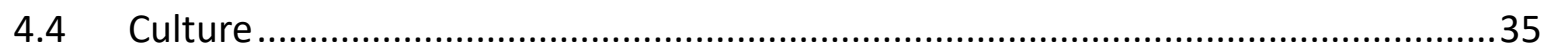




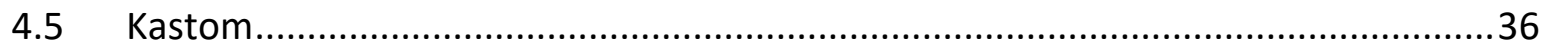

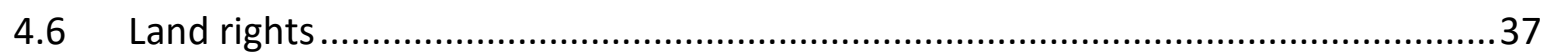

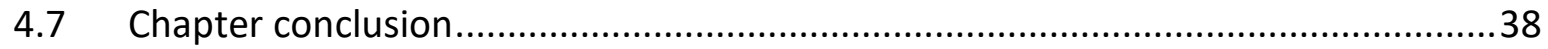

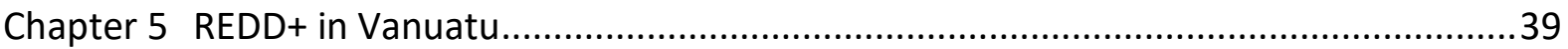

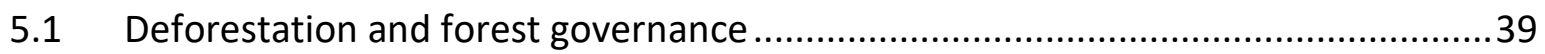

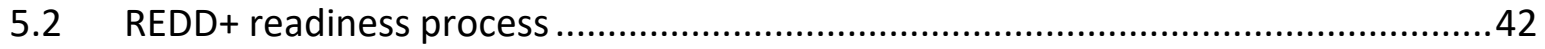

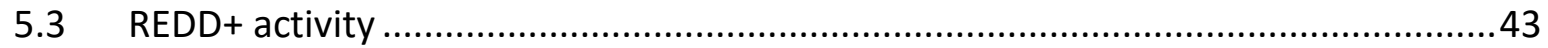

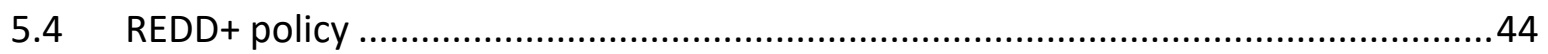

5.4.1 Government of Vanuatu acquires degraded agricultural leased land ..............44

5.4.2 Activity-based strategies at Province or Island level to encourage land use

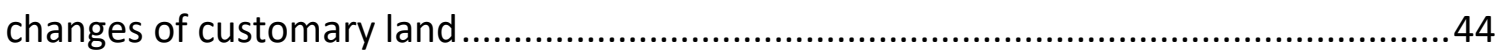

5.4.3 Area-based conservation of customary land .................................................45

5.5 Case study: Loru Community Carbon Forest Project .............................................45

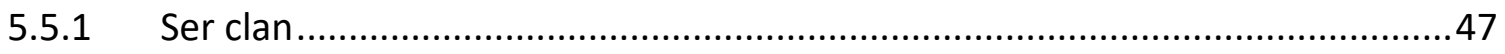

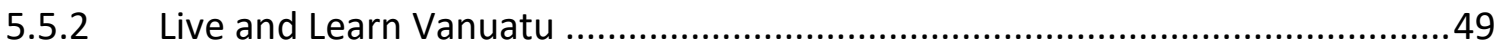

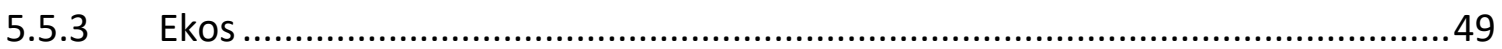

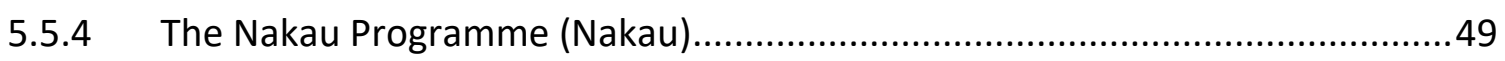

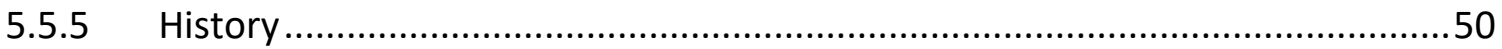

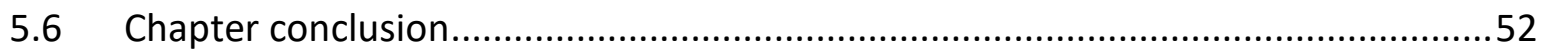

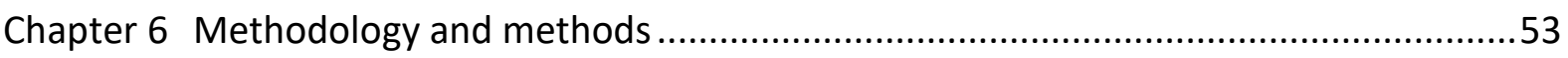

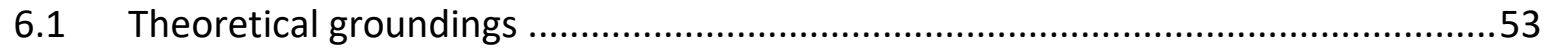

6.1.1 Epistemology: Social constructivism............................................................53

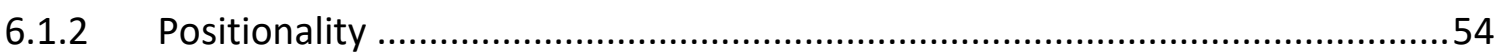

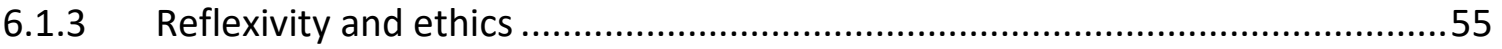

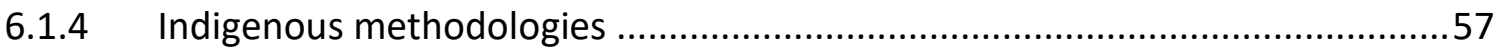

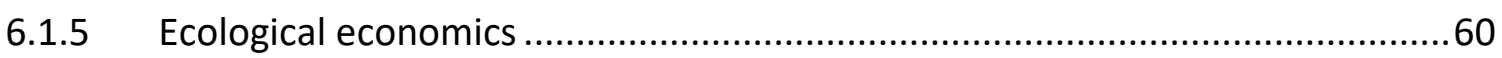

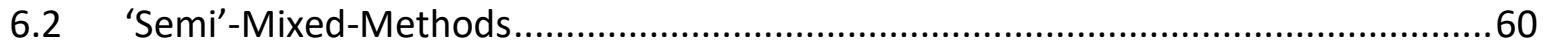

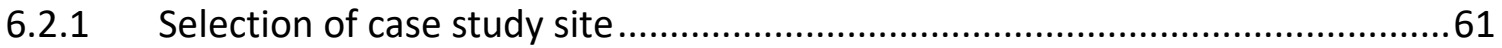

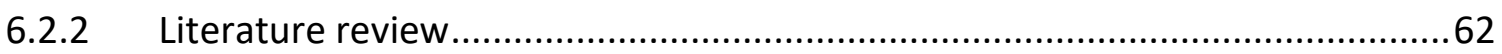

6.2.3 Field research and participant recruitment .................................................63

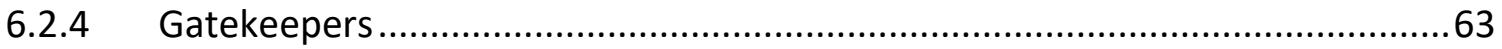

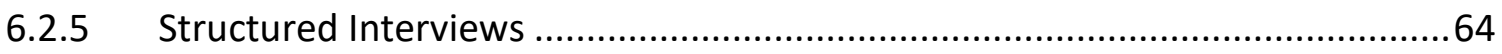




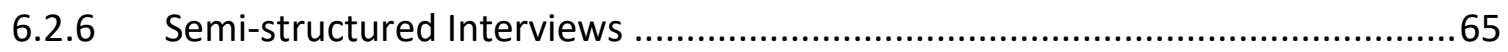

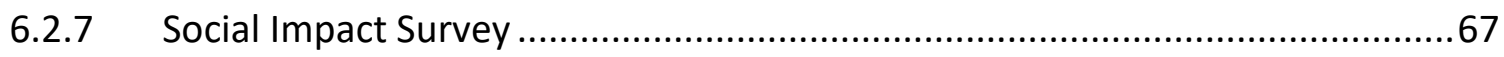

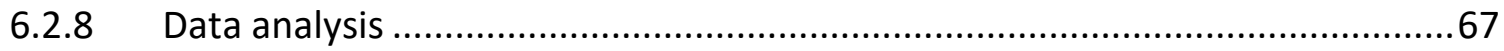

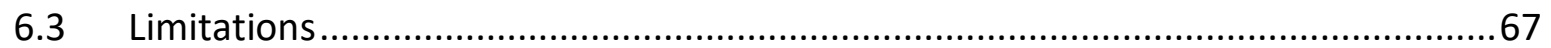

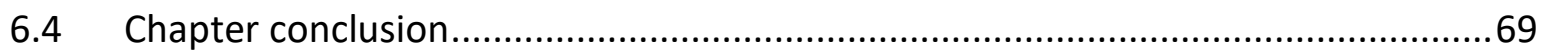

Chapter 7 Social impact and sustainability of the Loru project ........................................... 70

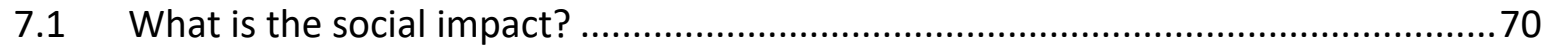

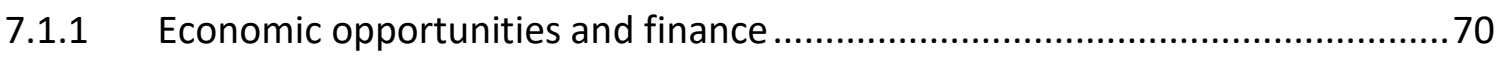

7.1.2 Improved forest governance capacity ......................................................... 78

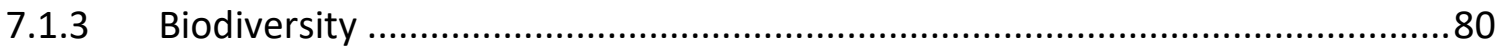

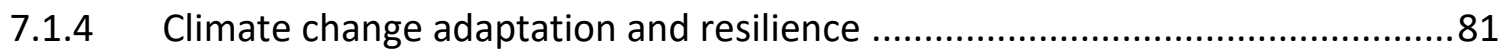

7.2 How does the social impact contribute to the sustainability of the Loru project? ..83

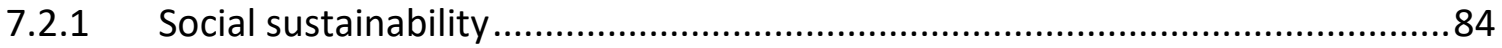

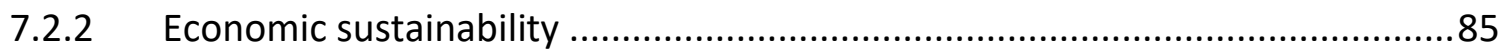

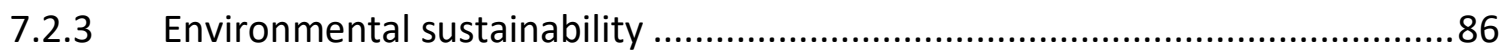

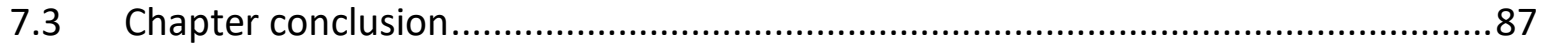

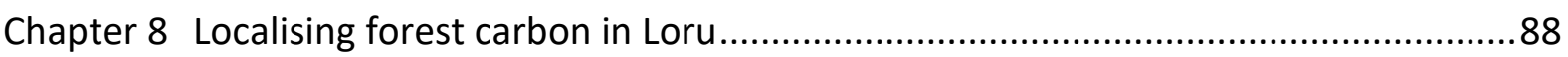

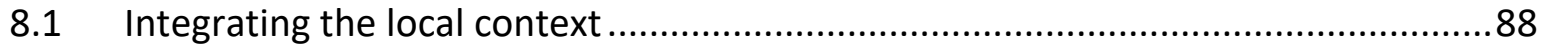

8.1.1 Community development aspirations ........................................................ 88

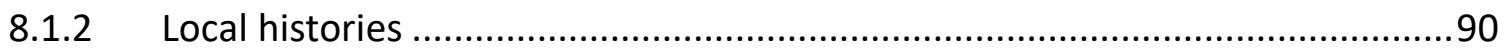

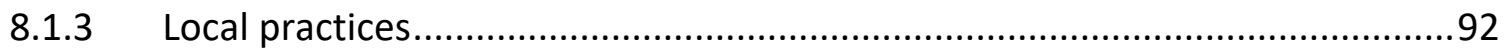

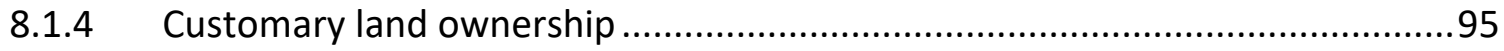

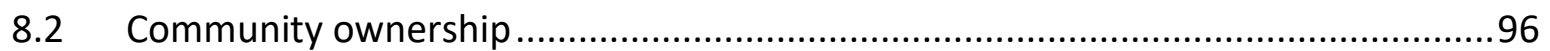

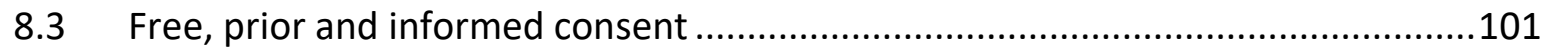

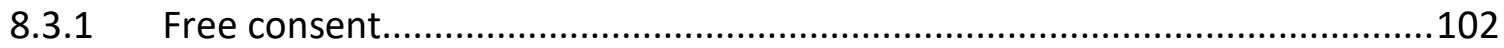

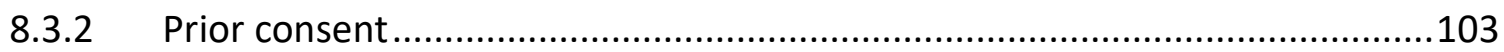

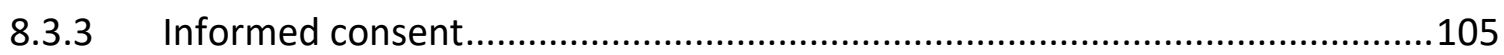

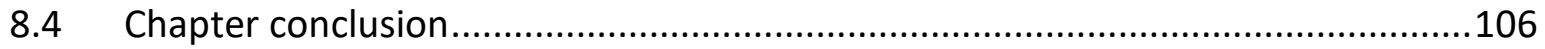

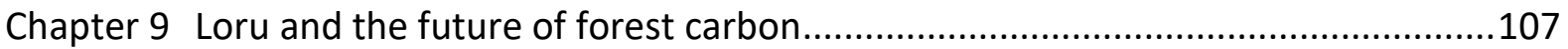

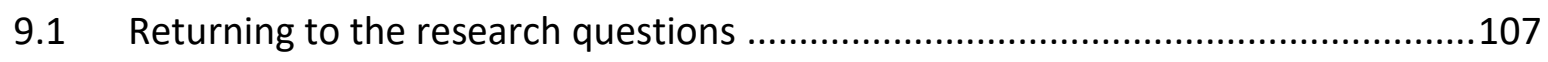

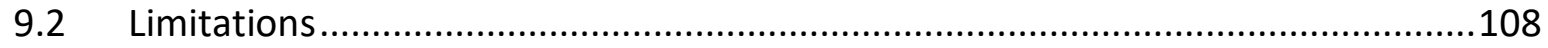

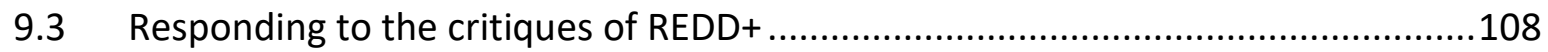




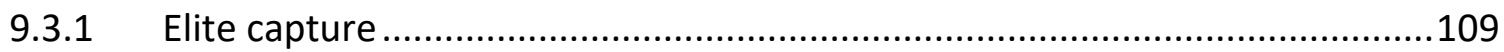

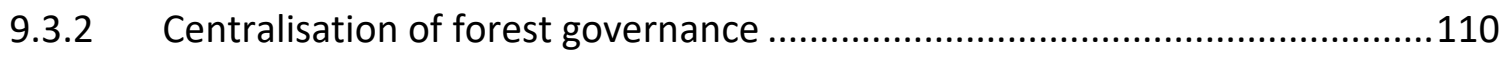

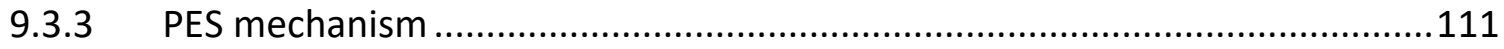

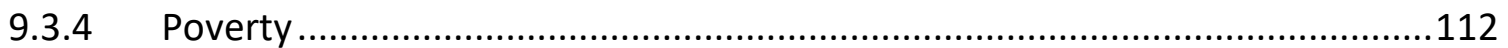

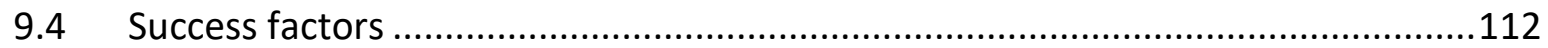

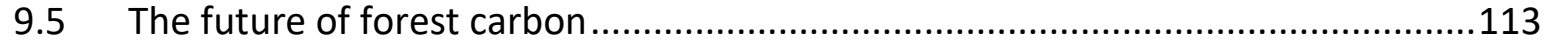

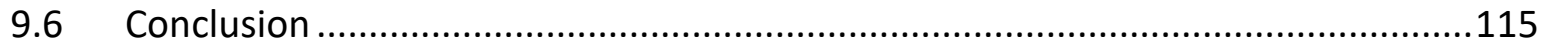

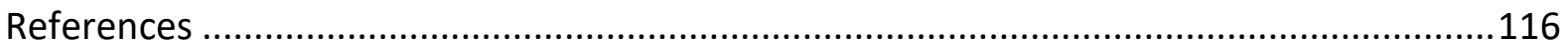

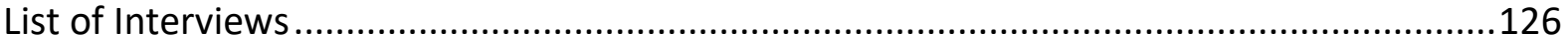

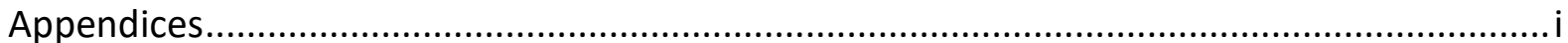




\section{Table of Acronyms}

CoP

Conference of Parties

DoF

Vanuatu Department of Forests

FAO Food and Agriculture Organization

FCPF Forest Carbon Partnership Facility

FPIC Free, Prior and Informed Consent

GIZ Deutsche Gesellschaft für Internationale Zusammenarbeit

IPCC Intergovernmental Panel on Climate Change

LL Live \& Learn Environmental Education International

LLV Live \& Learn Vanuatu

MP $\quad$ Member of Parliament

NGO Non-Governmental Organisation

PES Payment for Ecosystem Services

R-PIN Readiness Plan Idea Note

R-PP Readiness Preparation Proposal

REDD+ $\quad$ Reducing Emissions from Deforestation and Forest Degradation Plus conservation, sustainable management of forests and enhancement of forest carbon stocks

SIDS Small Island Developing State

SPC Pacific Community (formerly South Pacific Commission)

UN United Nations

UN-REDD United Nations programme on Reducing Emissions from Deforestation and forest Degradation

UNFCCC United Nations Framework Convention on Climate Change

UNDRIP United Nations Declaration on the Rights of Indigenous Peoples 


\section{Table of Figures}

Figure 2.1 Environmental Kuznets Curve

Figure 3.1 Attendees protest the Indigenous Peoples' Forum on Climate Change at launch of the FCPF .26

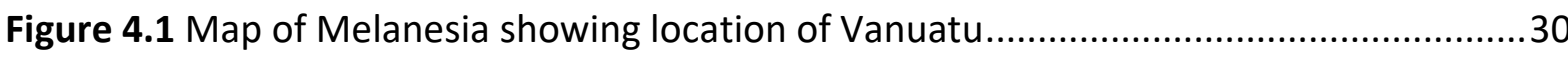

Figure 4.3 Map of Vanuatu showing location of Loru Project............................................ 31

Figure 5.1 Drivers, agents and underlying causes of deforestation in Vanuatu .................... 40

Figure 5.2 Map of Espiritu Santo showing location of Loru Project Site ...............................46

Figure 5.3 Loru Project site showing surrounding land use ............................................. 46

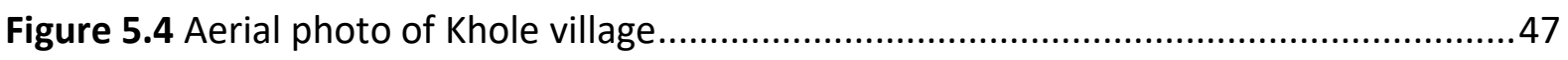

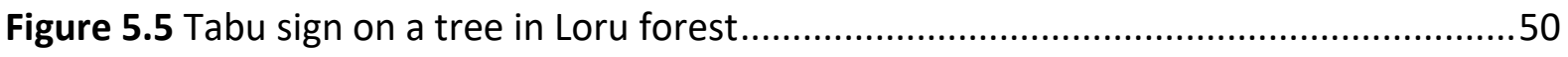

Figure 5.6 Glarinda Andre and Serge Warakar receive the UN Equator Prize in New York, USA

Figure 7.1 Project area showing management zones .................................................... 74

Figure 7.2 Locally grown food consumption of Ser clan members 2014 and 2019 ...............75

Figure 7.3 Ser clan access to water 2014 and 2019 .........................................................76

Figure 7.4 Ser clan trust of Loru project 2014 and 2019 ...................................................76

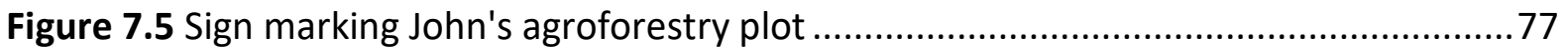

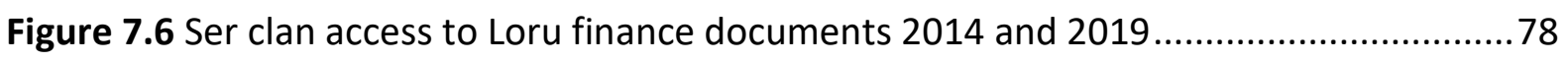

Figure 7.7 Participants of biodiversity training including Ser clan members in Khole village.80

Figure 7.8 Unharvested coconuts left to rot on ground near in Loru forest..........................82

Figure 7.9 Ecological Economics three concentric circles of sustainability..........................83

Figure 8.1 Typical dwelling in Khole village ...................................................................90

Figure 8.2 Serge Warakar shows me a young Coconut Crab during a walk of Loru forest .....93

Figure 8.3 Agroforestry plots with Papaya trees ...............................................................94

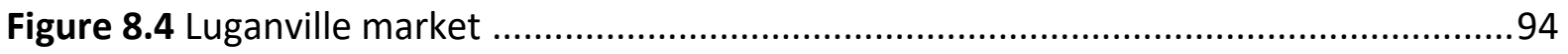

Figure 8.5 Institutional structure of the Loru project......................................................98 


\section{Table of Tables}

Table 6.1 Demographics of Structured Interview Participants ..........................................65

Table 7.1 Bank Account Cash Flow and Closing Balance 1 July- 31 September 2018.............71 


\section{Chapter 1 Introduction}

"Inside our heart, inside our blood. When we were a child, we were part of it-until now"Kal Ser, member of Ser clan, Espiritu Santo, Vanuatu

Forests are the gardens, pharmacies, playgrounds and temples of local communities. Yet, forests also provide timber, palm oil, rubber, coffee, cocoa and coconuts to people thousands of kilometres away. Critically, forests are the largest global reservoir of carbon in a rapidly warming world. The tensions between local and global human-forest relationships play out in communities involved in forest carbon farming. These communities are predominantly located in the global South; current deforestation is concentrated in the tropics of Africa, Latin America and the Asia Pacific (Watson et al., 2018).

The largest carbon sequestration programme and the global solution for conserving forests is REDD+: Reducing Emissions from Forest Degradation and Deforestation plus conservation, sustainable management of forests and enhancement of forest carbon stocks (Corbera, 2012). REDD+ conceptualises forests as a global resource and its implementation increases the role of national governments in forest governance.

This thesis explores a community at the nexus of local and global forest interactions. The Loru Forest Carbon project (hereafter the Loru project) is community-owned and -managed, yet the conservation of the Vanuatu forest, recognised as a carbon reservoir that stabilises the global climate, is funded by carbon offset credits sold in Europe and New Zealand. While first established as a pilot REDD+ project, the Loru project now sits outside REDD+, allowing the community greater agency over forest governance.

Deforestation contributes $20 \%$ of global greenhouse gas emissions, equivalent to the global transport industry (Campbell et al., 2008; Watson et al., 2018). The International Panel for Climate Change (IPCC) recognises deforestation as one of the greatest contributors to climate change (IPCC, 2018). The last IPCC report stressed the importance of including carbon sequestration in the global climate policy package to reach the target of well below $1.5^{\circ} \mathrm{C}$ of pre-industrial warming and avoiding catastrophic and irreversible climate-related damage (Watson et al., 2018). 
Extractive industries involved in deforestation and forest degradation exploit and displace forest-dependent communities (Allen, 2013; Barr \& Sayer, 2012). This occurs through the systematic marginalisation of forest peoples, while governments in tropical countries inflicted by colonially-imposed government and economic systems subsidise foreign investment in extractive industries. Much of the extracted resources-timber, cocoa, chocolate and palm oil-are destined for the global North, yet local communities lose access to forest resources and are frequently alienated from customary land, poorly compensated, and inadequately consulted.

Forest folk are uniquely vulnerable to climate change. Forest dwellers are dependent on natural resources which can be destroyed in fires, cyclones, floods and droughts-already observably increasing in severity in many parts of the world (Richmond \& Sovacool, 2012). Climate change also reduces the predictability of natural phenomena. Forest folk, particularly Indigenous peoples, hold traditional ecological knowledge from observing, nourishing and breathing land, country, whenua over generations (Ford et al., 2016). But environmental markers such as the flowering of a plant or patterns of rainfall are disrupted by the changing climate. These environmental markers can warn of an impending natural disaster, or signal when to plant crops. Weakening these systems threatens livelihoods and food security.

Protecting forests therefore, protects forest livelihoods, locally and globally, and stabilises the climate for everyone. But trade-offs can occur between maximising the carbon storage capacity of forests and communities' use of forests (Corbera, 2012). Further, scholars warn that unless underlying power imbalances are addressed, REDD+ could lead to greengrabbing where forest peoples are driven off their land, and free prior and informed consent is not adequately sought (Fairhead, Leach, \& Scoones, 2012).

Furthermore, community-managed forests frequently result in better environmental and social outcomes (Agrawal \& Angelsen, 2009). When local people create and implement their own forest governance rules, it can be designed around local needs, motivations and land rights, and organised through local institutions. Research shows social and environmental outcomes improve when intermediary organisations such as NGOs can play a support and capacity-building role and state regulation can improve transparency and environmental outcomes (Hayes \& Persha, 2010; Sayer, Margules, \& Boedhihartono, 2017). 
REDD+ policy enforces national state regulation, but largely overlooks the importance of local and intermediary institutions. The international REDD+ policy agenda is determined by the Forest Carbon Partnership Facility (FCPF) of the World Bank and the United Nations Programme on Reducing Emissions from Deforestation and Forest Degradation (UN-REDD). Only national governments are eligible for FCPF funding and must first establish national carbon accounting systems such as forest monitoring, a deforestation baseline and reference emission levels (Lujan et al., 2018). While understandably, this intends to ensure recipients are meeting emission reduction targets, it increases the state's role in forest governance which can reduce local forest governance rights. Studies have found that REDD+ can threaten local livelihoods and wellbeing if local communities do not have the agency to influence forest governance rules, give and withdraw consent or claim rights to customary land (Astuti \& McGregor, 2017; Sunderlin, Ekaputri, et al., 2014).

Given the potential of REDD+ to limit local agency, but the urgency needed to reverse deforestation in a rapidly warming planet, I wished to research a forest carbon project which is locally-owned and appeared to be leading to positive community outcomes.

The Loru Project is the pilot forest carbon farming project of the Nakau Programme Pty Ltd (hereafter Nakau) (A. Nelson, Andre, Warakar, Weaver, \& Henderson, 2015). Nakau is a company registered in Australia and is co-owned by the international charity Live \& Learn Environmental Education International (LL) and the charitable arm of an international social enterprise, Ekos. Live \& Learn Vanuatu (LLV) coordinates the project locally and Nakau and Ekos sell carbon offsets to the European and New Zealand voluntary offset markets. The buyers are voluntary rather than part of government-mandated carbon offset schemes, such as businesses opting to become zero-carbon (i.e. measuring, reducing and offsetting their greenhouse gas emissions). Like REDD+, the scheme produces carbon offset credits. However, the Indigenous landowners retain rights to the offsets and revenue is paid to the family business, Ser-Thiac, to fund community development. Executive Director and Founder of Ekos, Sean Weaver describes the initiative as "fair trade carbon" (S. Weaver, personal communication, 16 August 2019). The 'fair trade' goal helps command a premium for the carbon offsets to enable higher revenue flows to community landowners. The project and associated carbon credits are certified to the Plan Vivo standard which guarantees the carbon offsets produce carbon, as well as social and biodiversity co-benefits (Plan Vivo, 2013). 
This research sought to answer the following questions:

\section{Research Questions}

1. What has been the social impact of the Loru Forest Carbon Project on the local Indigenous community, the Ser clan?

1.1. How does this social impact affect the social, economic and environmental sustainability of the Loru Forest carbon project?

2. How does the community exercise ownership over the Loru Forest Carbon project?

2.1. How has the Loru Forest Carbon project met the principles of free, prior and informed consent?

The thesis is structured as follows:

Chapter two, the first of two literature review chapters, analyses scholarly perspectives of deforestation in global South, explaining the drivers and causes of deforestation. Chapter three discusses the literature surrounding Forest Peoples and REDD+, particularly outlining potential risks of REDD+ to local communities. The fourth chapter situates the research in Vanuatu, explaining Vanuatu's sociohistorical background. Chapter five continues to contextualise the research, describing forest carbon in Vanuatu and introducing the case study. The sixth chapter explains my methodology and methods. I root my research in social constructivism and explain the influence of Ecological Economics and my attempts to decolonise the research. This chapter also details my 'semi'-mixed-methods. While this thesis is largely qualitative, I also include some quantitative findings from the Loru Social Impact Survey which I conducted on behalf of LLV. Next, the two findings chapters each answer one of my research questions. Chapter seven presents my findings on the social impact of the Loru project. It also links this social impact to social, environmental and economic sustainability. Chapter eight presents findings on how the project has been 'localised,' the ways it has been adapted to the Ser community, how the Ser clan exercise ownership, and how the project approaches free, prior and informed consent. Finally, chapter nine discusses my findings, responding to the risks of REDD+ arising from the literature in chapter three.

The Pacific is a particularly interesting context to study forest carbon farming. The vast majority of forest-dependent communities in the Pacific are Indigenous peoples. While this is not unusual, and many forest-dependent peoples across the globe are Indigenous, distinctly, 
Indigenous people make up the majority in the Pacific. This means that unlike other regions, forest carbon farming is not being implemented in minority communities, changing the power dynamic between forest-dependent communities and the state. In Vanuatu for example, 95.5\% of its population are Indigenous ni-Vanuatu, most rural smallholder farmers living on customary land in kinship groups (VNSO, 2017). Most of the population are in some way directly dependent on forests for their livelihoods - forest protection is a mainstream issue. As forest carbon farming initiatives begin to emerge in the Pacific Islands, pioneering studies such as this thesis will be valuable in exploring how this power dynamic affects outcomes to communities.

Despite this, forest carbon farming is relatively unstudied in the Pacific Islands. Of the literature that exists, none focuses on the community impact of forest carbon farming or are based on qualitative research with community members. Babon and Gowae (2013) and Venuti (2014) write about the legal context of REDD+ in Papua New Guinea. Weaver (2015) discusses the commercial challenges in accessing forest carbon funding in the Pacific. Godden's (2017) book chapter outlines the policy context of REDD+ in Fiji and Vanuatu. Therefore, this thesis significantly contributes to literature on forest carbon farming in the Pacific.

Additionally, this thesis is the first qualitative study of an Indigenous-owned forest carbon project, contributing to literature beyond the Pacific context. A comprehensive literature review found only one mention of an Indigenous-owned forest carbon project, the Luma project in the Brazilian Amazon, which Lawlor, Madeira, Blockhus, and Ganz (2013) do not study in detail but include in a quantitative study of 41 REDD+ projects. While many scholars criticise the lack of community agency in REDD+ projects, there has been little opportunity to study alternative community-owned approaches. The FCPF coordinates forest carbon funding through national governments, a significant barrier for grassroots initiatives. Therefore, studying the Loru project provides valuable insight into how community ownership might mitigate the risks of forest carbon farming. As this thesis is based upon interviews with community members, the research can give detailed insight into the community's experiences.

Literature on Community Forest Management (CFM) is relevant, and suggests granting greater forest governance rights to local communities allows programmes to be adapted to 
the local context, improving social and environmental outcomes (Gautam, Shivakoti, \& Webb, 2004; Lima et al., 2006; Maraseni, Neupane, Lopez-Casero, \& Cadman, 2014; Stocks, McMahan, \& Taber, 2007). Nevertheless, there are aspects of forest carbon farming which differ from community-managed forests, such as the inclusion of a payment for ecosystem services (PES) funding mechanism. Critics have argued the results-based funding mechanism of REDD+ commodifies nature and is incompatible with Indigenous conceptions of nature, ultimately harming forest-based livelihoods (Büscher, Sullivan, Neves, Igoe, \& Brockington, 2012; Corbera, 2012). This research addresses this assertion, hypothesising that if communities retain ownership over forest resources and agency over the implementation of forest carbon projects, communities can operate forest carbon farming in a way which does not diminish connection with land or harm livelihoods.

On top of its academic contribution, this research is relevant to policy-makers, practitioners and local communities involved in forest carbon farming. Consequently, parts of this research were presented at an academic conference (Payne, 2020) and has generated outputs for government, NGOs and community groups. 


\section{Chapter 2 Deforestation in the global South}

This chapter explores deforestation and forest degradation in the global South. First, I describe the current state of forest peoples and explain the impacts of forest loss on forestdependent communities. Secondly, I examine the scholarly debate on the drivers and causes of land clearing.

Forest-dependent communities are threatened by mass deforestation. Indigenous peoples, who legally own $11 \%$ of forestland are systematically marginalised (Bayrak \& Marafa, 2016). Uneven bargaining power and insecure land rights has enabled forest degradation to displace communities and restrict Indigenous peoples' access to traditional land. Moreover, deforestation is a major cause of climate change and Indigenous peoples worldwide are disproportionately threatened by the local effects of climate change.

\subsection{Forest peoples and Indigenous peoples}

In this review, I examine literature which discusses both Indigenous and non-Indigenous forest dwellers, which I refer to as 'forest peoples'. Nevertheless, as the customary custodians of forestland and victims of colonisation, I acknowledge that Indigenous forest peoples have unique perspectives and face unique challenges (Birrell, Godden, \& Tehan, 2012; Dehm, 2016). Additionally, the Ser clan from Espiritu Santo which this thesis studies are Indigenous ni-Vanuatu, so literature on Indigenous peoples' experiences with forest carbon is particularly relevant. However, indigeneity and forest dependence are multi-dimensional and complex concepts, and people tend to exist on a spectrum rather than fitting neatly into discrete categories.

A large, though contested proportion of forest dwellers are Indigenous peoples, often with additional barriers to resources and institutions (Bayrak \& Marafa, 2016; Chao, 2012; Dehm, 2016). A definition of forest-dependent must determine a certain level of 'dependence' based upon distance to forests and degree of reliance on forest resources (Chao, 2012). Applying a universal definition hides the complexity of communities' interrelationships with forestland and necessarily excludes groups. The United Nations State of Indigenous People's Report explains, "a single definition will inevitably be either over- or under-inclusive, making sense in some societies but not others" (Carino et al., 2009, p. 6). Dehm (2016) warns against defining a universal definition of Indigenous peoples but bases 
the concept on self-identification, and a 'historical continuity' to pre-invasion or pre-colonial societies.

Without a clear definition of 'who counts' as forest-dependent or Indigenous, estimating numbers is difficult. After conducting a literature review on publications from UN bodies, national governments, NGOs and Indigenous peoples' organisations, the Forest Peoples Programme estimated 1.3 billion forest peoples and half a billion Indigenous peoples worldwide (Chao, 2012).

Forest peoples are often characterised by remoteness and poverty. Chomitz (2006) explains that as the most favourable land for agriculture and plantations has already been cleared, the remaining forest is mostly remote and unfavourable, and the areas tend to have a low population and high poverty rate. Moreover, forest peoples are often unable to benefit from forest resources due to insecure land tenure or lack of user rights (Barr \& Sayer, 2012).

The United Nations (UN) Food and Agriculture Organization (FAO) reported that governments own $86 \%$ of the world's forests, $10 \%$ are privately owned and $4 \%$ under communal ownership arrangements (Chao, 2012). However, Sandbrook, Nelson, Adams, and Agrawal (2010) claims around $27 \%$ of tropical forest is under some form of communal ownership as formal forest statistics under-report communal ownership which are often informal in nature.

\subsection{Deforestation and forest degradation}

Deforestation threatens the livelihoods of forest peoples reliant on forest resources. Deforestation is a significant driver of climate change, releasing carbon into the atmosphere equal to the total emissions of the global transport industry (Campbell et al., 2008). While Earth has lost $35 \%$ of pre-agricultural forest cover over the last three centuries, forests still cover $25 \%$ of Earth's land area (Watson et al., 2018). A further $82 \%$ of forestland is degraded due to logging, urbanisation, agriculture and infrastructure (Watson et al., 2018).

Deforestation is the transformation of forest to permanent non-forested land use such as agriculture, livestock grazing or urbanisation (Chakravarty, Ghosh, Suresh, Dey, \& Shukla, 2012). FAO classify timber plantations as forests, so land that is transformed from natural forest to timber plantations is classified as forest degradation rather than deforestation. 
However, land conversion for non-timber products (e.g. coconuts or oil palm) and land clearing are classified as deforestation.

Current deforestation is concentrated in tropical forests, biodiversity 'hotspots' home to a significant number of the Earth's endemic species. Tropical regions are disproportionally located in the global South within Africa, Latin America and the Asia Pacific (Chakravarty et al., 2012). Historically, deforestation has occurred in the global North, largely in temperate and sub-tropical areas, but deforestation in these areas has slowed, and in some cases reversed (Chakravarty et al., 2012).

The International Panel on Climate Change (IPCCC) recognises deforestation as a major driver of climate change (Campbell et al., 2008). The 2015 Paris Agreement acknowledges the importance of forests in sequestering carbon to keep global temperatures at well below $2^{\circ} \mathrm{C}$ above pre-industrial levels (Watson et al., 2018).

Native forests untouched by significant anthropogenic degradation, including those that are home to remote Indigenous communities, are particularly important for preserving biodiversity and other ecosystem services (Watson et al., 2018). However, $50 \%$ of tree plantations in the tropics are established on cleared native forest. Watson et al. (2018) argue that native forests are 'intact forest ecosystems' which deserve special attention in policymaking. Intact ecosystems absorb more carbon as carbon is absorbed in healthy soil and seeds are more effectively dispersed by animals.

Rozzi (2012) describes the rich cultural diversity that is eroded when Indigenous peoples are displaced from ancestral land. He argues that the urbanisation of Indigenous communities is a major driver of cultural and ecological homogenisation, as diverse interrelationships between communities and ecology are replaced by a small number of exotic species, languages and cultures. Indigenous peoples understand ecological knowledge through multiple worldviews, expressed through native languages. As Indigenous peoples are displaced and urbanised, languages and ways of understanding ecology is narrowed.

\subsection{Drivers of deforestation and forest degradation}

Literature on deforestation focuses on two major drivers: land cleared to plant plantations for global export markets, and subsistence farmers clearing land for food crops. As Chomitz (2006, p. 1) explains, "expansion is driven by both wealth and poverty. A huge rural population 
relies on low-productivity agriculture for subsistence. A growing, increasingly wealthy urban population demand commodities produced at the forest's edge: beef, palm oil, coffee, soybeans, and chocolate." There is much debate on the relative significance of these two drivers, with economic growth proponents stressing the impact of shifting-cultivation to justify industrialisation of forest regions.

\subsubsection{Export-led deforestation and forest degradation}

Since colonisation, forestland in the global South has been cleared at an incredible rate to produce resources for export markets. Colonising societies brought economic globalisation and capitalist expansion which attracted foreign buyers to capitalise Indigenous forestland, exploiting forest peoples in the process (Barr \& Sayer, 2012). Prior to colonialization, Indigenous peoples used customary forest governance regimes to protect forest livelihoods. Colonisation disrupted these customary approaches, displacing peoples from land to sell forest resources to export markets. Across the global South, in the pursuit of economic growth, governments have created environments which encourage multinational corporations to degrade forests and restrict forest peoples' rights to land (Bhattarai \& Hammig, 2001).

Nevertheless, some literature justifies the industrialisation of forest land and displacement of forest peoples. Modernisation theory claims that countries must first increase their income to cover basic needs before 'secondary' processes such as distribution and environmental protection can occur (Bhattarai \& Hammig, 2001). Modernisation proponents use tools such as the environmental Kuznets curve to suggest that this process is inevitable, overlooking the vital role of institutions and governance to create and implement policies which protect forests and forest peoples (Shandra, 2007). The environmental Kuznets curve is a U-shaped curve suggesting that as a country increases its income, some form of environmental degradation inevitably occurs, before a turning point is reached where the increased income results in environmental protection (see Figure 2.1). 


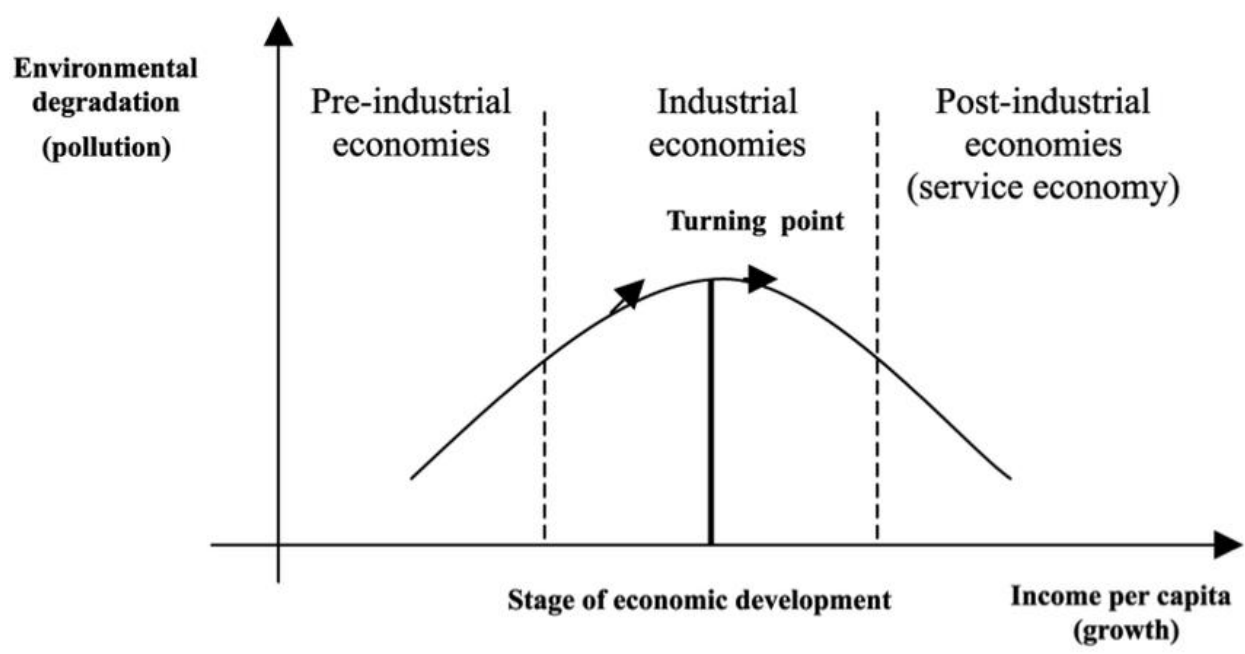

Figure 2.1 Environmental Kuznets Curve

Note: From Panayotou, T. (1997). Demystifying the environmental Kuznets curve: turning a black box into a policy tool. Environment and Development Economics, 2(4), 465-484. https://doi.org/10.1017/S1355770X97000259

The concept is empirically contested and creates dangerous policy incentives that threaten forests and forest livelihoods. Bhattarai and Hammig (2001) tested deforestation rates using the environmental Kuznets curve with data from 66 countries in Latin America, Africa and Asia and found mixed results. Problematically, the environmental Kuznets curve justifies some level of environmental degradation as necessary for economic development. Further, it relies on the assumption that (eventually) economic gains will be spent on protecting the natural environment but without any mechanism or incentive structure to guarantee this. In practice, the benefits flow to elites with no incentive to protect forests or forest people (Barr \& Sayer, 2012).

Dependency theorists argue that richer countries of the global North externalise their environmental costs to the global South (Shandra, 2007). Southern countries export large volumes of natural resources to countries in the global North. In exchange, the global South imports high-priced technologically-advanced goods to expand their local production. Natural resources such as timber, mined goods and agricultural monocultures often require forest degradation and deforestation. Jorgenson (2006) shows that Southern countries with higher levels of exports experience greater rates of deforestation. Governments from the South compete against each other to attract foreign investment, often at the expense of local communities. Governments from countries with the highest rates of deforestation have several initiatives which encourage foreign investment in industries that result in forest 
degradation. Brazil has government subsidies for livestock grazing and corporate forestry, Indonesia has timber concession rights, and the Malaysian government supports the logging industry (Bhattarai \& Hammig, 2001).

The pressures for state-sponsored export-led deforestation in the global South was most severe during the Structural Adjustment Programmes (SAPs) of the neoliberal 2000s (Shandra, 2007). SAPs are foreign loans intended for the economic development of the global South. Southern governments were required to spend SAP funds on expanding export industries while removing barriers to foreign investment and cutting government spending. The simultaneous expansion of export industries and the attraction of foreign investment encouraged the transformation of forests into export-producing plantations. Meanwhile, government spending cuts reduced the capacity of community and conservation institutions to slow deforestation and protect forest peoples' rights.

Shandra (2007) found that practices by the Southern governments to create a 'good business climate' intensified the level of deforestation in export-oriented Southern economies. The initiatives include policies which intensify environmental degradation and repress forest peoples. For example, Indonesia outlawed strikes, protests and unions, and passed a law permitting the government to ban NGOs from the country (Shandra, 2007). The Malaysian government blocked anti-logging protests of the Indigenous Penan community and their allies by censoring the press and arresting Penan leaders while increasing logging in the region (Bryant and Bailey 1997). More recently, Special Agricultural and Business Leases in Papua New Guinea facilitated what P. N. Nelson et al. (2014) call a 'large scale land grab' under the guise of oil palm development, with majority of the proposals unlikely to eventuate into economic gains to forest communities who gave up customary land.

\subsubsection{Deforestation and forest degradation due to shifting cultivation}

Forest degradation and deforestation occurs when small scale farmers clear land to plant food crops for survival. This often occurs in remote areas where there are few economic opportunities, but the cost of deforestation is highest, as the forests are less degraded and likely to be native and intact ecosystems (Watson et al., 2018). Creating economic opportunities and alleviating poverty can slow shifting cultivation. It is widely acknowledged in the literature that deforestation slows as a country's national income increases (Bhattarai 
\& Hammig, 2001; Repetto, 1990; Shandra, 2007). However, economic growth can increase deforestation if it is linked to extractive industries or is not distributed to forest peoples.

Some authors argue population growth in the global South drives deforestation, indicting the global poor (Myers, 1993; Rudel \& Roper, 1997; Shandra, 2007). The lack of nonagricultural economic opportunities and increased household size increases shifting cultivation as farmers clear more land to plant crops. Rudel and Roper (1997) describe the 'frontier' model of deforestation. Subsistence farmers on undeveloped forestland work with companies to clear land rapidly for roads, timber and agriculture. This process intensifies with population increases in tropical Southern countries demanding an expanding resource base and creating a labour force to speed up land clearing. Rudel and Roper (1997) assert that the pressure on forests is reduced with greater economic opportunities in urban centres. This trickle-down argument has been criticised by Shandra (2007) as having a Malthusian overtone and asserting economic growth will protect forests without providing a distribution mechanism.

Land clearing by subsistence farmers is on a much smaller scale than agricultural intensification for export industries. The role of shifting cultivation in deforestation has likely been overstated by governments seeking to encourage foreign investment. Economic development of forested areas has been used to justify state-sponsored deforestation (Barr \& Sayer, 2012; Ceddia, Gunter, \& Corriveau-Bourque, 2015; Harwell, 2003).

The focus on economic growth to mitigate deforestation has resulted in incorrectly associating land clearing with poverty in policy. A World Bank project attempted to deter deforestation in Sumatra, Indonesia by providing financial assistance to local people. Instead, the driver of deforestation were foreign businesses exporting cinnamon, and the povertyreduction initiative failed to reduce deforestation (MacKinnon, 2005 through Chomitz, 2006).

The contention around the drivers of deforestation highlights the importance of context-specific policy. Many studies stress that the causes of forest degradation are different in different regions and interact with context-specific institutions and conservation policy (Chomitz, 2006; Kronenberg, Orligóra-Sankowska, \& Czembrowski, 2015; Sandbrook et al., 2010). 
Chomitz (2006) distinguishes between deforestation pressures based on where the forest lies in relation to the agricultural frontier. The agricultural frontier is the boundary where native habitats are being converted into plantation forests and agriculture (Peterson St-Laurent, Gélinas, \& Potvin, 2013). Areas beyond the frontier are typically large, native forests with ecosystems largely untouched by human interaction. The consequences of environmental degradation are high, but pressures are lower as these areas have fewer inhabitants. Typically shifting cultivation is the largest driver of deforestation in these regions. Forests on the frontier are those with pressures to clear land for export markets, often susceptible to be acquired by governments and multinational corporations due to insecure and conflicted land tenure. A policy priority is securing land tenure, so forest peoples are protected, accountable and incentivised to protect the land long term (Chomitz, 2006).

\subsection{Reasons for deforestation}

There are many reasons why landowners choose to clear land. An effective conservation regime will understand and address local reasons for land clearing.

Forests provide local and global ecosystem services that are degraded and destroyed when forestland is converted (Bhatta, Bigsby, \& Cullen, 2011; Warren-Rhodes et al., 2011). Many of these ecosystem services such as carbon reservoirs, biodiversity and air quality occur downstream, so landowners undervalue their benefits in land-use decisions. Payments for Ecosystem Services (PES) programmes attempt to measure and compensate landowners for downstream ecosystem services. For example, results-based REDD+ payments measure and pay landowners for the value of forest carbon reservoirs.

Poverty can increase forest peoples' dependence on shifting cultivation as a livelihood strategy. Shifting cultivation can reach unsustainable levels if forest dwellers are forced to over-clear land to plant crops (van Kooten, Nijnik, \& Bradford, 2019). Forest peoples may be pressured into agreements with logging companies due to poverty and disempowerment. Corporations and states marginalise forest dwellers by restricting access to information, not respecting consent and repressing dissent, often forcing forest peoples into exploitative agreements which endanger customary land and livelihoods (Shandra, 2007).

Insecure land tenure can increase both shifting cultivation and export-driven deforestation. Secure land rights encourage owners to consider the long-term impact of land- 
use changes and make sustainable decisions, reducing shifting cultivation. Insecure local land rights can enable private and state actors to claim land from forest peoples to be converted into export plantations (Sunderlin, Larson, \& Cronkleton, 2009). Much of state-subsidised land clearing occurs on contested land claimed by governments.

\subsection{Chapter conclusion}

This chapter has highlighted the multitude of factors which drive deforestation and forest degradation. For conservation policy to be effective, policymakers must accurately identify the drivers and causes of deforestation. However, whether deforestation is led by export or shifting cultivation, policy which empowers forest peoples and internalises downstream benefits is likely to result in more sustainable land use decisions. 


\section{Chapter 3 Forest peoples and REDD+}

This chapter explores the current policy landscape and scholarly perspectives on REDD+. First, I introduce REDD+, its history and safeguard policy. Second, I explore the risks of REDD+ on forest peoples. Third, I discuss how the literature on community-managed forests can apply to REDD+. Lastly, I express the importance of a multi-scalar institutional network in implementing REDD+.

The largest carbon sequestration programme and the global solution for conserving forests is REDD+: Reducing Emissions from Forest Degradation and Deforestation plus conservation, sustainable management of forests and enhancement of forest carbon stocks (Corbera, 2012). However, REDD+ projects are not achieving the emissions reductions they had hoped, potentially weaken local forest governance and restrict community access to forest resources (Sandbrook et al., 2010).

\subsection{Development of REDD+}

REDD+ attempts to recognise the ecosystem services that forests contribute to the global community. Recipient countries monitor forest degradation to calculate carbon reservoirs and receive results-based payments accordingly. This increases the economic value of intact forests, reducing financial pressures to clear land.

REDD+ was developed over a series of United Nations Framework Convention on Climate Change (UNFCCC) Conferences of Parties (COPs). The programme was first proposed in 2005 by Costa Rica and Papua New Guinea at COP11 as REDD (Reducing Emissions from Deforestation in Developing Countries) (Bayrak \& Marafa, 2016). The concept: wealthier countries provide funding to the global South to protect their tropical forests. These forests act as a carbon sink or reservoir and an important mechanism for climate stability.

Following COP13 in Bali in 2007, several large programmes were developed to coordinate REDD+, now with the 'plus' added to include sustainable management of forests, conservation of forest carbon stocks, and enhancement of forest carbon stocks. Two multilateral programmes, the UN-REDD Programme and the World Bank's Forest Carbon Partnership Facility (FCPF) coordinate REDD+ funding and regulation at a global level (Lujan et al., 2018). The Cancun Agreement in 2010 established the three-staged implementation process of REDD+: readiness, implementation and results-based finance (Lujan et al., 2018). 
The Cancun Agreement also determined a list of seven safeguards (see section 3.5) to support implementation (Dehm, 2016; Rey et al., 2013). COP19 in Warsaw, Poland in 2013 saw the adoption of the 'Warsaw Framework on REDD+' (Dehm, 2016). The Warsaw Framework developed rules for the measurement, monitoring and reporting of carbon for results-based actions. This carbon accounting framework creates the potential for REDD+ credits to be incorporated into international carbon markets (Dehm, 2016).

The Paris Agreement adopted at COP21 in 2015 is the most critical piece of international climate policy of the last decade (Rogelj et al., 2016). The Paris Agreement established the concept of nationally determined contributions: countries determine and are bound to their own emission reduction targets. Carbon credits can be used to help meet their emissions targets by offsetting emissions through carbon storage. Countries can offset using carbon credits created within their borders or purchase carbon credits from carbon generated offshore, such as REDD+ results-based payments. This creates the potential for REDD+ to be a mechanism to meet emission reduction obligations under the Paris Agreement. To date, no formal decisions have been made on how REDD+ credits could be incorporated into international carbon markets (Dehm, 2016). Nevertheless, the German, Japanese and Norwegian governments provide bilateral results-based funding under REDD+ (Lujan et al., 2018).

\subsection{Risks of REDD+ to forest peoples}

REDD+ has been subject of a lively academic debate. Many scholars criticise REDD+, highlighting the risks to forest peoples, in large part due to their poor bargaining power relative to private and state elites (Wallbott \& Florian-Rivero, 2018). The next section discusses the major risks of REDD+ to forests peoples discussed in the literature. Critics worry that REDD+ will increase the value of forestland and incentivise elites to gain greater control of forest governance, further marginalising forest peoples and capturing REDD+ payments. In particular, literature has criticised the neoliberal nature of REDD+ with its results-based mechanism of valuing forest services. Nevertheless, practitioners stress that this criticism can do more harm than good, slow or inhibit policy action and leave space for extractive industries such as logging and palm oil extraction - characterised by elite capture and forest degradation (Weaver, 2015). Comparatively, REDD+, with its social safeguards and international attention, has the potential and intention to be implemented in a pro-poor way which protects forest 
peoples' rights. Unlike private companies, the UN-REDD Programme is guided by the principles of the UN Development Group including a human-rights- based approach and capacity development (UN-REDD, 2008).

\subsubsection{Centralisation of forest governance}

Critics argue REDD+ encourages nation states to recentralise forest governance, reducing the rights of forest peoples to self-govern their land. REDD+ payments increase the market value of forests, creating political incentives to centralise forest governance. Additionally, FCPF policies require national systems of carbon accounting which increases the central government's role in forest governance.

In recent years, local forest governance has been strengthened across many highlyforested countries (Sandbrook et al., 2010). This trend is particularly strong in the tropics, where local communities govern an additional 200 million ha of forests compared to the 1980s (Sandbrook et al., 2010).

Many studies find forests with greater local governance achieve better social and environmental outcomes (Agrawal \& Angelsen, 2009; Dehm, 2016; Sandbrook et al., 2010). In Nepal, Gautam et al. (2004) provide evidence that community-controlled and -owned forests have had greater improvements to forest cover than government forests. Additionally, Lima et al. (2006) and Stocks et al. (2007) find Indigenous forest ownership is associated with lower deforestation rates.

However, REDD+ threatens to reverse the trend of decentralised forest governance. Sandbrook et al., (2010, p. 330) coin the 'REDD+ paradox,' arguing, "increasing value of forest resources through global carbon markets without attending to local governance and rights will create political incentives towards centralized governance, which could lead to greater forest loss and lower forest-related benefits for the poor."

REDD+ funding is structured to flow to national governments and is inaccessible to community organisations (Weaver, 2015). Multilateral organisations control a third of REDD+ funding and determine the global REDD+ policy agenda (Lujan et al., 2018). UN-REDD and the World Bank's FCPF work in partnership to facilitate funding and enforce funding requirements to national governments. To receive the third stage of REDD+ funding, national governments must develop country safeguard systems and systems of carbon accounting. This requires 
national governments to develop a system of forest monitoring, a deforestation baseline, and calculate reference emission levels (Lujan et al., 2018).

FCPF requirements create a massive bureaucratic burden yet fail to improve the institutions of recipient governments that could mitigate the risk of elite capture. Recipient governments lack both the resources to meet World Bank requirements and the incentives to ensure REDD+ benefits are distributed to forest-dependent communities. Kronenberg et al. (2015) found that the institutional capacity of REDD+ recipient governments had not improved despite implementing REDD+ readiness activities aimed at improving governance. Interestingly, Kronenberg et al. (2015) found the only REDD+ eligible country with 'good' institutional quality is Vanuatu, the location of this study, which has since failed to meet the FCPF's requirements for REDD+ results-based payments (A. Nelson, personal communication, 18 June 2019).

\subsubsection{Elite capture of benefits}

Forest peoples are marginalised and have limited access to networks and infrastructure. As aforementioned, this results in uneven bargaining power between forest-dependent communities and state and private elites. The forestry sector is notorious for elite capture and the exclusion of forest peoples (P. N. Nelson et al., 2014). This power imbalance has resulted in extractive industries dispossessing forest peoples from land and capturing the benefits of forest resources (Allen, 2013).

When the market value of forestland is high, state and private elites work in partnership to marginalise forest peoples and capture forest resources (Astuti \& McGregor, 2017; Dehm, 2016). The expectation of returns create political incentives for governments to centralise forest governance, restrict community access to information and create policy which supports corporate activity (Astuti \& McGregor, 2015). Sandbrook et al. (2010, p. 332) argue:

strengthening local rights to manage and benefit from economically valuable natural resources such as forests can change power relations between local citizens and the state. Central governments may resist such changes, particularly where existing political relationships are undemocratic and public authority is maintained through various forms of social coercion. 
The potential for REDD+ to recentralise forest governance led to the Indigenous Environmental Network describing REDD+ as a form of neo-colonialism (Dehm, 2016). Governments have subsidised and supported companies which operate on land that supports (or used to support) forest livelihoods. The Rights and Resources Initiative found that in eight out of ten 'frontier countries,' $93-99 \%$ of government-granted concessions across oil, gas, mining, agriculture and timber were granted on inhabited land (Alforte et al., 2014).

Studies have found this phenomenon extends to forest conservation programmes. In a review of reforestation and forest restoration in the Asia Pacific, Barr \& Sayer (2012) found commercial plantation companies frequently participated in several unethical practices: extending credit to farmers to gain negotiating power, bribing officials, understating their harvest to avoid paying levies, and pushing state bureaucracies to declare land as 'degraded forest' so it could be converted into timber plantations. This resulted in rural smallholders entering into agreements which threatened their long-term livelihoods.

REDD+ promises to be a viable alternative to extractive industries, however, critics warn that unless underlying power imbalances are renegotiated, elites will capture REDD+ benefits and further marginalise forest peoples (Astuti \& McGregor, 2017; Dehm, 2016).

Fairhead et al. (2012, p. 238) worry REDD+ could facilitate 'green grabbing,' "the appropriation of land and resources for environmental ends." If REDD+ increases the market value of forestland, elites may use their relative power to dispossess forest peoples from land to capture associated benefits. This follows a history in the forestry sector of multinational corporations subsidised by governments alienating forest-dependent communities to gain control of profitable forest resources (Dehm, 2016).

In REDD+ policy documents, governments in India and Nepal list contested land as under government control (Kashwan, 2015). Cronkleton, Bray, and Medina (2011) and Cotula and Mayers (2009) argue land tenure rights must be strengthened to avoid elite capture. This strengthens forest peoples' ability to claim carbon property rights and associated benefits (Sunderlin, Larson, et al., 2014). However, in forest-dependent communities, land rights are often communal, customary and informal (Anderson \& Lee, 2010). Formalising customary land rights can lead to conflict and exclude marginalised groups. Furthermore, access to customary land is often gendered (Napua, 2017; Thu, Scott, \& Van Niel, 2007). 
Nevertheless, there are other mechanisms for renegotiating the power of forest peoples. Howson and Kindon (2015) found in Indonesia, in a context of no formal land rights, local access to benefits depended on social relationships, REDD+ knowledge, and access to local markets and capital. Howson and Kindon (2015) finds that REDD+ benefits are more widely shared in Mexico compared to Tanzania and India due to accountability mechanisms which limit the power and authority of forest government bodies, resulting in greater agency for local people. This suggests accountability mechanisms, information-sharing and building the capacity of local institutions increases forest peoples' ability to access REDD+ benefits.

\subsubsection{PES mechanism undermines forest conservation}

Critics warn the neoliberal mechanism of REDD+ interferes with forest conservation goals (Büscher et al., 2012; Corbera, 2012). The final phase of REDD+ funding, results-based payments, introduces a Payment for Ecosystem Services (PES) mechanism to forest governance. Landowning forest peoples are compensated for the opportunity cost of conserving forestland and costs imposed by REDD+ activities.

Corbera (2012, p. 612) argues that REDD+ as a PES mechanism "eases the transition from an ethically informed conservation ethos to a utilitarian one that simplifies nature and undermines socio-ecological resilience." Corbera (2012) criticises the concept of ecosystem services, arguing that simplifying nature into discrete services undermines the complexity and interconnectedness of ecosystems. Further, commodifying natural phenomena into ecosystem services implies that nature is only valuable when useful to humans. Furthermore, Corbera (2012) argues that tying conservation activities to monetary outcomes can undermine intrinsic motivations for conservation.

Corbera (2012) further argues that PES schemes increase the cost of natural resource management. Valuing and measuring ecosystem services requires substantial monitoring and assessment. This is particularly expensive when externally-funded PES schemes must use external agencies and cannot internalise monitoring costs.

Relatedly, scholars question the environmental effectiveness of carbon offsetting schemes (Dehm, 2016). Such schemes assume commensurability between emitted and sequestered carbon, despite different metabolic interactions (Dehm, 2016). Critics also argue schemes distract from structural changes to move to a post-carbon economy, distracting from 
structural regulation of heavy-emitting industries and providing a mechanism for these industries to continue emitting. Dehm (2016) extends this argument, arguing that REDD+ forces forest peoples into the green growth agenda, as high-emitting multinational corporations can pay to offset their emissions to forest peoples in the global South.

However, to date, non-market forest conservation programmes often struggle to finance ongoing livelihoods, particularly when directly competing with the lucrative and immediate offers of logging. Weaver (2015) argues that the results-based financing of REDD+ is more attractive to investors. REDD+ payments are conditional on results and programmes must undergo carbon accounting monitoring and verification, reducing investor risk. This means that REDD+ could attract more funds and potentially offer a viable solution to extractive forest industries.

Moreover, offsetting schemes do not need to be mutually exclusive with broader climate reform, which seeks to reduce emissions outright. Nevertheless, this tension shows the importance of transparency and regulation to ensure state and private elites cannot coopt REDD+.

\subsubsection{Poverty and exclusion}

Scholars worry REDD+ can exacerbate poverty and exclude poorer community members. While REDD+ payments can increase community income, REDD+ places an administrative burden on communities through its monitoring requirements and restricts livelihood activities such as timber collection.

Studies have found conflicting results on the impact of REDD+ projects on poverty and livelihoods. Maraseni et al. (2014) find that in Nepal, the costs to the community imposed by REDD+, such as community meetings, are not offset by REDD+ payments. While these activities potentially have social and environmental benefits, if communities are not properly compensated, REDD+ risks exacerbating poverty. In a review of the benefits of 41 REDD+ projects, Lawlor et al. (2013) found half were producing material benefits such as jobs or payments for the community. The authors found that longer-running projects produced greater benefits, suggesting this number should increase.

REDD+ payments have the greatest potential for poverty alleviation where other economic opportunities are limited. Maraseni et al. (2014) found that REDD+ increased the 
participation of Dalit (untouchable caste), Indigenous peoples, women and the poor in local forest governance, perhaps due to limited alternative livelihoods for marginalised groups. Lawlor et al. (2013) found projects in Africa delivered the greatest community benefits, the authors suggesting due to lack of other income-generating opportunities.

\subsection{Community Forest Management and REDD+}

The first decade of the $21^{\text {st }}$ century saw a move to decentralise forest governance, giving greater rule-making authority to local communities (Sayer et al., 2017). A large part of this was the rise of Community Forest Management (CFM), which as defined by Newton et al. (2015, p. 27), "refers broadly to forest use and governance arrangements under which the rights, responsibilities, and authority for forest management rest, at least in part, with local communities." Bottom-up forest governance that gives local communities the right to manage forests has existed in many forms for several decades (Pagdee, Kim, \& Daugherty, 2006).

Local communities are more likely to change behaviour or allocate resources towards forest conservation if they have a stake in forest governance (Hayes \& Persha, 2010). In a study of 69 community forest case studies, Pagdee et al. (2006) found 'expectation of benefits' and 'clear land tenure' as determinants of success. Hayes and Persha (2010) find that successful CFM gives forest-dependent communities the authority to determine their own conservation rules.

To date, much REDD+ activity occurs in existing forest conservation sites (Newton et al., 2015). Forests with conservation arrangements such as CFM have conservation institutions and local actors with experience in forest conservation. Many existing CFM sites have improved environmental and social outcomes with REDD+ funding (Maraseni et al., 2014). In a study of the interactions between CFM and REDD+, Newton et al. (2015) found that REDD+ funding strengthens CFM in Nepal and expands CFM forest area in Tanzania. Notably, the Loru forest, the case study of this thesis, is a community conservation site turned forest carbon project. While not accessing REDD+ funds, the Loru project operates as a PES scheme and partners with the carbon credit on-seller Ekos.

Many of the potential risks of REDD+, such as elite capture and poverty exacerbation, are common generally in forest governance settings, rather than a product of REDD+ itself 
(McGregor et al., 2014). Lessons learned from CFM can help REDD+ policymakers and practitioners identify success factors and barriers to just and sustainable forest governance (Agrawal \& Angelsen, 2009).

Nevertheless, scholars warn of tensions between the goals and mechanisms of REDD+ and CFM. CFM was developed to protect forest resources needed to support forestdependent livelihoods (Newton et al., 2015). However, REDD+ is chiefly a climate change mitigation programme. Forest-dependent livelihoods are considered a secondary co-benefit, particularly in the early development of REDD+ (Newton et al., 2015).

REDD+ programmes which do not prioritise forest livelihoods fail to meet, what climate justice scholars label, a 'just transition' (Marion Suiseeya, 2017; McCauley \& Heffron, 2018). Local communities in the global South have contributed the least to climate change yet are the most vulnerable to its local effects (Whyte, 2013). A REDD+ programme which upholds climate justice principles acknowledges the need for retributive justice inherent in this inequity through prioritising social justice outcomes to local communities (McCauley \& Heffron, 2018).

\subsection{Multi-scalar forest governance}

A success factor arising from CFM literature is the importance of institutional arrangements. Specifically, building the capacity of local institutions and a robust regulation and accountability system at a national level. In a study of CFM initiatives, Cronkleton et al. (2011) found that CFM results in social and environmental benefits only when local institutions are supported by fair governance.

Therefore, many scholars recommend a nested or multi-scalar approach to forest governance (Brugnach, Craps, \& Dewulf, 2017; Hayes \& Persha, 2010; Pahl-Wostl, 2009). Put differently, a forest governance package such as REDD+ should operate at multiple scales. Importantly, forest use and rulemaking rights should be allocated to local people. Organisations which act as intermediaries such as NGOs can break down knowledge barriers (Dawson et al., 2018), provide technical support, and offer capacity building in skills such as forest monitoring. National-level institutions should regulate corruption, elite capture and conservation practices. Multi-national organisations can play a role by providing funding for forest conservation externalities like carbon capture that occur a global scale. As Corbera 
(2012, p. 612) states "to be effective, REDD+ will require several coordinated national and regional policy programs, subnational projects, and involve multiple actors, including governments, non-governmental organizations (NGOs), multilateral agencies, private organizations, communities and individuals." Failure to do so risks REDD+ being co-opted by elite groups, endangering forest communities.

Capacity building allows communities to manage forests themselves by strengthening local institutions and building necessary skills such as forest monitoring (Dawson et al., 2018). Hayes and Persha (2010) and Cronkleton et al. (2011) find community-managed forests are more successful when local rule-making institutions are supported with technical and financial assistance. When considering how this could apply to REDD+, Cronkleton et al. (2011) recommend strengthening the rights and capacity of forest peoples and their institutions. Likewise, Collen, Krause, Mundaca, and Nicholas (2016, p. 1) argue, "complementing top-down policy measures with bottom-up institutional development could provide a stronger platform to achieve the shift from current land use driving deforestation to a lower-carbon-emissions land management trajectory."

Regulation prevents some elite capture, for example for by making local leaders accountable through transparent reporting. Hayes and Persha (2010) find communitymanaged forests are more likely to be successful if there is a mechanism which acts as a buffer of elite capture and corruption. Additionally, regulation can improve conservation outcomes. Not all communities are intrinsically concerned with sustainability, especially if connection to forestland is weak and ecosystem benefits occur downstream (Agrawal \& Angelsen, 2009). Sayer et al. (2017) found that locally-managed forests do not meet biodiversity outcomes when trade-offs occur between the local needs of forest dwellers and long term ecological health. Sayer et al. (2017) recommend biodiversity declines can be mitigated through regulation, suggesting a role for national governments.

However, REDD+ eligible states perform poorly on governance indicators such as corruption (Kronenberg et al., 2015). Multi-national organisations are needed to provide funding and support for local and national governments. Critically, REDD+, with its links to the UNFCCC and the Paris Agreement, is the closest to a multilateral financing instrument of the scale needed to curb global deforestation and forest degradation. With the magnitude of the 
threat posed by climate change on forest-dependent communities, effective, international action is vital.

\subsection{UNFCCC REDD+ Safeguards}

REDD+, especially in its third stage-results-based payments, has been controversial among academics and Indigenous and activist groups (Dehm, 2016; SommerFilms, 2008). At the launch of the FCPF at COP 13 in Bali, the then Chair of the United Nations Permanent Forum on Indigenous Peoples, Victoria Tauli-Corpuz criticised the World Bank for failing to consult with Indigenous peoples (Dehm, 2016). At the same event, at the Indigenous Peoples' Forum on Climate Change, attendees protested, stopping proceedings to express their lack of support for REDD+ (see Figure 3.1). Around the same time, several scholars condemned REDD+, highlighting the risk to forest-dependent livelihoods if communities are not properly consulted and included (for example see Griffiths, 2007; Hall, 2008).

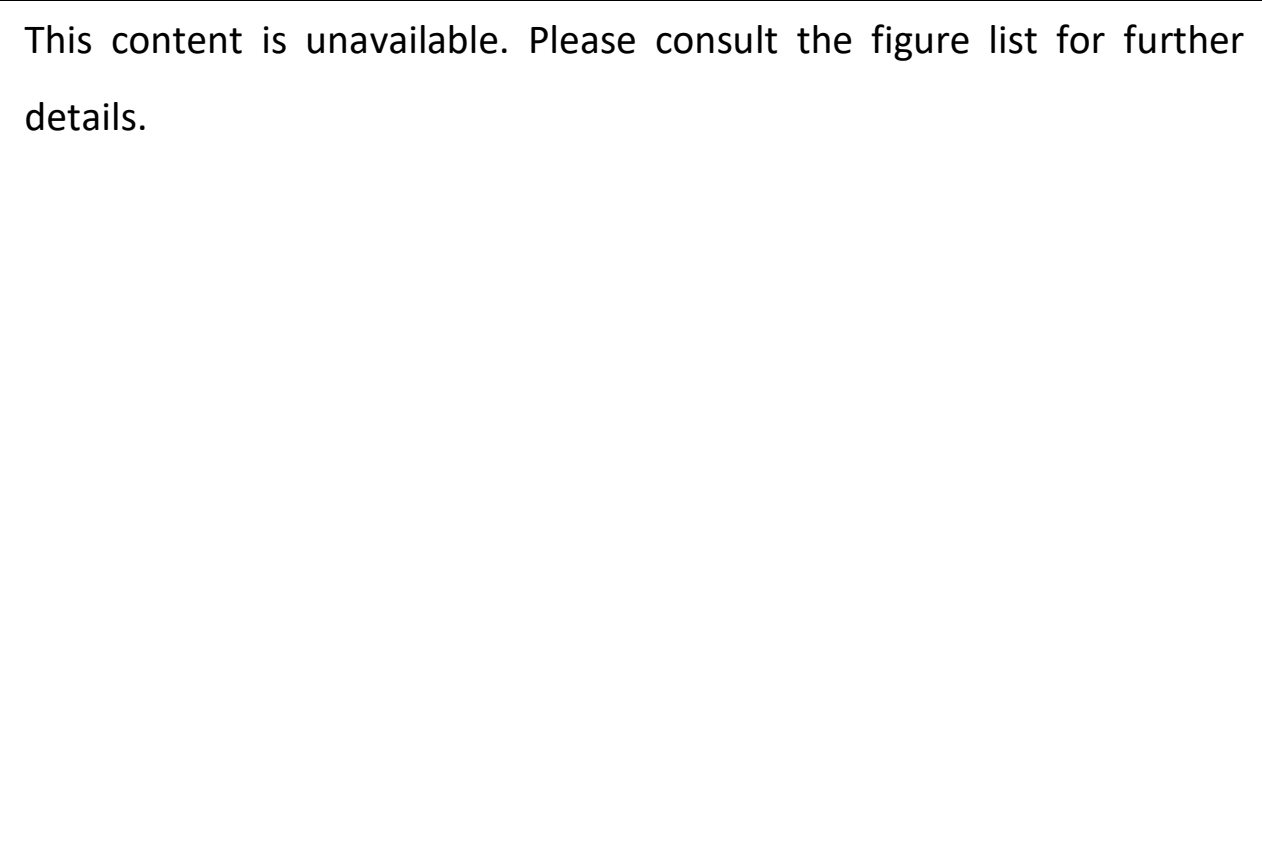

Figure 3.1 REDACTED-Attendees protest the Indigenous Peoples' Forum on Climate Change at launch of the FCPF Note: From SommerFilms. (2008, 11 May). REDD "2nd MAY REVOLT" at the UNPFII (REDD, CDM). YouTube. https://www.youtube.com/watch?v=UtORVi7GybY 
This led the UNFCCC to adopt a set of seven safeguards to attempt to mitigate these risks (see Box 1). The safeguards were agreed to in Cancun at COP16 in 2010. The seven safeguards intended to:

mitigate the risk of adverse social and environmental impacts of REDD+ activities... (and) actively promote benefits beyond carbon emission reductions, such as increased land tenure security, enhancing biodiversity, improving forest governance and empowering relevant stakeholders by ensuring their full and effective participation. (Rey et al., 2013, p. 13)

The UNFCCC hopes the establishment of REDD+ Safeguards will encourage recipient governments to develop a Country Safeguard System which "define(s) how safeguards are to be dealt with in a cohesive manner... (and) lead to considerable forest governance improvements" (Rey et al., 2013, p. 19). As part of implementation activities, countries must report on how UNFCCC REDD+ Safeguards are being addressed through a national Safeguard Information System. In 2011 at COP17, The Durban decision determined recipient countries must implement a Safeguard Information System to be eligible for results-based finance (Rey et al., 2013). 


\section{Box 1: UNFCCC Safeguards}

From Rey, Roberts, Korwin, Rivera, and Ribet (2013)

1. That actions complement or are consistent with the objectives of national forest programmes and relevant international conventions and agreements;

2. Transparent and effective national forest governance structures, taking into account national legislation and sovereignty;

3. Respect for the knowledge and rights of indigenous peoples and members of local communities, by taking into account relevant international obligations, national circumstances and laws, and noting that the United Nations General Assembly has adopted the United Nations Declaration on the Rights of Indigenous Peoples;

4. The full and effective participation of relevant stakeholders, in particular indigenous peoples and local communities, in the actions referred to in paragraphs 70 and 72 of this decision;

5. That actions are consistent with the conservation of natural forests and biological diversity, ensuring that the actions referred to in paragraph 70 of this decision are not used for the conversion of natural forests, but are instead used to incentivize the protection and conservation of natural forests and their ecosystem services, and to enhance other social and environmental benefits, taking into account the need for sustainable livelihoods of indigenous peoples and local communities and their interdependence on forests in most countries, reflected in the United Nations Declaration on the Rights of Indigenous Peoples, as well as the International Mother Earth Day.

6. Actions to address the risks of reversals;

7. Actions to reduce displacement of emissions.

At the initial drafting of the safeguards in COP14 in 2008, the United States, Canada, New Zealand and Australia successfully lobbied to remove the reference to 'rights' and the UN Declaration of the Rights of Indigenous Peoples ${ }^{1}$ (Dehm, 2016). Civil society groups including the Indigenous Peoples' Forum on Climate Change protested this change, insisting an "unequivocal reference to rights and the UN Declaration on the Rights of Indigenous Peoples be reinserted into the Draft COP14 Decision text on REDD" (Lang, 2008).

\footnotetext{
${ }^{1}$ In the same year, the four countries voted against the UN Declaration on the Rights of Indigenous People, but all have since endorsed the declaration (Dehm, 2016).
} 


\subsection{Chapter conclusion}

REDD+, as the largest global financing instrument to protect forests, offers an opportunity to mitigate climate change in the forestry sector. However, critics warn REDD+ can facilitate elite capture of forestland, reduce local forest governance and exacerbate poverty. Nevertheless, institutional frameworks can mitigate the risks of REDD+. Local communities should be supported, and regulation can promote accountability and transparency to improve social and environmental outcomes. 


\section{Chapter 4 Socio-historical background of Vanuatu}

This chapter situates this thesis research, providing context for the research location: the Melanesian archipelago nation of Vanuatu. I give an overview of Vanuatu; its history, geography, political-economic systems and culture, and explore ni-Vanuatu (Indigenous Vanuatu) concepts of kastom (Bislama for tradition, custom) (Crowley, 2003) and land rights.

Vanuatu is an archipelago of 82 islands, 67 of which are inhabited, and eight with a significant population (Bradacs, Heilmann, \& Weckerle, 2011). Vanuatu, along with its neighbours: Solomon Islands, Fiji, Papua New Guinea, New Caledonia and the Indonesian region of Western New Guinea, make up Melanesia. Of Vanuatu's 276,244 residents, 95.5\% are Indigenous ni-Vanuatu and half are under 18 (Bolton, 2003). In the $20^{\text {th }}$ century, Vanuatu was jointly colonised by France and Britain and gained independence in 1980 (Geary Nichol, 2014). Three-quarters of ni-Vanuatu live in rural areas and rely on subsistence production (Napua, 2017). The UN classifies Vanuatu as a Small Island Developing State (SIDS) with barriers to economic development due to its remoteness and climate vulnerability (UNDP, 2019). However, customary land norms and local traditional economies have buffered poverty and are a source of resilience for ni-Vanuatu (Napua, 2017; Regenvanu, 2010). Customary rights to land are embedded into its Constitution and traditional kastom. It is the responsibility of village leaders or kastom jifs (custom chiefs) to ensure all have enough land to meet livelihood needs.

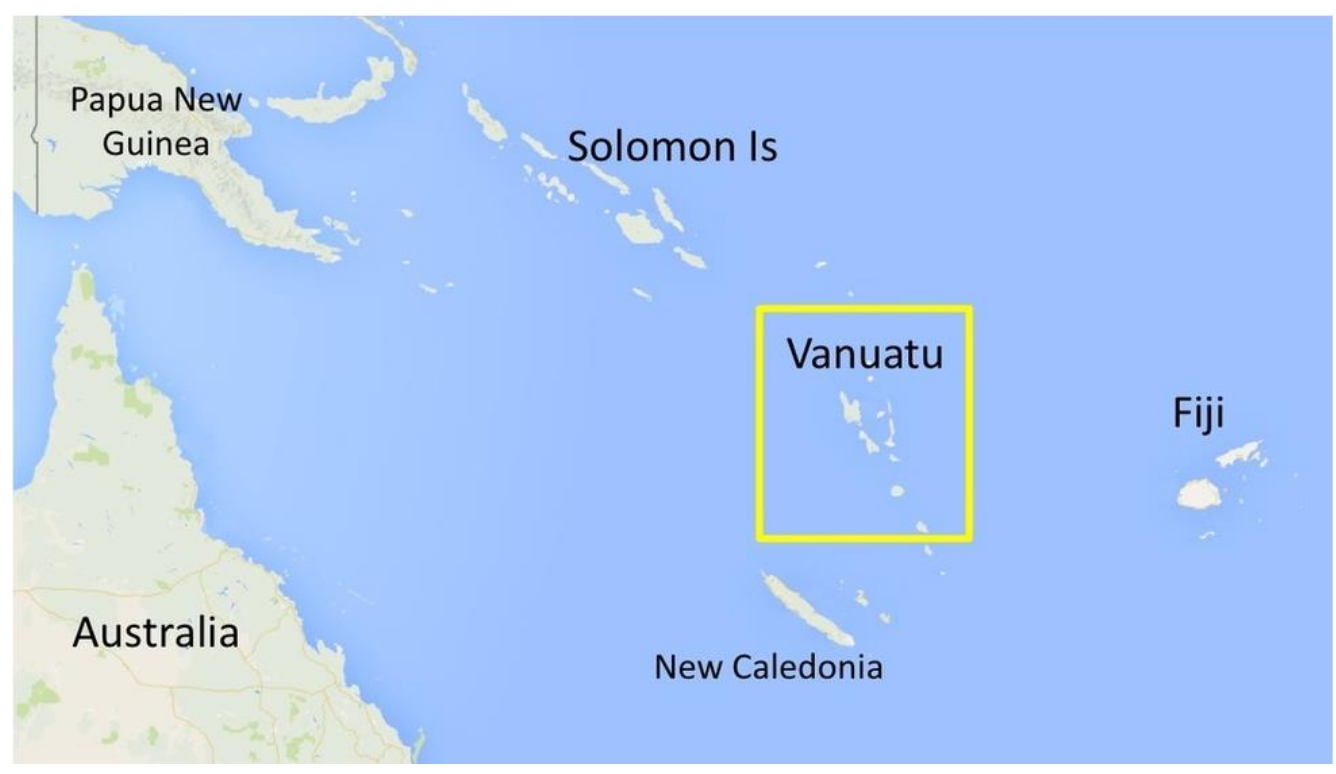

Figure 4.1 Map of Melanesia showing location of Vanuatu

Note: From Nakau. (2019). Loru Forest Project-Vanuatu. http://www.nakau.org/loru---vanuatu.html 


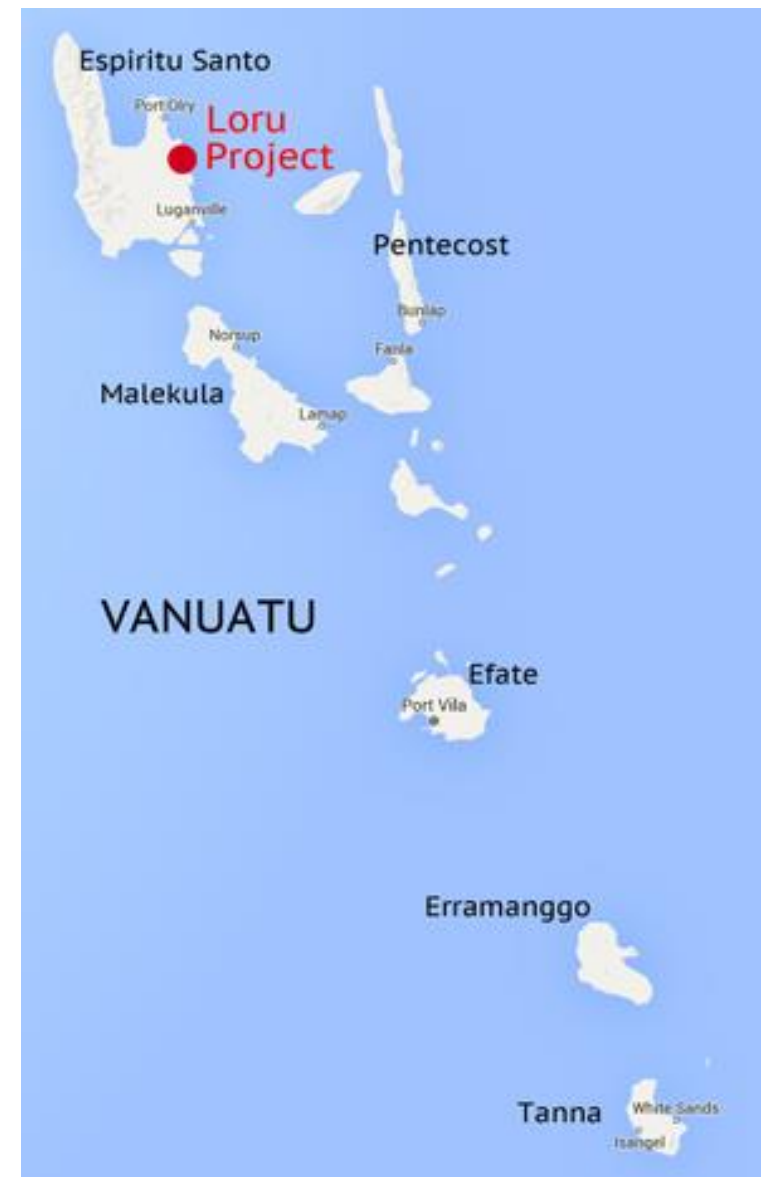

Figure 4.2 Map of Vanuatu showing location of Loru Project

Note: From Nakau. (2019). Loru Forest Project- Vanuatu. http://www.nakau.org/loru---vanuatu.html

\subsection{History}

The first human settlers of Vanuatu were the Lapita people, and Lapita pottery has been found that dates back to 3200 years B.P. (Bedford, Spriggs, \& Regenvanu, 1999). Archaeologists believe settlers first arrived at coastal sites with access to freshwater, before moving inland as resources depleted, and later re-occupying the initial sites as the population grew (Bedford et al., 1999).

The first European arrival, Spaniard Pedro Fernandez de Quiros, anchored in Espiritu Santo in May 1606, believing it to be Australia (MacClancy, 2002). Quiros attempted to build a settlement in Santo, 'Nouva Jerusalem,' granting knighthoods and appointing ministers. However, Quiros encountered increasing local resistance after his men shot, kidnapped and stole food from villagers, and Quiros left 50 days after arriving. Captain James Cook arrived six years later, exploring and naming most of the islands, declaring the archipelago the New Hebrides', which Vanuatu was known until independence in 1980. The ni-Vanuatu believed 
the European arrivals were reincarnations of their ancestors, "the dead, returning in bodily form, sailing in floating villages which had been manufactured out at sea" (MacClancy, 2002, p. 22).

Typically, Vanuatu's colonial history is characterised by opportunistic Europeans exploiting ni-Vanuatu for political, social and economic gain. In the $19^{\text {th }}$ century, Australian traders sought Vanuatu sandalwood and labour for Queensland's sugar industry in a trade known for atrocities and massacres (MacClancy, 2002).

Throughout colonisation, ni-Vanuatu were implicated in the opposing interests of their colonisers, Britain and France (Bolton, 2003). In the $19^{\text {th }}$ century, French and English settlers were frequently in conflict with each other and mistreated ni-Vanuatu labourers. The AngloFrench Joint Naval Commission, established in 1887, but could only deal with acts of war and did not sail to Vanuatu for six months during the hurricane season. The British-French Condominium of New Hebrides (as Vanuatu was then known) was established in 1906 with the aim of regulating European settlers. For the 74 years of the Condominium, ni-Vanuatu were officially stateless. Both countries prevented the other from naturalising ni-Vanuatu as national citizens (Rawlings, 2015). The Condominium duplicated functions of government and had dual healthcare, currencies, police forces, prisons and legal systems. Missionaries controlled the English and French school systems (Protestant and Catholic respectively) until the 1960s (Bolton, 2003).

Kastom understandings of land are incompatible with the capitalist notion of 'owning' land imposed by Europeans. European settlers exploited this, 'buying' ni-Vanuatu land without the knowledge and consent of kastom holders. Captain Simon Bridge wrote in 1882, "there has been difficulty in getting the natives to understand the real nature of an out-andout sale of land and its alienation in perpetuity" (McDonnell, 2013, p. 4). In one fortnight in the 1880s, one-twelfth of Vanuatu's total land area was claimed by French settlers (MacClancy, 2002). Ni-Vanuatu had no conception that land could be sold permanently, and colonial powers enlisted naval patrols to protect "the lives and property of nationals" (McDonnell, 2013).

Prompted by the French land grab, the New Hebrides National Party established in 1970 and pushed for independence. While France resisted independence, the colonial powers 
agreed independence would be granted on 30 July 1980 under Prime Minister Walter Lini, head of the New Hebrides National Party, now renamed the Vanua'aku Party.

\subsection{Physical geography and climate change}

Vanuatu is in the Pacific ring of fire and its islands are mountainous and volcanic. Along with frequent earthquakes and four active volcanoes, Vanuatu experiences four to six cyclones a year (Bradacs et al., 2011). Vanuatu's climate consists of a dry season from May and October, and a wet hurricane season from November to April. Droughts and flooding in the respective seasons are common and exacerbated by El Nino and La Nina cycles (McCarter \& Gavin, 2014).

Although Melanesia features significant biodiversity, Vanuatu has less diverse flora and fauna than its neighbours due to its relative geological youth (McCarter \& Gavin, 2014). Forested land, including plantation forests (mainly coconuts), make up three-quarters of Vanuatu's total land area.

As a SIDS, Vanuatu is vulnerable to the local effects of climate change (Mele, Killmann, Glauner, \& Bartlett, 2013). Vanuatu's majority rural population have livelihoods based on the local environment. Climate change will increase the severity of cyclones, which Vanuatu is already susceptible to (Mele et al., 2013). Cyclone Pam, which hit Vanuatu in 2015, damaged 96\% of food crops. Climate change is expected to damage agriculture and marine food supplies and associated livelihoods. Diseases such as malaria, dengue fever and dysentery are expected to increase (UNDP, 2019).

Vanuatu's susceptibility to natural disasters has meant ni-Vanuatu have developed robust traditional resilience strategies (Granderson, 2017). Vanuatu's adaptation response seeks to integrate capacity and traditional knowledge at the local level. Traditional resilience strategies include growing diverse crops, using local and weather-resilient building materials and sharing resources with kinship networks (Granderson, 2017). A frequently documented traditional resource management practice in Melanesia is a tabu, a customary ban on hunting and gathering in the area (Granderson, 2017; Hickey, 2007; A. Nelson et al., 2015).

Changes to land use and ownership under the impact of global capitalism have undermined traditional resilience. Much native forest has been replaced with monoculture copra (coconut) plantations, and a push to legally register land for commercial purposes has 
contributed to land conflicts and eroded kinship networks (Granderson, 2017; McDonnell, 2013).

Vanuatu's contribution to global greenhouse gases is negligible and Vanuatu has been a strong advocate of global climate mitigation and the Paris Agreement's commitment to limit the rise of global temperatures to $1.5^{\circ} \mathrm{C}$ above pre-industrial levels (The REDD Desk, 2013).

\subsection{Political and economic system}

Vanuatu operates as a constitutional democracy with a representative parliamentary system. Vanuatu has both a President, the head of the Republic, and a Prime Minister, the head of government. Vanuatu practises a dual system of governance: loa, involving the formal parliament and judiciary, and traditional kastom. This dual system has been criticised as it leaves room for interpretation that can be taken advantage of by elite groups (Bolton, 2003; Jolly, 2014; McDonnell, 2013). The National Council of Chiefs, elected by district chiefs, advises the government on matters relating to kastom such as land.

Vanuatu has experienced some corruption and political instability but performs moderately on governance indicators compared to other SIDS (Kronenberg et al., 2015). In 2015, 14 MPs were imprisoned, convicted of accepting bribes to support a motion of no confidence against the Prime Minister (Forsyth \& Batley, 2016). Votes of no confidence are common in Vanuatu, and in a six-month period between 2010 and 2011, Vanuatu saw five changes of prime ministership (Forsyth \& Batley, 2016). Nevertheless, the successful conviction of the MPs demonstrates a degree of effectiveness of Vanuatu's anti-corruption mechanisms and the legitimacy of its judiciary (Forsyth \& Batley, 2016). Vanuatu's political system distributes power broadly. It has a multi-party system so parliaments are formed by coalition governments, and the Council of Chiefs and judiciary balance out the political power of the parliament (Forsyth \& Batley, 2016).

Vanuatu has been described as a tax haven and offshore financial centre and criticised for facilitating global tax avoidance (Van Fossen, 2015). Vanuatu has zero income or corporate tax. Foreigners can buy Vanuatu passports for around USD150,000 which provides the largest source of government revenue (Van Fossen, 2015). Along with offshore financial services, tourism and fishing are major exports. However, small-scale agriculture provides the livelihood for the majority of ni-Vanuatu (Van Fossen, 2015). 
Importantly, Vanuatu has a strong traditional economy, an important source of resilience for its majority rural population (Regenvanu, 2010). Vanuatu suffered negligible impacts during the global financial crisis due to its low integration in the global economy (Regenvanu, 2010). Rural ni-Vanuatu are largely self-sufficient, growing most of their own food and relying on kinship networks for other needs (Regenvanu, 2010).

\subsection{Culture}

Vanuatu culture reflects its culturally-diverse Indigenous population scattered throughout the archipelago and modern introductions of Western religions, languages and ideologies.

Christianity is widespread in Vanuatu, and $83 \%$ of ni-Vanuatu are Christians (Jolly, 2014). Missionaries from many denominations arrived in Vanuatu in the $19^{\text {th }}$ and $20^{\text {th }}$ century, and several denominations have a significant membership today, often with multiple churches in a single village (Jolly, 1991).

Vanuatu has the highest concentration of languages in the world, with 138 Indigenous languages, some spoken by only a few villages (François, Franjieh, Lacrampe, \& Schnell, 2015). Bislama, Vanuatu's lingua franca, became Vanuatu's national language upon independence in 1980 (François et al., 2015). Most ni-Vanuatu speak an Indigenous language, Bislama and either English or French.

Status is traditionally important in Vanuatu, particularly in the Northern islands (Bolton, 2003). Men achieve higher status by taking part in ceremonies such as hunting and sharing wild pigs in a ritual feast. Traditionally, women gain status through exchanging woven mats (Jolly, 2014). In some communities, status-alteration ceremonies were exclusively the domain of men, performed in secret societies (Bolton, 2003). These ceremonies are still of importance in some ni-Vanuatu communities, adapted to be relevant for today. Members of the Ser clan attended a status ritual feast while I was in the village for fieldwork.

Women have been marginalised in Vanuatu. Kastom societies were male-dominated and with colonisation, missionaries brought ideologies that restricted women in new ways (Jolly, 2014). Early missionaries described widespread domestic violence towards women, female infanticide and widow strangling (Jolly, 1991; Spriggs, 1993). However, these practices may have been over-stated as missionaries had a vested interest in portraying ni-Vanuatu communities as barbaric to justify their evangelical practices (Jolly, 1991). 
While missionaries ended violent patriarchal practices such as (disproportionately female) infanticide and widow strangling, they promoted gender relations based on a strict division of domains that limited women to the home. Evangelical Protestantism, in particular, promoted the ideal of 'compassionate' women being restricted to the home, and 'rational' men in the public space of work and commerce (Jolly, 1991). Today, women are restricted from owning customary land, which is passed down patrilineal lines (Smith, 2017). Vanuatu has a high rate of violence towards women and only $49 \%$ of girls complete primary school (Napua, 2017).

\subsection{Kastom}

Kastom is a Bislama word roughly translated to mean ni-Vanuatu culture and ways of life. It is an adaptive, multi-dimensional concept deeply embedded into ni-Vanuatu identity (Jolly, 2014). Pre-independence, kastom was contrasted to European, mainly missionary-introduced beliefs and traditions (Bolton, 2003). Post-independence, the concept was reclaimed and, "kastom became, by means of political discourse, constituted as a defining characteristic that united people throughout the archipelago" (Bolton, 2003, p. 15). Although kastom was developed as an oppositional concept to missionary-introduced beliefs, 'skul,' Christianity is now embedded within ni-Vanuatu identify and enshrined in its Constitution alongside kastom (Jolly, 1996).

Kastom has served to unify ni-Vanuatu towards a sovereign post-colonial identity. However, kastom has also been co-opted to resist progressive change and serve political interests (Jolly, 2014; Napua, 2017). Jolly (1996, p. 176) describes kastom as "not so much the totality of ancestral practices as a particular selection of such practices for the present." Powerful groups have controlled the kastom narrative, determining what counts as kastom to support their interests and keep their power. As Jolly (1996, p. 182) explains:

In acting against the power of western-derived laws and the expatriate male judiciary, some men at both local and national levels are not so much reclaiming powers which they had in kastom as asserting new and more strenuous forms of male control over women, in contestation with outside powers and foreign values.

In the lead up to independence, the New Hebrides National Party's representative assembly established a Council of Chiefs to advise on matters of kastom. Ni-Vanuatu communities were traditionally organised by a graded system of rank rather than a hereditary 
chiefly system (Smith, 2017). Chiefs were a Condominium introduction, influenced by the chiefly systems of Polynesia (Bolton, 2003). The power of chiefs can be seen in the interpretation of the chiefly title of land that is used to claim ownership and control of traditional land (Smith, 2017).

\subsection{Land rights}

At independence, Vanuatu's Constitution established that foreigners cannot own land in Vanuatu and all ni-Vanuatu have a right to land needed to support their livelihoods (Anderson \& Lee, 2010; Napua, 2017). As stated in the Constitution:

73. All land in Republic of Vanuatu belongs to the Indigenous custom owners and their descendants...

75. Only Indigenous citizens of the Republic of Vanuatu who have acquired their land in accordance with a recognised system of land tenure shall have perpetual ownership of their land (Vanuatu Constitution. Ch. 12)

Customary land is recognised through chiefly claims of land, a 'big chief' owns and controls land (Napua, 2017). Smith (2017, p. 350) explains, "overlapping rights and interests in land may apply through membership of a descent group, but also through ties of kinship with other groups, as well as through interpersonal transactions." The chiefly system of land ownership has been criticised for excluding women who cannot be chiefs (Napua, 2017).

The framework of universal land rights have protected Vanuatu from state-sponsored land grabs by foreign businesses that occurred in much of the global South (Napua, 2017). However, many ni-Vanuatu are alienated from their kastom land. While foreigners cannot own land, land can be leased out for 75 years (the lifespan of the coconut palm). At the end of the lease, lessor landowners must compensate lessees for 'improvements' to the land such as building developments, pricing ni-Vanuatu out of reclaiming their land. Areas that were sold to Europeans during the Condominium retain their titles and boundaries making them easier to lease (McDonnell, 2013). As of 2013, 9.5\% of Vanuatu's total land area is leased out, 99\% of which is land in rural areas with customary claims (McDonnell, 2013). McDonnel (2013) found that the Vanuatu government acts in the interests of the foreign lessees, and leases are often made without the consent and knowledge of traditional landholders. 
The duality of governance systems and unwritten nature of customary law has made it difficult to determine who are the rightful customary landholders to return alienated land to traditional owners (McDonnell, 2013). There is no legal requirement for the registration of customary ownership, so only small pockets of customary land are registered. Land conflicts are common, posing problems for establishing use and carbon rights.

\subsection{Chapter conclusion}

Vanuatu's colonial history shapes Vanuatu's perception to foreign interventions, influencing how ni-Vanuatu people might perceive REDD+. Vanuatu has retained a sense of national identity and independence, fostering local resilience and maintaining Indigenous ownership over land. This context has influenced Vanuatu's deforestation and REDD+ policy discussed in the following chapter. 


\section{Chapter 5 REDD+ in Vanuatu}

This chapter discusses Vanuatu's experiences with deforestation, forest governance and REDD+. Firstly, I describe deforestation and forest governance in Vanuatu. Next, I explain REDD+ progress and policy. Finally, I describe the case study site, the Loru forest and Khole village located on the island of Espiritu Santo.

Vanuatu has supported REDD+ as part of the Coalition of Rainforest Nations (The REDD Desk, 2013). Vanuatu experiences a relatively low rate of forest loss compared to other countries in the tropics. As a SIDS, the country is extremely vulnerable to climate change (UNDP, 2019). Vanuatu forest policy highlights the importance of forests as a means of resilience and adaptation to climate change (Mele et al., 2013).

Vanuatu was an earlier adopter of REDD+, starting its readiness process in 2007 (The REDD Desk, 2013). However, progress has stalled and Vanuatu has yet to become a UN-REDD member (Tehan, 2017). Vanuatu was due to submit its R-Package in 2019, to be eligible for results-based funding; however it lacks several components needed for carbon accounting such as a national forest inventory (REDD+ Unit Department of Forests, 2019). While Vanuatu includes REDD+ as a mitigation strategy to meet its nationally-determined contributions under the Paris Agreement, it notes this requires significant international assistance (Godden, 2017).

Vanuatu is the only country in Melanesia with a statutory framework for forest carbon rights, the Forestry Rights Registration and Timber Harvest Guarantee Act 2000 (The REDD Desk, 2013). The Act only applies to leased land, not providing a framework for customary landowners to claim carbon rights on the $89.7 \%$ of unleased customary land. The Act understands forest carbon rights as a forestry right, allowing carbon to be decoupled from the land (Corrin 2012).

\subsection{Deforestation and forest governance}

Vanuatu has a relatively low rate of deforestation although accurate, up-to-date data is not available (The REDD Desk, 2013). FAO's Global Forest Resources Assessment found no deforestation between 1990 and 2000 but other sources have found over 4600 hectares of forest loss in the same period (The REDD Desk, 2013). The most recent forest inventory, conducted in 1993 , found that forests made up $74 \%$ of Vanuatu's land area, although $36 \%$ of 
this was non-native production forest, and only $20 \%$ of production forest was in current commercial use (Mele et al., 2013)

Vanuatu played a role in supporting the inclusion of countries with low deforestation rates in REDD+ (The REDD Desk, 2013). While global attention has been mainly on tropical forests with immediate threats of deforestation, countries with lower deforestation rates have patches of native forest that provide significant carbon and non-carbon co-benefits (Watson et al., 2018). These activities can fit into the 'plus' of REDD+: conserving and enhancing forest carbon stocks and sustainable management of forests.

As displayed in Figure 5.1, Vanuatu's Department of Forests identify both small-scale farmers and commercial businesses as agents of deforestation for a variety of underlying reasons.

This content is unavailable. Please consult the figure list for further details.

Figure 5.1 REDACTED-Drivers, agents and underlying causes of deforestation in Vanuatu Note: From National REDD+ Unit. (2017). Addressing the drivers of deforestation and forest degradation (Reducing Emissions from Deforestation and Forest Degradation (REDD+) in Vanuatu, Issue 1.

https://forestcarbonpartnership.org/system/files/documents/Policy\%20Brief\%20Drivers\%20of\%20deforestations\%20\%20GoV.pdf

Vanuatu's Department of Forests identifies that half of its deforestation is due to subsistence land use (Mele et al., 2013). Vanuatu's REDD+ unit recognises agriculture, land 
clearing to plant cash crops and natural occurrences as the major drivers of deforestation and forest degradation (National REDD+ Unit, 2017a). The growing population of rural smallholders require increasing amounts of land and natural resources to support their livelihoods. This results in more intensive agriculture such as shorter fallow periods leading to soil degradation, and expansion into forested areas.

Forest clearing for export has also been a significant driver of deforestation. The Department of Forests state forestland is cleared for livestock grazing and to plant cash crops (Mele et al., 2013). Monocultures of cash crops damage forest ecosystem services such as soil health maintenance, water supply and purification, and eradication of disease (National REDD+ Unit, 2017a). Further, monocultures are less sustainable livelihood options. Many copra (coconut) plantations planted several decades ago are no longer productive, leaving customary owners with large areas of degraded, unproductive land. Livestock production is increasing in Vanuatu, often resulting in forest degradation in surrounding areas as cattle are left to roam in forests.

Small-scale farmers moving from varied horticulture or agriculture to monoculture cash crops exacerbates Vanuatu's vulnerability to natural disasters (Regenvanu, 2010). Vanuatu suffers extreme cyclones, such as Cyclone Pam in 2015 that generated loss and damage worth $64 \%$ of Vanuatu's GDP. When forests are disturbed due to natural disasters or human activity, the invasive vine merremia restricts forests' ability to recover, exacerbating degradation (Mele et al., 2013).

Deforestation threatens ni-Vanuatu forest-dependent livelihoods. Vanuatu's largely rural population depends on forest resources for food, fuel and building materials (Mele et al., 2013).

For the two decades following independence in 1980, Vanuatu experienced widespread logging for timber export resulting in significant degradation of native forest; $40 \%$ of commercial forestland is now considered 'degraded' (The REDD Desk, 2013). However, in 1998, the Vanuatu government banned the export of whole round logs and expelled international loggers, mainly Malaysian firms. Today, unlike many tropical countries, Vanuatu has no active industrial logging concessions and logging is only permitted using small-scale mobile sawmills (The REDD Desk, 2013). Vanuatu imports most of its timber from Fiji and New 
Zealand. However, small-scale logging for timber and fuel still exceeds the rate of re-planting (National REDD+ Unit, 2017a).

All forestland is customarily held by ni-Vanuatu. Despite no government-owned forestland, the Department of Forests is administratively responsible for forest management and enforces forestry legislation (Mele et al., 2013). The Department of Forests recognises the role of chiefs and communities in deciding how forest resources are managed such as identifying tabu sites (Mele et al., 2013).

In 2002, the Vanuatu government introduced the Environmental Management and Conservation Act (The REDD Desk, 2013). The Act allows for the establishment of Community Conservation Areas to legally protect areas under customary land conservation agreements and incorporates traditional Indigenous knowledge. Vanuatu has five formally registered forest protected areas covering 8336 hectares and dozens of unregistered community and private areas. In total, only 3\% of Vanuatu's forestland is in protected areas (Mele et al., 2013)

\subsection{REDD+ readiness process}

Vanuatu began its REDD+ process in 2006 with the launch of the Vanuatu Carbon Credits Project. Through this project, Vanuatu developed its Readiness Preparation Idea (R-PIN) and was awarded its first FCPF grant in 2010. In 2011, Vanuatu began developing its Readiness Preparation Proposal (R-PP) under the regional programme, 'Climate Protection through Forest Conservation in Pacific Island Countries,' funded by the Secretariat of the Pacific Community (SPC) and the German government, Deutsche Gesellschaft für Internationale Zusammenarbeit (GIZ) (The REDD Desk, 2013).

Vanuatu submitted its R-PP in 2013 (Viji et al., 2013). Additional funding was requested in 2017 (REDD+ Unit Department of Forests, 2017) and granted in 2018 (International Bank for Reconstruction and Development, 2018). In total, Vanuatu has received \$US6.1 million for REDD+ readiness activities (REDD+ Unit Department of Forests, 2019). While Vanuatu has made good progress on the institutional and governance preparation for REDD+, it lacks capacity for the technical arrangements such as monitoring systems and reference emissions levels. To receive the FCPF's next stage of funding under a readiness package, Vanuatu must deliver on four components:

1. Readiness Organisation and Consultation 


\section{Preparing the REDD+ Strategy}

3. Forest Reference Emission Level

4. Forest monitoring systems and Safeguards

Vanuatu has not conducted a national forest inventory since 1993 in a programme funded by Australia (The REDD Desk, 2013). The Vanuatu government has contracted the German firm, UNIQUE, to conduct a national forest inventory and create a national forest monitoring system. The national forest inventory was due to be completed in November 2019 (REDD+ Unit Department of Forests, 2019). Once completed, work can start on forest reference emission levels. The Vanuatu government performed a study of REDD+ strategy options but are yet to develop a National REDD+ Strategy which will be needed to secure results-based FCPF funding. Vanuatu continues to conduct stakeholder consultations and outreach for its REDD+ programme (REDD+ Unit Department of Forests, 2019).

\subsection{REDD+ activity}

The only active forest carbon project in Vanuatu is the Loru project run by LLV, the case study of this thesis. While the regional SPC-GIZ project identified REDD+ pilot sites, these did not eventuate due to the government moving away from an area-based approach (The REDD Desk, 2013). Nevertheless, the REDD+ unit recognised the need to prioritise demonstration activities to facilitate learning and maintain community interest (National REDD+ Unit, 2017b).

LLV has had a leading role in Vanuatu's REDD+ process and are the major nongovernmental stakeholder (The REDD Desk, 2013). In 2013, LLV produced an Extension \& Outreach Consultancy Report after engaging with 273 community stakeholders through focus groups, interviews and community consultations (A. Nelson, Thomas, \& Nickllum, 2013). LLV specialise in environmental education and have created educational resources for the local implementation of REDD+ such as assuring Free, Prior and Informed Consent (FPIC) (A. Nelson et al., 2013).

Vanuatu's National Forest Policy 2013-2023 aimed to establish 20,000 hectares of planted forests by 2020 (Mele et al., 2013). Part of the tree-planting programme is to "develop compensatory incentive schemes for forest plantations (e.g. REDD+)" (Mele et al., 2013, p. 
20). As of February 2020, Vanuatu's Department of Forests are yet to report whether they have met this goal.

\subsection{REDD+ policy}

In its R-PP, Vanuatu explains that it plans to adopt a unique 'activity-based' national REDD+ scheme (Viji et al., 2013). Rather than implement area-based REDD+ projects, Vanuatu proposes to use REDD+ funds for centralised land-use planning. This allows the national government to address deforestation without legally registering ni-Vanuatu land. However, it is not clear whether the FCPF will allow the Vanuatu government to receive results-based payments for REDD+ activities on customary land. Further, this approach applies a standard forest reference 'emission' level to all forestland. This means all forests are assumed to store the same amount of carbon, reducing the incentive of landowners of forests with a higher carbon storage potential to leave forests intact.

Despite the 2013 R-PP's stated commitment to an activity-based national scheme, a policy brief produced by Vanuatu's REDD+ unit in 2017 explored three strategy options for implementing REDD+ (National REDD+ Unit, 2017b). This included activity-based strategies at the Province or Island level, but also, acquiring and transforming degraded agricultural leased land, and area-based conservation of customary land.

\subsubsection{Government of Vanuatu acquires degraded agricultural leased land}

This option involves the government acquiring degraded agricultural leased land and subleasing it to community groups. The sub-lease agreements would enforce sub-letters to use the land for REDD+ activities such as agroforestry. This option gives greater control to the government and centralises forest governance. However, it provides a mechanism to return land leased by foreign investors to ni-Vanuatu and allocate this land to marginalised groups such as internal migrants (National REDD+ Unit, 2017b). This option is not mutually exclusive with other strategies as it only applies to leased land, about $10 \%$ of Vanuatu's total land area.

\subsubsection{Activity-based strategies at Province or Island level to encourage land use changes of customary land}

This option is in line with Vanuatu's 2013 R-PP. REDD+ funding would be used to support services to encourage smallholder farmers to move to sustainable, REDD+ eligible land use options. A cost-benefit analysis conducted by Vanuatu's Department of Forestry (DoF), found 
that REDD+ eligible land use options such as reforestation and agroforestry provide higher returns for local communities compared to business-as-usual options such as cattle or coconut farming. The DoF argue communities benefit from REDD+ land options even without receiving payments (i.e. there is an opportunity benefit to switching to a REDD+ eligible landuse option). Therefore, the DoF argues REDD+ funds should be used to fund regional policies that promote these land-use changes rather than payments to local landowners to cover the opportunity cost of changing land use (National REDD+ Unit, 2017b). This option potentially offers a way for Vanuatu to implement REDD+ without establishing and registering kastom landowners and boundaries which can cause and exacerbate land disputes (Tehan, 2017).

\subsubsection{Area-based conservation of customary land}

This strategy extends Vanuatu's protected area network using REDD+ funding. This option increases local forest governance and requires legally registering customary land (National REDD+ Unit, 2017b). This is difficult in Vanuatu's context of informal customary land rights and common land disputes and risks excluding traditional users of the land. However, if rolled out successfully, this approach supports initiatives led by local communities and localised forest governance. Communities could adopt a range of land use options best suited to their needs such as eco-tourism, non-timber forest products and sustainable firewood logging. Area-based schemes can be rolled out intermittently and require less bureaucratic preparation than the other strategies. This strategy also allows Vanuatu to prioritise areas that produce greater climate mitigation benefits such as intact native forests.

\subsection{Case study: Loru Community Carbon Forest Project}

The Loru Forest Project is an avoided deforestation project located in Espiritu Santo, Vanuatu (Figure 5.2). The Loru forest is customarily owned by Chief Stephen Skip and held by the Ser clan living in Khole village in East Santo. The project area covers 293 hectares of tropical rainforest. It is the first project in the Pacific to generate carbon credit sales (Tehan, 2017), producing 2442 carbon offsets annually since 2016, each offset representing a tonne of carbon dioxide sequestered (Nakau, 2019). The Loru forest maintains large sections of intact native forest but is surrounded by degraded forest cleared for coconut plantations and cattle ranching (Figure 5.3). 


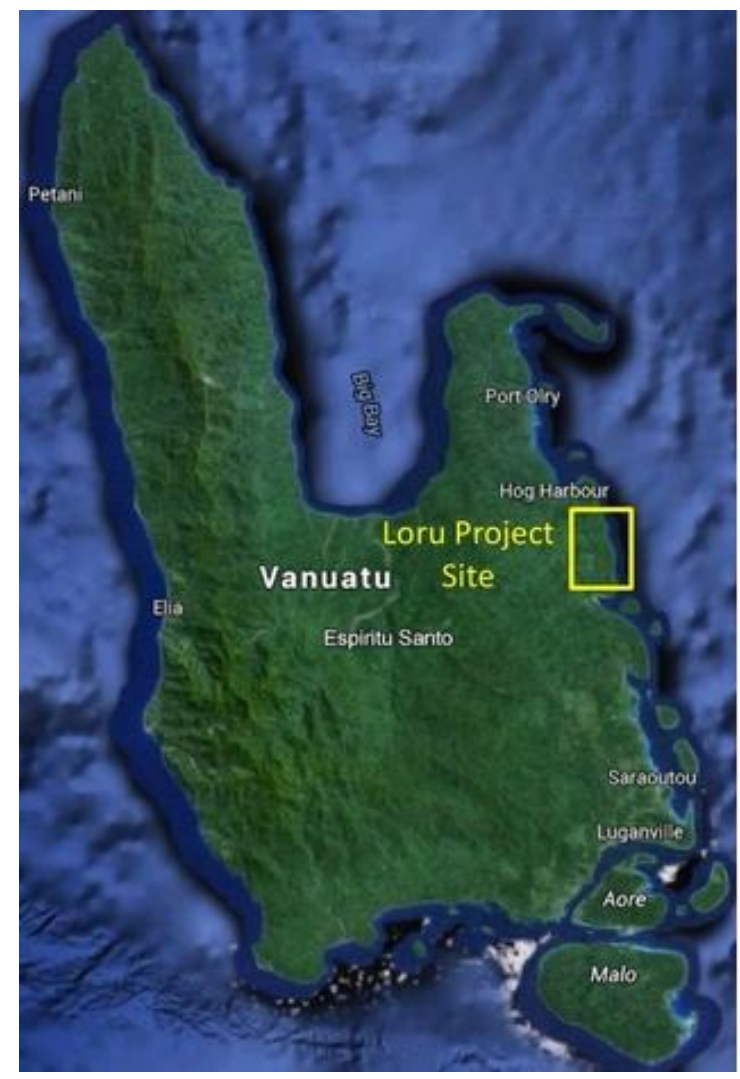

Figure 5.2 Map of Espiritu Santo showing location of Loru Project Site

Note: From Nakau. (2019). Loru Forest Project- Vanuatu. http://www.nakau.org/loru---vanuatu.html

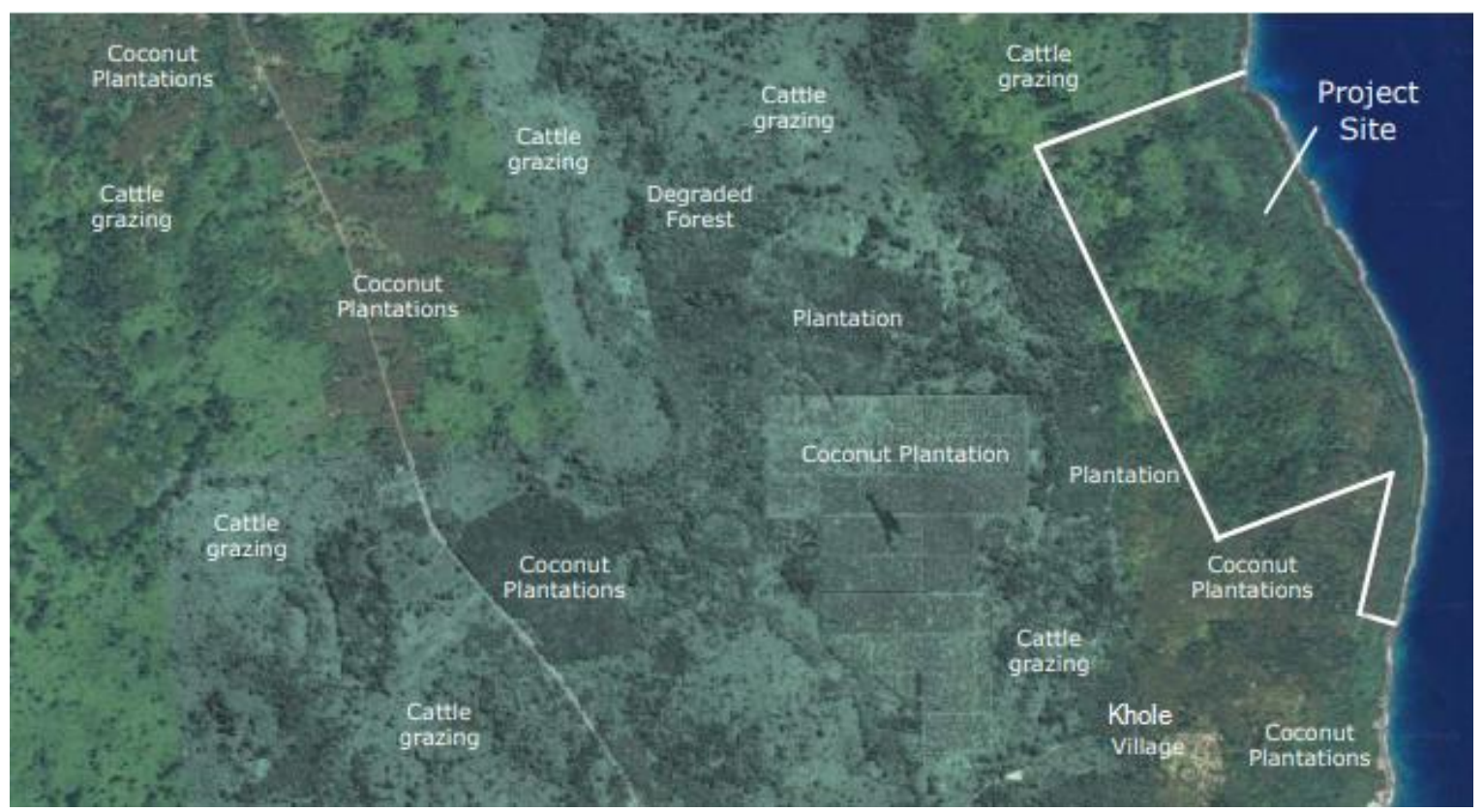

Figure 5.3 Loru Project site showing surrounding land use

Note: Adapted from Nelson, A., Andre, G., Warakar, S., Weaver, S., \& Henderson, R. (2015). Loru Forest Project- Project Description Part A: General Description. An avoided deforestation project at Loru, Santo,

Vanuatu.http://www.nakau.org/uploads/5/2/2/5/52251233/loru pd part a d3.2a v1.0 20151009b.pdf 


\subsubsection{Serclan}

The Ser clan are the community owners of the Loru forest. The members of the Ser clan can track their family history to a common ancestor, late Chief Kaleb Serakar. Chief Serakar was the kastom landowner of the Loru forest and as per kastom, the land was passed down patrilineal lines to his grandson, Chief Skip when Chief Serakar died in 2007. The clan are relatively small, with about 60 members, descended from the five children of Chief Serakar. In 2011, LLV assisted the Ser clan to establish a family business, legally registered as Ser-Thiac.

The Ser clan live in Khole village with two other clans (see Figure 5.4). Khole is located on the East coast of Espiritu Santo, accessible by dirt road. Compared to other rural villages in Espiritu Santo, Khole is reasonably accessible. Khole is close to the popular tourist attraction, Champagne Beach and is a 90 -minute drive from the island capital, Luganville.

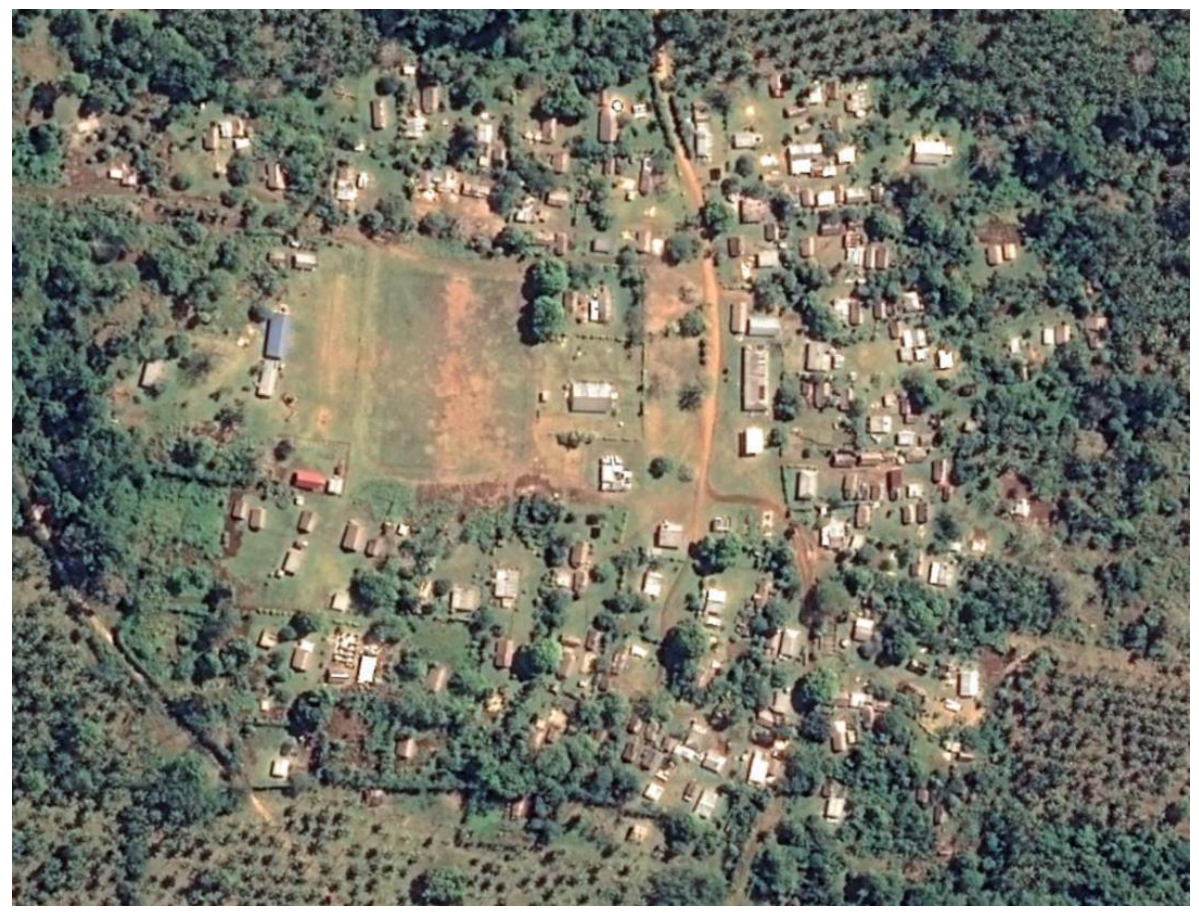

Figure 5.4 Aerial photo of Khole village

Note: From Google Earth. (2019). https://earth.google.com/web/@-

$\underline{15.23035676,167.15812756,125.68664934 a, 1239.87955886 \mathrm{~d}, 35 \mathrm{y}, 0 \mathrm{~h}, \mathrm{Ot}, \mathrm{Or}}$

Most of the Ser clan members are smallholder farmers. Each family is allocated one or more plots of agricultural land that they manage, about one hours' walk from Khole village. During fieldwork, I observed that the villagers typically walk to their plots to work on their land for about eight hours each day from Monday to Friday and attend church on Sunday. The 
clan are largely self-sufficient, growing much of their own food. Villagers trade with each other, engaging more with the cashless, local economy than the globalised cash economy.

The male villagers historically spent most of their time tending coconut plantations to sell copra for export, while women tended gardens (A. Nelson, personal communication, 18 June 2019). However, in the last few years, villagers have not sold much copra and both men and women spend most of their time farming a variety of local food crops. The Ser clan own land with coconut plantations, cleared and planted by ancestors several decades ago. Like most of rural ni-Vanuatu, the Ser clan rely on the income from selling copra to pay for school fees. However, a low global copra price and preference against copra labour has meant current clan members only work on coconut plantations for upkeep rather than to harvest and sell, and no new coconut palms have been planted.

As I observed during fieldwork, some villagers work locally as a taxi driver (the only car in the village), carpenter, church leader or primary school teacher. The Ser clan have established eco-tours around the Loru forest and host small numbers of tourists. Several villagers have jobs outside Khole, commuting into Luganville, the second largest city of Vanuatu with a population of 16, 312 (VNSO, 2017). Others have moved to the capital Port Vila which has a total population of 51, 437 (VNSO, 2017). Several join the 8000 ni-Vanuatu working seasonally in New Zealand and Australia (RNZ, 2018).

Women in Vanuatu typically move to their husband's village when they get married. Several of the women living in Khole village have moved there from villages around Espiritu Santo or from other islands in Vanuatu. Across Vanuatu, 'mamas' (village women) travel to the island capital to sell food crops. Women from Khole travel together once or twice a month to sell food crops at the market in Luganville and sometimes tend a local stall on the main tourist road. The women spend a whole week at the market, sleeping on mats under their stalls. On average, villagers leave Khole village once a week to visit Luganville (see Social Impact Survey 2019, Appendix A). Public buses regularly go past the main road.

Khole village has a primary school where children attend between ages five and eleven. Older children typically board at secondary schools around Espiritu Santo. Children's access to post-primary education is largely limited by family access to cash to pay for fees and 
many children drop out before finishing, or work for a couple of years before returning to school. Only one member of the Ser clan has attended university.

Most Khole villagers speak their local language, Bislama and either English or French. The local primary school teaches the local language and Bislama. Secondary schools typically teach English and a minority teach French.

\subsubsection{Live and Learn Vanuatu}

Live and Learn Vanuatu (LLV) is part of the Live \& Learn Environmental Education International network. Live and Learn International (LL) consists of nine locally-registered NGOs in Asia and the South Pacific, with its head office in Melbourne, Australia. LL builds networks of community groups, UN agencies, local communities and academic institutions and delivers environmental education to rural communities (Live \& Learn, 2019). Its work focuses on six areas; human rights and freedoms, environmental protection, water, sanitation and hygiene, climate change, disaster risk reduction and response, and gender and women's empowerment (Live \& Learn, 2019). LLV has its head office in Port Vila. It is comprised mostly of local, ni-Vanuatu staff and maintains close links to the rural communities it works with.

\subsubsection{Ekos}

Ekos is a social enterprise based in New Zealand. It was founded by Sean Weaver, who has worked in REDD+ policy and implementation in the Pacific Islands and worked with the Vanuatu government to submit their R-PP. Ekos has two projects in New Zealand, the Rarakau Rainforest Conservation Project and the Rameka Forest Carbon Project. Ekos partners with communities to conserve Indigenous forests and deliver community and biodiversity cobenefits on top of climate mitigation (Ekos, 2019).

\subsubsection{The Nakau Programme (Nakau)}

The Nakau Programme Pty Ltd is a company registered in Australia and co-owned by LL and Ekos. It is co-directed by Anjali Nelson, Sean Weaver and Robbie Henderson. Nakau is the only regional Payment for Ecosystem Services (PES) programme in the Pacific Islands. It aims to improve the climate resilience of Indigenous communities, supported by funding through the sale of carbon offset credits generated through forest conservation (Nakau, 2019). Nakau launched the Loru project as a pilot in 2013. It now has two other projects: Drawa in Fiji and Sasaboe in the Solomon Islands. Its later projects are substantially bigger in size, 4120 
hectares and 2407 hectares respectively compared to Loru's 293 hectares, and unlike Loru, cover areas owned by multiple customary landowners.

\subsubsection{History}

Late Chief Kaleb Serakar placed a traditional tabu on the Loru forest in 1993, protecting it from degradation and deforestation. Most of the surrounding area had been cleared of native forest to plant monoculture coconut plantations for copra export. Chief Serakar had noticed declines in biodiversity, notably the native coconut crab which held cultural significance. The traditional tabu boundary is marked with a namele leaf and surrounding villages understand that this prohibits hunting and logging within the site. Creating the tabu site set an important precedent of conservation for the Ser clan who continue to resist economic pressures to degrade the Loru forest.

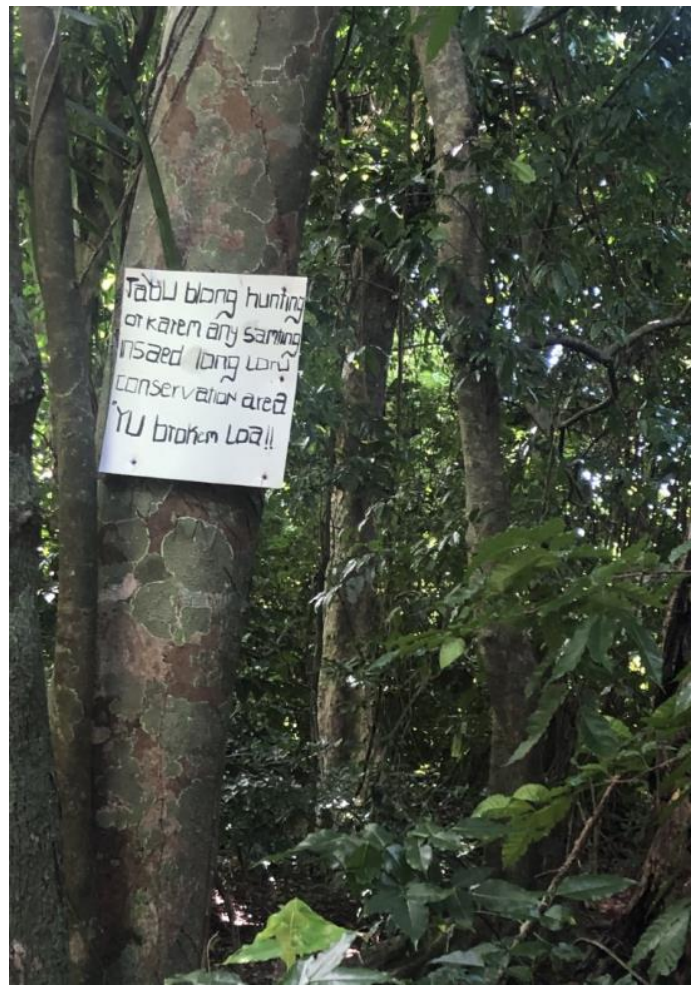

Figure 5.5 Tabu sign on a tree in Loru forest

Following Chief Kaleb's death in 2007, the Ser clan faced increasing financial pressures to clear the forest and plant cash crops (A. Nelson et al., 2015). The community needed cash for school fees and lacked the funds to protect the forest from the invasive vine, merremia.

The Loru Forest was registered under the Vanuatu Protected Areas Initiative in 1995 under Chief Serakar (VPAI, 2002). Chief Serakar's son, Warakar Ser was a member of Vanuatu 
Protected Areas Initiative and later started working at LLV's Port Vila office. When LLV were looking for a pilot site for a community forest carbon project, Warakar Ser recommended Loru due to its clear land tenure, close links with LLV and history of conservation (Anjali Nelson, interview, 15 August 2019).

The Loru project started in 2011 alongside an Invasive Species project to control meremia also coordinated by LLV. The project started as a REDD+ pilot project to be integrated into Vanuatu's national REDD+ scheme. However, as the Vanuatu government moved towards a centralised land-use planning approach to REDD+, area-based projects were deprioritised and the Loru project distanced itself from national REDD+.

The Loru project produced its first carbon credits in 2016 and the project is now selffunded, with sales income of carbon credits flowing to Ser-Thiac (Nakau, 2019). In 2019, it won the United Nation's Equator award for Indigenous peoples' solutions to climate change and sustainable development (Figure 5.6).

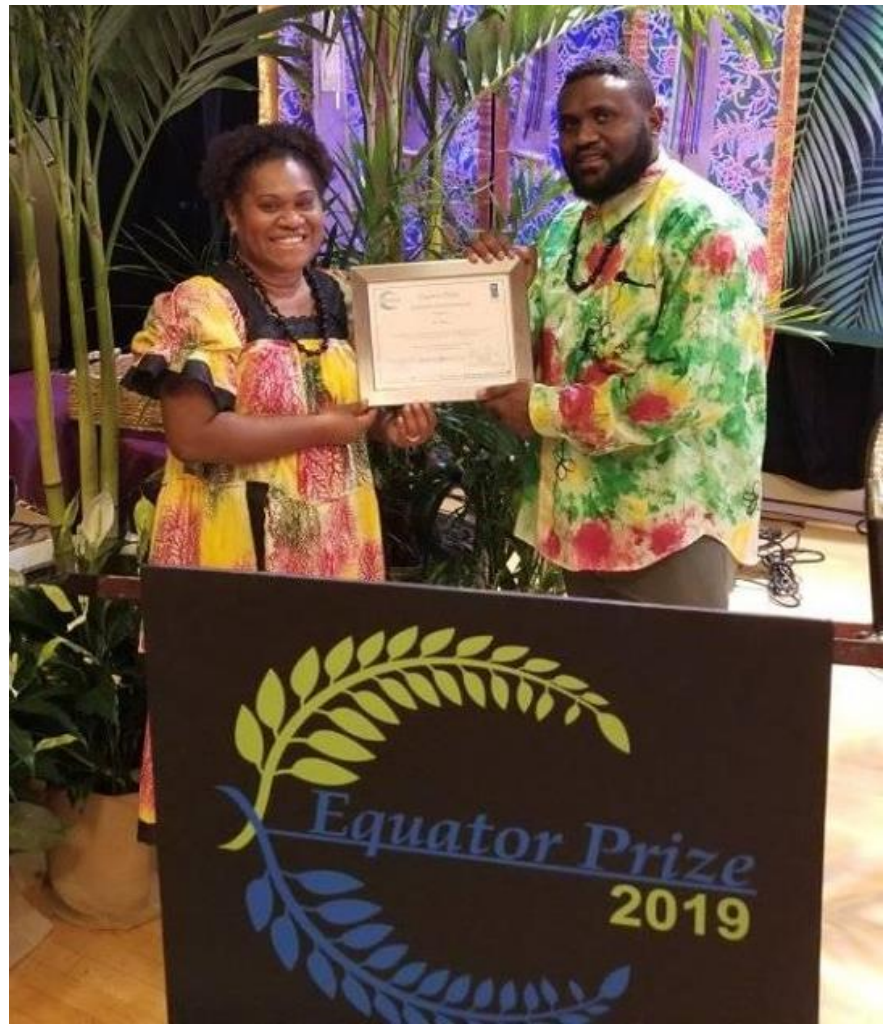

Figure 5.6 Glarinda Andre and Serge Warakar receive the UN Equator Prize in New York, USA

Note: From Live \& Learn Vanuatu. (2019, 25 September). Finally Congratulations Ser-Thiac efforts and Committments recognized!! Amongst the 800 competitors of 2019 UN prestigious award Ser-Thiac is amongst the 22 Winners of this year's equator Prize. Facebook. https://www.facebook.com/livelearnvanuatu/photos/a.1892728930989338/2360685090860384/ 


\subsection{Chapter conclusion}

This chapter outlined the REDD+ policy and practice in Vanuatu, including the case study of this thesis, the Loru project. While the DoF supports REDD+, its readiness progress has stalled, and it is yet to meet requirements for results-based funding. 


\section{Chapter 6 Methodology and methods}

This chapter will detail the methodology adopted to investigate the research questions. The first half will explore the epistemology and lenses that shaped my approach: social constructivism, Indigenous methodologies and ecological economics. The second half will explain the practical application: the research methods, gatekeepers and data analysis.

\subsection{Theoretical groundings}

\subsubsection{Epistemology: Social constructivism}

This thesis is grounded within a social constructivist epistemology. This research takes the view that knowledge is a social construct and "reality, the world, as the subject of research does not exist independently from our experiences... that multiple realities exist which are intangible, local and specific in nature" (Sumner \& Tribe, 2004, p. 5). This contrasts to a positivist epistemology: that an objective reality exists which can be observed through research. While positivist research aims to uncover 'the' objective truth, the goal of constructivist research is to "strive towards an ever more sophisticated, informed and inclusive constructions of the world" (Sumner \& Tribe, 2004, p. 5).

Compared to positivism, social constructivism is more aligned with an Indigenous worldview that "emerges as a result of people's intimate relationship with the environment, and there are various metaphysical beliefs which shape this relationship and thus impact knowledge production" (Scheyvens, 2014, p. 73), and thus better suited to researching Indigenous peoples. The notion within positivism that there is a single way of knowing has been used to dismiss alternative realities, particularly from oppressed groups such as Indigenous peoples (Hart, 2010).

Constructivism recognises that the researcher influences the research findings, necessitating a discussion of the researcher's positionality and biases. As social constructivism allows for multiple and alternative perspectives and ways of knowing, it is often favoured amongst queer, decolonising and feminist scholars who research share the stories of nondominant groups. This thesis is informed by the methodologies of the 'researchers from below,' particularly on the importance of positionality and reflexivity (Scheyvens \& Leslie, 2000). 
This thesis, therefore, does not claim to discover an objective answer to the research questions. Instead, I acknowledge that my findings have been affected by my positionality, but I aim to contribute to a greater understanding of forest carbon farming and Indigenous ownership in the Pacific. In fact, my constructivist philosophy was strengthened during the process of research (particularly fieldwork) as I become exposed to and aware of the factors that influenced what data I had access to and how I understand that data.

Like much of development studies research, this thesis is normative, "it is not concerned with knowledge creation for its own sake, but as an instrumental means of contributing to the improvement of natural and social conditions for the sake of improved welfare" (Sumner \& Tribe, 2004, p. 7). It was therefore important that my thesis could be useful to a practitioner audience and this is reflected in the topic and style of writing.

\subsubsection{Positionality}

Positionality refers to a researcher's background and existing beliefs which can influence the research design, process and findings. Social constructivism acknowledges that a researcher brings existing biases that shape research findings. These biases come from the researchers' economic, social and cultural backgrounds (among other things) which lead to preconceptions and beliefs that affect the research design, process of conducting research and findings. Sumner and Tribe $(2004$, p. 7) argue, "[development studies] research is subjective and... there is 'bias' some of which is acceptable and some which is not." While development researchers cannot prevent the influence of their positionality on research, they should seek to acknowledge it through 'self-reflexivity', minimise 'unacceptable biases' and inform readers of how positionality might have affected findings. Unacceptable biases include when a researcher deliberately misrepresents data or designs the research to serve the purpose of the researcher (Sumner \& Tribe, 2004).

My positionality comes from my background as a young pākehā female. I have had a privileged upbringing, exposed to other cultures through travel but in sheltered situations (visiting a country is not the same thing as lived experiences of poverty). This has contributed to my egalitarian values and desire for social justice, but unfamiliarity with the daily realities of poverty and oppression. My ontological stance has likely been influenced from 18 years in Western pedagogy which promotes a dominant narrative and marginalises Indigenous 
worldviews and ways of knowing (Tuhiwai Smith, 2012). Nevertheless, as discussed below, I seek to challenge this dominant narrative through self-reflexivity.

\subsubsection{Reflexivity and ethics}

I have practised critical self-reflection during my research to reduce bias, conduct my research ethically and 'decolonize' my research (Nicholls, 2009). For example, development research in the Pacific islands has stressed the vulnerability of small island states to climate change, so I may design the research questions, conduct the interviews and analyse the data with a preconceived idea that the community are vulnerable. However, since I was aware of this vulnerability narrative, I reflected on how it may have affected how I conceptualised Vanuatu and attempted to counter the narrative during the research design, data analysis and fieldwork.

The process of reflexivity is especially critical during fieldwork. As an 'outsider' I was treated as a guest. Research participants went out of their way to welcome me into their community. This may have affected how they answered interview questions, and I experienced what is a common challenge of development research where participants 'tell you what you want to hear' (Scheyvens, 2014). However, positionality does not always negatively impact development research. As a young woman, I was welcomed into certain spaces such as communal kitchens where I spoke candidly with women which likely increased their openness and trust during the research interviews and contributed to a more authentic reflection of their perspectives in this research.

The second purpose of reflexing is to ensure I conduct research in an ethical way by acknowledging and renegotiating the power imbalance in the researcher-researched relationship (Nicholls, 2009). Sumner and Tribe (2004, p. 10) explain, "the researcherresearched relationship is far more problematic if those involved in the research are at a completely different level of economic and political power." My social class, connections and education contributed to the power I held in the community. For example, when I arrived, I was immediately welcomed by the chief and often ate meals with his family. At the Sunday church service, I was introduced by the Reverend who invited me to shake everyone's hands at the end of the service. This positioned me alongside those who held traditional power. During my fieldwork, I was aware that this power may have led to community members feeling pressured into or nervous about talking to me. Being aware of this allowed me to try 
to mitigate some of the power imbalance by using some Bislama words and adopting a friendly, casual style.

As a self-reflexive researcher aiming to conduct ethical research, I reflected on ways that I may be (consciously or not) designing and conducting my research to suit my own interests. I am writing this master's thesis in part for my own career. I interviewed participants whose approval and connections could help my career goals. I have reflected particularly in the representation of these interviewees, ensuring I have not misrepresented them in pursuit of my own interests.

Through reflecting on myself as a beneficiary of this research, I developed a commitment to reciprocity. I had planned to help with written English or job and university applications. However, once I was in Khole village I found the best contribution I could make was through conducting the social impact assessment with LLV, and I dedicated time to complete that to a high standard. I also prepared an accessible report of results which has been shared with the community. As many development researchers have reflected on, the best way to avoid extractive research is to return to the community and share results yourself (Scheyvens, 2014). Unfortunately, time and resources do not allow for a return visit. Nevertheless, LLV continue to work closely with the community and the work I completed hopefully has an ongoing positive impact.

While personally benefitting from the research is not unethical, it is essential that this does not come through exploiting research participants. At the bare minimum, this means participants give their full, prior and informed consent, and that responses are not misrepresented. I entered fieldwork with a strong commitment to university ethics armed with consent forms (see Appendix B, Ethics Approval). However, I found participants enthusiastic and eager to talk to me, often making light of the formal consent processes. The community had welcomed me into their community, housed me, fed me and handed me their children. Their signature on a form signalling their willingness to be interviewed seemed hollow when they had expressed their trust in more meaningful ways. Therefore, while I followed the formal consent process, I found the displays of warmth towards me from the community more important in ensuring I had conducted research in an ethical way. 
Part of the ethical commitment to the community was allowing enough time to 'just be,' participating in daily life and casual conversation so I was not just extracting research and leaving. However, while my hosts would never show it, I felt I was adding a burden to the daily life of the women who were housing and feeding me, and I found it difficult to encourage them to accept my offers to help. I could never subvert the power imbalance from being an educated foreign researcher, and my hosts would cook me fish and meat (considered luxuries) for most meals, often waiting for me to finish before they started eating themselves. On my last night in the village, the daughter of the woman hosting me gave birth. I had finished the 40 surveys for Social Impact Survey, but I had planned a couple more interviews, as well as some extra time to 'just be'. While my hosts would not make me feel unwelcome, I thought it was important for them to be together as a family and I left a few days earlier than planned. This situation demonstrates the benefit of a reflective approach to ethical research, responding to situations with compassion rather than rigid ethical guidelines.

\subsubsection{Indigenous methodologies}

The term 'Indigenous Methodologies' has been used by social scientists to mean different things. It can describe established methodologies inspired by Indigenous concepts such as the Polynesian Talanoa or ni-Vanuatu Storian ${ }^{2}$. Indigenous authors such as Linda Tuhiwai Smith (2012) describe Indigenous or Decolonizing Methodologies as a mechanism to decolonize research in pursuit of Indigenous social justice. Authors such as Hart (2010) develop their own Indigenous methodology using an Indigenous ontology, epistemology and axiology.

Methodologies based on Indigenous concepts of the Pacific have been rising in popularity (Suaalii-Sauni \& Fulu-Aiolupotea, 2014; Tunufa'I, 2016; Vaioleti, 2014). The Polynesian concept of Talanoa is particularly popular in development research, however, Tunufa'l (2016, p. 234) advocates against its use in Melanesia.

The concept of Talanoa is predominantly Tongan, Fijian, Tokelauan and Samoan; it does not resonate with epistemological processes of most Melanesian and Micronesian cultures. Talanoa's jump from being a "Tongan concept" to become a Pacific methodology is colonising in itself.

\footnotetext{
2 "to yarn, tell stories" (Crowley, 2003)
} 
Warrick (2009, p. 83) describes storian as, "essentially a Vanuatu-specific form of 'Talanoa': an established, culturally appropriate Pacific research methodology referring to a 'personal encounter where people story their issues, their realities and aspirations.'" However, there is debate around the classification of Talanoa and storian as methodologies or whether they better describe methods. Tunufa'I $(2016$, p. 237) points to the "conundrum... in terms referring to Talanoa as both a methodology and method at the same time," and Warrick (2009) uses storian as a method after introducing it as a methodology.

Tuhiwai Smith (2012, p. 62) argues that that need for Indigenous methodologies arises as conventional research has been used as an imperial tool of oppression:

Knowledge was also there to be discovered, extracted, appropriated and distributed... Western knowledge and science are 'beneficiaries' of the colonization of Indigenous peoples. The knowledge gained through our colonization has been used, in turn, to colonize us in what Ngugi wa Thiong'o calls the colonization 'of the mind'

Social Darwinism, the idea that societies, like animals, 'evolve' into more sophisticated ones, and the 'weakest' will naturally die out, was used to explain Indigenous deaths due to introduced diseases and justify oppressive practices such as forced adoption. Ethnographic studies of Indigenous people were used in the Pacific and elsewhere to justify Social Darwinism, for example measuring and comparing the skulls of Indigenous peoples (Tuhiwai Smith, 2012).

During my fieldwork, I noticed the internalised oppression that has been used to colonise the community, the 'colonisation of the mind' (Wa Thiong'o, 1992). I heard from Indigenous women that children from kastom communities were born with defects, and that ni-Vanuatu could not be good teachers.

To recognise the historically oppressive impact of Western research on Indigenous peoples, I have attempted to 'decolonize' my research. As Tuhiwai Smith (2012, p. 41) explains,

the methodologies and methods of research, the theories that inform them, the questions which they generate and the writing styles they employ, all become significant acts which need to be considered carefully and critically before being applied. In other words, they need to be 'decolonized' 
First, as discussed above, I critically reflected on the attitudes towards Indigenous peoples I have absorbed due to my positionality (Nicholls, 2009). I have reflected on how these biases may affect my research design, process and analysis and particularly my fieldwork in a ni-Vanuatu community. This meant, for example, unlearning the vulnerability narrative that promotes Indigenous peoples as victims. Rather than focusing just on the threat of climate change, I also noticed and asked about traditional resilience strategies.

Secondly, I attempted to conduct interviews in a way which stressed ni-Vanuatu agency and strengths rather than as research subjects in need of 'development'. I attempted to recognise the work of other community members and 'stuck around' after the recording had stopped. Nicholls (2009, p. 119) argues that participant-empowering research "demands the researcher not be control of the research process." While I do not claim I ceded enough control of the research process to result in participant empowerment, I subverted some power by speaking Bislama in some of the interviews. My Bislama is poor so I could not communicate as naturally as participants, who possibly gained some control of the research process.

Thirdly, I have been informed by Indigenous concepts. Rather than adopting an Indigenous concept such as Talanoa (Tunufa'I, 2016) or ni-Vanuatu storian (Warrick, 2009) and appropriating it into a methodology, I believed it more appropriate as a Western 'outsider' to educate myself on ni-Vanuatu customs and values such as reciprocity and rispek (respect), build them into my research and use them as guiding principles for how I conducted fieldwork. As Tuhiwai Smith (2012, p. 52) explains:

some methodologies regard the values and beliefs, practices and customs of communities as 'barriers' to research or as exotic customs with which researchers need to be familiar in order to carry out their work without causing office. Indigenous methodologies tend to approach cultural protocols, values and behaviours as an integral part of methodology.

Although I conducted formal interviews that started and stopped with the press of a recorder, my impact on the community was not confined to the recorded minutes. I was not just there to extract information, but my hope was to create trust and practice reciprocity; participating in daily life, contributing to LLV's monitoring, and sharing findings. 


\subsubsection{Ecological economics}

This thesis draws on the framework of ecological economics in considering how to maximise human wellbeing while keeping resource use within planetary boundaries. Unlike mainstream environmental economics, ecological economics views the economy as a subsystem of the earth's natural ecosystem. Ecological economics stresses the complex, systems-based consequences of resource use and the importance of protecting natural capital (Costanza et al., 2015). Ecological economists believe that the economy should be managed to preserve social and natural capital and protect future wellbeing (Costanza, 1991).

An ecological economics lens influences how this thesis conceptualises development. Post-development theory provides a view of development aligned with ecological economics. Like ecological economics, post-development theory challenges the notion of productionbased development (Kiely, 1999). This promotes development policy that places the equity and justice of resource allocation above resource growth (Rammelt \& Boes, 2013). Ecological economists and post-development theorists promote an alternative form of development that decouples development from economic growth (Nakashima, Galloway McLean, Thulstrup, Ramos Castilo, \& Rubis, 2012).

\section{2 'Semi'-Mixed-Methods}

The methods I adopted in this thesis were structured and semi-structured interviews. This was complemented by the results of the Social Impact Survey, which I conducted during fieldwork on a voluntary basis for LLV and is being used for the monitoring of the Loru project.

My choice of methods was informed by my social constructivist epistemology. The research was predominantly qualitative, allowing for a nuanced insight into different perspectives. 'Semi'-mixed-methods balance the trade-off between breadth and depth of research. The bulk of the research is qualitative, reflected by the high use of quotations and relatively few statistics.

These perspectives can, to an extent, be triangulated and generalised when coupled with the quantitative statistics from the Social Impact Survey. Due to the limited representativeness of the Social Impact Survey (see Appendix C), I only included statistics that were confirmed by information from the interviews. Answers recorded in the Social Impact Survey were frequently misunderstood or unable to be recalled by participants, so data that 
were not confirmed by other sources was excluded. This demonstrates a shortcoming of quantitative data. It is left to the participant to interpret questions and it can be difficult for the researcher to prevent or identify misleading responses. However, when information from the Social Impact Survey was backed up by interview data or observation, I was confident the survey question had been understood and the data was representative. Nevertheless, these statistics should be interpreted cautiously with this caveat in mind, and not assumed to be statistically significant.

The Social Impact Survey increased my confidence in the qualitative interview data. The survey acted as a check and balance as interviewees could not claim a benefit of the Loru project that was contradicted by the findings of the survey.

\subsubsection{Selection of case study site}

I developed an interest in how the frameworks of ecological economics can be used to meet the greatest largest challenge of development: how to manage natural resources to mitigate climate change while improving community wellbeing and equality in the global South (Costanza et al., 2016). I noticed examples of industries such as logging where resource exploitation was harming local communities and contributing to climate change by emitting greenhouse gases (Allen, 2013). However, governments from the global South often claim their development depend on the economic gains from logging. At the same time, I acknowledged the importance of Indigenous peoples to be involved in natural resource management, as traditional custodians of the Earth, and amongst the most vulnerable to the local effects of climate change.

Further research led to me to REDD+, as the current attempt to manage the Earth's forest resources in the global South. Deforestation is a challenge facing both environmentalists and development practitioners. For environmentalists, deforestation is responsible for $20 \%$ of global greenhouse gas emissions (Campbell et al., 2008). For development practitioners, deforestation by commercial logging has traditionally exploited forest-dependent communities (Allen, 2013). However, early REDD+ projects were not achieving the emissions reductions they had hoped for, and were often leaving forestdependent communities worse off by restricting their access to forest resources (Bayrak \& Marafa, 2016). I wanted to see if it was possible to use a PES mechanism to achieve forest conservation and development outcomes for the local community. 
In 2018, I became aware of the Nakau Programme which attempted to facilitate an Indigenous-owned forest carbon programme. Like REDD+, the scheme produces sellable carbon offset credits, but the Indigenous community retains ownership of the carbon credits, and the profits go to local development managed by the community. I was interested in whether the programme was legitimately community-owned and achieving development outcomes. Nakau launched the Loru pilot scheme in Vanuatu in 2016, which I selected as a case study site. I contacted Sean Weaver, the founder of the programme who suggested that I could assist LLV with project monitoring and conduct my own research with the Indigenous landowning community, the Ser clan.

I have not come across any qualitative studies of an Indigenous-owned forest carbon project worldwide (Bayrak \& Marafa, 2016), and forest carbon sequestration is relatively unstudied in the Pacific outside Papua New Guinea (Babon \& Gowae, 2013; Weaver, 2015). Most of the available material is grey literature such as policy reports and REDD+ guidelines (for example see Rey et al., 2013; Weaver, 2011). The Loru project presents a significant opportunity to contribute to the literature. There is widespread policy and practitioner interest in the area due to the challenges of deforestation in the Pacific. This made Loru a prime candidate for a case study on the social impact of a community forest carbon project.

\subsubsection{Literature review}

The first step of my research was a desktop review of relevant literature. My literature search had two steps. First, a thorough literature review on academic and policy material on Forest peoples, Indigenous peoples, deforestation and REDD+. This formed the basis of chapters three and four, developed my understanding of the current policies and body of knowledge available. Secondly, I researched the ni-Vanuatu context, forming chapter four and five, focusing on forest policy and REDD+. Due to the direct relevance of the topic on climate change policy and community development practice, I found grey literature such as reports by multilateral organisations, governments and non-governmental organisations as informative as literature from academia.

I undertook the literature review systematically. I searched for key terms using three main databases; Google Scholar, ProQuest and Victoria University of Wellington's Te Waharoa. I frequently deepened my search by reading the literature referenced in other material. When searching for grey material, I used Google and the websites of multilateral 
organisations such as UN-REDD and the World Bank. I had access to unpublished working papers from LLV and the Nakau Programme while based in Port Vila, Vanuatu.

\subsubsection{Field research and participant recruitment}

Most of my primary research occurred during my field research in Vanuatu. I spent one month in Vanuatu between June and July 2019. I was based in LLV's head office in the capital Port Vila and travelled to Khole village, Espiritu Santo to conduct the structured interviews, one semi-structured interview and the Social Impact survey.

My contact with the community was through my connection with LLV and the volunteer monitoring work I was doing simultaneously to the fieldwork. LLV organised my transport and accommodation while in Khole and Serge Warakar, a Ser clan member and LLV employee, accompanied me to Khole village. I recruited participants through conducting the Social Impact Survey for LLV. At the end of the survey, I asked community members if they would like to undertake a short additional interview for my research.

I conducted two semi-structured interviews once back in Wellington, one in-person and one via video conferencing. The interviewees, Sean Weaver and Anjali Nelson were recruited via email and selected as due to their detailed knowledge of the Loru project.

\subsubsection{Gatekeepers}

Bonnin (2010, p. 183) defines gatekeepers as "individuals who directly facilitate or inhibit researchers' access to resources such as people, institutions, information and logistics". Several development researchers have reflected on the ethical concerns of engaging with gatekeepers (Bonnin, 2010; Scheyvens, 2014). As Scheyvens (2014, p. 172) notes, local gatekeepers indicate their "informal 'permission...' by their degree of participation and enthusiasm for you and your work." Similarly to other development researchers, the 'gatekeepers' of my research ended up as vital facilitators and supporters of the research (Heller et al., 2011). The senior members of the Loru project, Anjali Nelson and Sean Weaver, helped me navigate the local gatekeepers so I could carry out the research. This included a signed letter of approval from The Department of Forestry (see Appendix D) and introductions to the village chief and Serge Warakar, a Khole villager and LLV employee who accompanied me to Khole village. 
An ethical concern arises when gatekeepers can push research in a direction that suits their own interests by limiting or granting access to certain research resources. Notably, the gatekeepers to my research had a vested interest in the positive portrayal of the Loru project. This was somewhat mitigated by my research methods that involved interviewing the population of the landowning Ser clan, rather than a snowballing sample that might be 'star' interviewees recommended by gatekeepers (Scheyvens, 2014). Nevertheless, the relationship formed with the gatekeepers (who were also interviewees) relied on an understanding of mutual trust. From me, that the project was being represented fairly and accurately by the people and information accessible, and from them, that I could be trusted to act in the best interests of the community. Fortunately, I found the gatekeepers trusting, trustworthy and transparent and have confidence in the accuracy of the data.

\subsubsection{Structured Interviews}

I conducted 40 structured interviews with all the members of the Ser clan available in Khole village during my fieldwork. These took place after I had surveyed participants for LLV's Social Impact Survey. I made sure to highlight the distinction between my survey work with LLV and the master's research and separated the two tasks by pausing to explain the information sheet and consent process with participants. I found participants understood this distinction, possibly as I was unfamiliar whereas the community were familiar with LLV staff. In the style of the Social Impact Survey, I wrote down responses on paper, and with consent audiorecorded eight of the 40 structured interviews.

All participants nominated a preference to use their real names when quoted. I opted to give participants the choice to be identifiable as providing a platform for community members to have their opinions published can be empowering (Nicholls, 2009). Particularly, Indigenous scholars have called for Indigenous peoples' to be identifiable in research to appropriately acknowledge Indigenous knowledge (Tynan, 2020). Additionally, the information discussed did not seem sensitive to participants, and there was no obvious tension between groups which could have meant identifiable data risked harm or discomfort to participants. This assumption was somewhat validated by all participants choosing to use their real names when given the option of a pseudonym. The information sheet and consent form are included as Appendix E and F. Participants tended to be referred to as either their first or second names. To follow the custom of the community and avoid confusion as many 
members have similar second names, I refer to community participants using their full or preferred name.

The purpose of the structured interviews was to hear from all Ser clan members directly impacted by the Loru project. Short, structured interviews were chosen to minimise the disruption to community members as they could be conducted quickly after the Social Impact Survey. To hear from a wide representation of the community, I aimed to for half of the participants to be female and a quarter under 25. However, as I was interviewing the population of the Ser clan who was available, I was limited to who was present in the village. In particular, young people often live outside the village, boarding at a secondary school, or moving inter-island or internationally for work. The demographics of the participants are included in Table 6.1.

Table 6.1 Demographics of Structured Interview Participants

\begin{tabular}{|l|l|l|l|}
\hline & Females & Males & Total \\
\hline Youth (18-25) & 2 & 4 & 6 \\
\hline Adult (>25) & 22 & 12 & 34 \\
\hline Total & 24 & 16 & 40 \\
\hline
\end{tabular}

To reflect an Indigenous ni-Vanuatu methodology, I initially intended to conduct all interviews in a relaxed storian style. Storian is the Bislama word for "to yarn, or tell stories" (Crowley, 2003) and been used as a method in development research as a style similar to unstructured interviews or as a Melanesian form of Talanoa (Warrick, 2009). However, due to my poor Bislama and unfamiliarity with the community, it was more effective to prepare a simple questionnaire and the interviews with the community ended up being structured. Participants were often keen to storian after the interview had finished, and I found the meaning of storian better describes a comfortable story-sharing session between friends rather than a recorded conversation intended for research (even if unstructured). The interviews were conducted in English or a mixture of English and Bislama, sometimes with the aid of other community members sitting by as informal translators.

\subsubsection{Semi-structured Interviews}

I conducted three semi-structured interviews with key individuals involved in the Loru project: 
Sean Weaver, the Executive Director and Founder of Ekos. Weaver was the lead consultant for the development of the Pacific Regional Policy Framework for REDD+ and the Vanuatu and Fiji national REDD+ programmes. From 2001 to 2007 Weaver worked as a Senior Lecturer in Environmental Studies at Victoria University of Wellington (Nakau, 2019).

Warakar Ser, a Ser clan elder who was previously employed by LLV during the establishment of the Loru project, and with a detailed memory of the history of the forest. He is the father of Serge Warakar, who currently works with LLV on the Loru project amongst other things. Serge travelled with me to Khole during my fieldwork, acting as a facilitator and translator and was present during Warakar Ser's interview. He occasionally interjected during this interview and has given his consent to be included so quotations from both Warakar Ser and Serge Warakar are included.

Anjali Nelson, the Project Liaison Manager of the Nakau Programme (the regional subsidiary of Ekos in the Pacific) and former Country Manager of LLV. Nelson was the Project Manager of the Loru project during its establishment and continues to work closely with LLV as a Board member. Nelson has also been a REDD+ advisor to the Government of Vanuatu (Ekos, 2017).

The interviews with Sean Weaver and Warakar Ser were conducted in person in their country of residence and consent was documented on paper. I interviewed Sean Weaver at a Wellington café and Warakar Ser in a community hall in Khole. I interviewed Anjali Nelson via video conferencing and her consent was recorded via audio. All participants gave their consent to be named and quoted.

These interviews were long, ranging from half an hour to an hour and a half, allowing for detailed explanations and follow-up questions. I had communicated with all participants several times before the interview, the participants were familiar with me and the topic and gave lengthy responses. While majority of the quotations included in the later chapters come from the lengthier, semi-structured interviews, the structured interviews were vital to understanding the community impact of Loru and supported many of the semi-structured interviewees' ideas. 


\subsubsection{Social Impact Survey}

LLV has given me permission to supplement my findings with the quantitative data I gathered from the Social Impact Survey. The questions from the survey are included as Appendix A. As the surveyor, I observed survey errors resulting in misleading data from the Social Impact Survey. For example, participants estimations of time in time-use questions, and conceptualisation of 'individual income' was inconsistent and poorly understood. Therefore, I have excluded the statistics from the Social Impact Survey that I judged to be misleading and/ or inaccurate. The 'Surveyor's Notes' I wrote detailing these survey errors is included as Appendix C.

\subsubsection{Data analysis}

I transcribed the three semi-structured interviews and seven of the structured interviews. While transcribing is time-consuming, it was a useful exercise. Transcribing familiarised myself with the data and I noticed nuances in the conversations that I had missed during the interviews. During fieldwork, I selected eight of the structured interviews to record as a representative sample. I felt the recording was unsettling for participants but also wished to more authentically represent participants' perspectives through quotes. Unfortunately, as I did not record all the interviews, I was unable to gather direct quotes from all the structured interviews.

I took detailed written notes during interviews and kept a field diary. The transcriptions and notes formed the basis of the qualitative data analysis. I interpreted the data manually rather than using software and grouped the data into themes. As previously explained, I did not trust the quantitative data enough to form conclusions, only as a supplement the interview data. I calculated simple descriptive statistics using Excel from the quantitative data of Social Impact Survey, grouping them into the existing themes.

\subsection{Limitations}

The methods and methodology of this research had numerous limitations, some of them common of much development research, some specific to this topic. Firstly, like many postgraduate researchers, I had limited time in the field. I do not claim I could ever understand the knowledge of my Indigenous participants, but extra time would have resulted in a more accurate understanding in the nuance and subtleties behind responses, and time to conduct longer interviews. 
Connectedly, I have only very basic Bislama. And while I felt that the survey which I conducted for LLV was perhaps one of the most effective ways to rapidly learn a new language-repeating the same questions up to 15 times a day, and many participants kindly commended my Bislama attempts, there is no doubt the research would be significantly enhanced if I was fluent in Bislama and the local language. Nevertheless, the nature of Bislama as a pidgin language based on English meant that I could interchange Bislama words into English sentences that could be understood without knowing the grammar and structure of Bislama.

Thirdly and most significantly, I engaged with the research through a relationship with LLV and Ekos. It would not have been possible to study the Loru project without engaging with these organisations, but my relationship with key members of the Nakau Programme, Sean Weaver and Anjali Nelson especially, extends beyond simply introducing me to the project. As previously mentioned, I conducted a Social Impact Survey on behalf of LLV simultaneously to data collection. This undoubtedly affected how the community perceived me and how critical they may have been towards the Loru project. Additionally, my own interactions with key members of the Nakau Programme has influenced how I perceived the project. I believe this bias is somewhat mitigated by the fact I interviewed the population of the Ser clan, meaning I was not just exposed to the local champions of the project. Nevertheless, in line with my social constructivist epistemology, the intention of this research was not to reveal the 'truth,' but contribute to greater understanding. I recommend, therefore, that this thesis is read with my positionality in mind and encourage readers to form their own conclusions.

Finally, the research would have been enriched with greater data. As previously explained, additional time in the field would have allowed for more interviews. In particular, I believe longer follow-up interviews with structured interview participants would have been valuable, as I had a gauge of who were keen to share their thoughts and who extra interviewing may have been purely extractive. Due to language constraints and unfamiliarity with the community, I could not understand the burden I may have been adding to everyday lives, so I kept questionnaires short and simple. Additionally, I could not access some project documents that would have aided the research such as complete records of community Finance Reports. This means, for example, I could not conclude how much of the carbon income is taken by the Chief. However, given the limited formal education of community 
Finance Officers and other constraints, I do not wish to criticise the records and as chapter seven explains, the transparency and accessibility of finance was a relative strength of the project.

\subsection{Chapter conclusion}

This chapter has summarised the philosophy and methods of my research. I have highlighted the social constructivist grounding and the influence of Indigenous methodologies. I have discussed the role of reflexivity and positionality in a social constructivist, decolonizing approach to research with Indigenous peoples. I explained how the frameworks of ecological economics has been insightful in examining the Loru forest carbon project. Additionally, I outlined the research processes of fieldwork, research methods and research analysis. Ethical considerations have been woven throughout the chapter and have influenced the way I have sought to conduct research. 


\section{Chapter 7 Social impact and sustainability of the Loru project}

This chapter is the first of two chapters which thematically presents the findings of my research. In this chapter, I investigate the social impact of the Loru project on the Ser clan. I find that the Loru project delivers community benefits through economic development, capacity building, biodiversity and climate change resilience. Next, I present findings related to the project's economic, environmental and social sustainability.

\subsection{What is the social impact?}

In this section, I discuss the social impact of the Loru project on the Ser clan. I find that the key positive impacts are; carbon revenue and economic opportunities, capacity-building, biodiversity and climate change resilience. I explain in detail the nature of economic development and highlight how it generates social outcomes for the Ser clan.

\subsubsection{Economic opportunities and finance}

The Ser clan receive income generated through the sale of carbon offset credits. The community then distribute that capital to local project expenses, community benefit activities and dividends. The Loru project has is designed and implemented to promote long-term, sustainable development. LLV ran financial literacy workshops and implemented safeguard measures to promote fair distribution and transparency. The following section identifies the income, but also how that income is distributed. Importantly, while LLV have had significant oversight in the allocation of funds, the Ser clan manage the distribution themselves and plan to increase their responsibilities as their financial skills improve.

\subsubsection{Carbon revenue}

The Loru project generates NZD 25,836 per year from the sale of carbon credits, which is transferred to Ser-Thiac in quarterly payments (A. Nelson et al., 2015).

LLV worked with Ser-Thiac to establish four accounts: Income Account, Expenses Account, Safety Account and Community Benefit Account. The Ser-Thiac Finance Committee dispenses funds from the Income Account to the other accounts. LLV worked with the community to set a target of VUV 700000 (NZD 8 953) for the Operational Account and VUV 1000000 (NZD 12,790) for the Safety Account (A. Nelson et al., 2015). Once these targets are met, $60 \%$ of excess income is transferred to the Safety Account, and $40 \%$ to the Community Benefit Account. 
Chief Stephen Skip is entitled to up to $40 \%$ of the Community Benefit Account and the remaining money is invested in community benefit determined by the Ser-Thiac Board ( $A$. Nelson et al., 2015).

As shown in Table 7.1, in the third quarter of 2018 (1 July- 31 September), Ser-Thiac received VUV 404000 (NZD 5 300.51) of which, VUV 190000 (NZD 2 492.81) was transferred to the Operational Account and VUV 107000 (NZD 1 403.85) to both the Safety Account and Community Benefit Account. The Finance Committee spent VUV 258920 (NZD 3 750.85) on project expenses out of the Operational Account. As of 31 September 2018, Ser-Thiac had VUV 516104 (NZD 6 770.52) in the Community Benefit account.

Table 7.1 Bank Account Cash Flow and Closing Balance 1 July- 31 September 2018

\begin{tabular}{|c|c|c|c|c|}
\hline \multicolumn{5}{|c|}{ Bank Account Cash Flow and Closing Balance } \\
\hline \multicolumn{5}{|c|}{$\begin{array}{c}\text { Q3 2018: } 1 \text { July- } 31 \text { September } \\
\text { All amounts in VUV }\end{array}$} \\
\hline & $\begin{array}{l}\text { Operational } \\
\text { Account }\end{array}$ & $\begin{array}{l}\text { Safety } \\
\text { Account }\end{array}$ & $\begin{array}{l}\text { Community } \\
\text { Benefit } \\
\text { Account }\end{array}$ & Total \\
\hline Income & 190,000 & 107,000 & 107,000 & 404,000 \\
\hline Expenditure & $(258,920)$ & 0 & 0 & $(258,920)$ \\
\hline $\begin{array}{l}\text { Closing } \\
\text { Balance }\end{array}$ & 54,434 & $1,003,183$ & 516,104 & $1,573,721$ \\
\hline
\end{tabular}

Note: Adapted from Finance Committee (2018) Appendix G

As shown in Table 7.1, payments out of the Community Benefit Account have been modest (and in quarter 3 2018, zero), and most revenue has been re-invested into the project and spent on project expenses, coming out of the Operations account. When asked where carbon offset income has been spent, community member Klarence Dan shared, "I think mostly the project spends the money." Nevertheless, many project expenses benefit the community, such as paying local wages and investing in agroforestry.

Anjali Nelson, Nakau's Project Liaison Manager, explained how the carbon credit revenue has been invested in economic diversification opportunities for the community: 
The carbon credit money, that's gone really well... the use of those funds to diversify has been used solely to support for the agroforestry plots. The money that's been made from the agroforestry plots... it's been from the sale of the crops at the market by the mamas. They get to sell whatever they plant in the agroforestry plots.

This suggests that the economic diversification that the carbon revenue supports is having a positive financial impact on the community.

The Nakau Programme is designed with long-term social sustainability in mind, encouraging the community to invest in projects that will continue after the 30-year lifespan of the carbon offset revenue. Sean Weaver, Founder and Executive Director of Ekos explained that the carbon credit income will be distributed evenly across its 30-year lifecycle, so the community can invest in economic opportunities that will continue beyond the lifecycle of the project.

We require them to think carefully about what's going to happen in year 31 so build something, build agroforestry, build honey production, build that. So, year 32,33 you use that period of carbon money to build your capacity to have a self-sustaining community and you've got 30 years of practice in governance and business management.

Anjali Nelson agrees: "We never wanted to just do carbon. We want the carbon to generate other economic opportunities."

Ser-Thiac trialled three avenues of economic diversification to run alongside the project: a tree nursery, canarium nut processing and packaging, and agroforestry. LLV provided training and secured Australian government co-financing for a solar nut dryer. The projects have been of varying success.

The nut business was never successfully implemented but remains a future opportunity and the community have access to the nut dryers. The tree nursery currently produces seedlings for the agroforestry zone of the Loru site, but there is still a gap in the market for tree seedlings and the community could expand the tree nursery further to generate additional income.

Anjali Nelson explained the canarium nut initiative, sharing the programme was not successfully implemented: 
So the idea was that we would develop a nut, nangai canarium drying and packaging program. So, the nut driers are just sitting there, solar dryers. There were two solar driers through an Australian programme, and they were then going to get further extension support through an Australian university. But that fell through in the end which was a shame. So, the idea was that they were going to solar dry and then, package, flavour and then package single-serve nuts to sell at Champagne beach to the tourists... They could have made a huge profit margin from that. But unfortunately, it's more just about the immense investment required as far as someone to champion long-term.

However, Nelson continues by highlighting the success of the agroforestry programme at providing livelihood diversification for the Ser clan, promoting an agroforestry livelihood that was preferable to copra farming:

Currently, they just grow the trees for their agroforestry plots... they are growing a lot of their own trees that they are then transplanting into the agroforestry plots which will be generating money for them, is already generating additional finances and will generate a lot more in the future... It's not, you know, huge and many hectares and producing lots of money but as a pilot, it's demonstrating an effective approach to reforestation, productive livelihood reforestation. And that was something that they were really keen in. There was quite a few of them that wanted to be tree farmers.

The Loru conservation area is split up into three zones depending on the forest cover and eligibility for PES credits. Zone C, non-forested area is gradually being reforested (see Figure 7.1) (A. Nelson et al., 2015). The Loru land management committee allocated agroforestry plots in Zone $\mathrm{C}$ to all Loru members, who care for the growing trees and grow food for consumption or to sell at the Luganville market. 


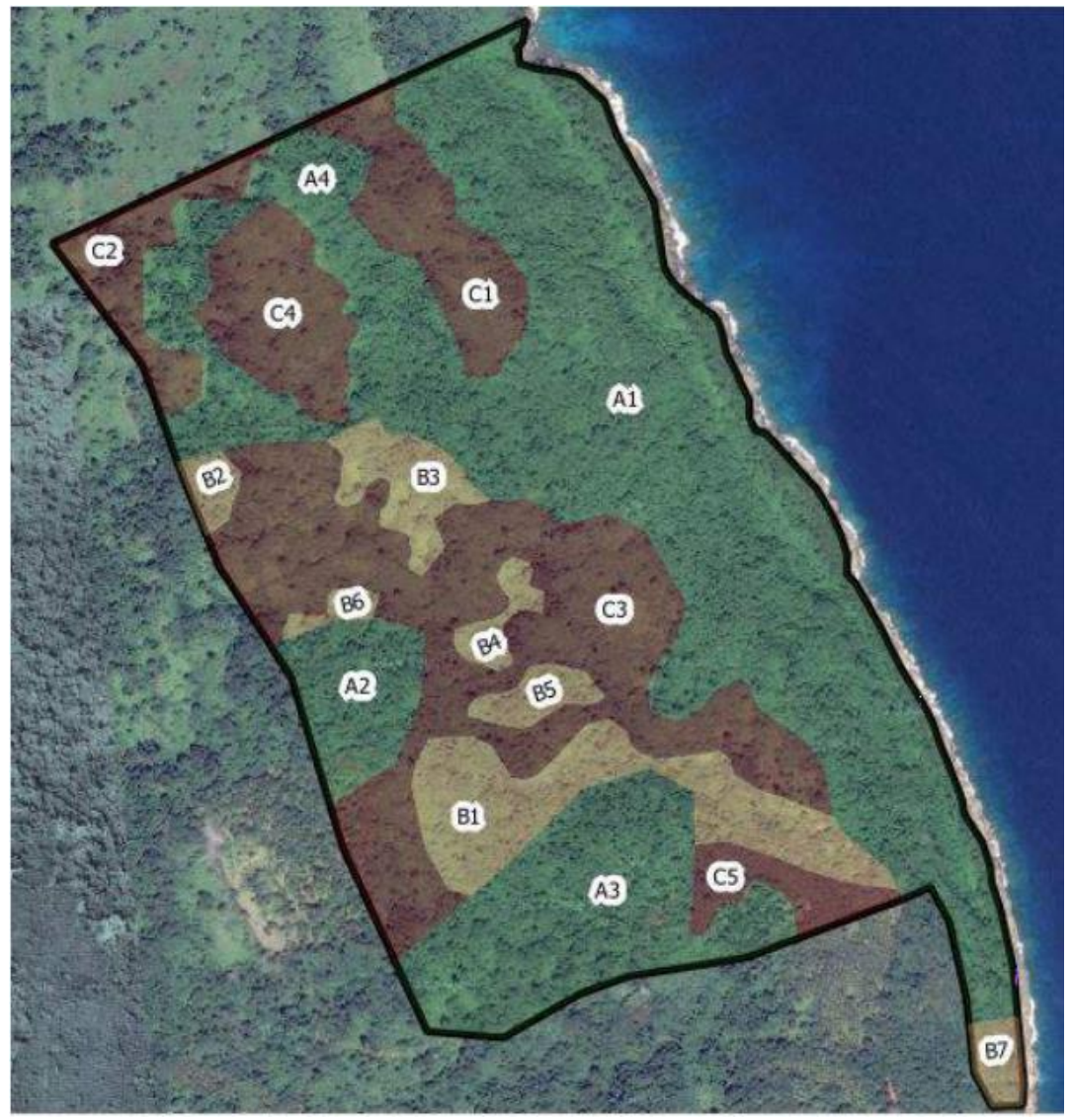

Figure 7.1 Project area showing management zones

Note: From Nelson, A., Andre, G., Warakar, S., Weaver, S., \& Henderson, R. (2015). Loru Forest Project- Project Description Part A: General Description. An avoided deforestation project at Loru, Santo, Vanuatu.

http://www.nakau.org/uploads/5/2/2/5/52251233/loru pd part a d3.2a v1.0 20151009b.pdf

Agroforestry provides the community with several important co-benefits. It increases food security by providing an increase in supply and variety of locally grown food. As displayed in Figure 7.2, the community reported they have increased their consumption of locally grown food since 2014 , with a $21 \%$ increase in community members who eat locally grown food every day. 


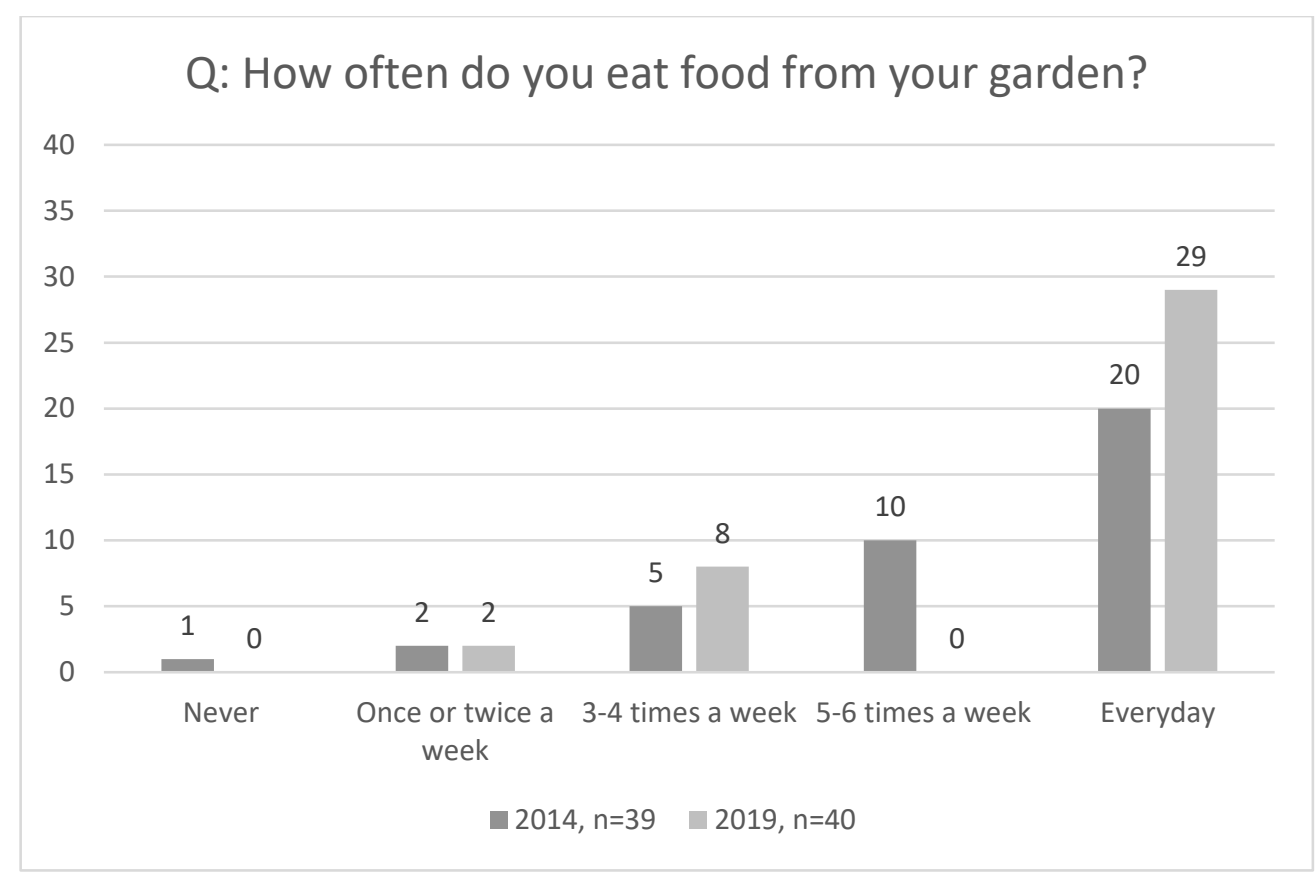

Figure 7.2 Locally grown food consumption of Ser clan members 2014 and 2019

Vitally, agroforestry is helping the community to rely less on copra for their livelihood and to transition towards a more resilient and enjoyable livelihood activity.

There are signs that the increased economic capital is improving community wellbeing. For example, community members have bought or upgraded water tanks to increase their water storage capacity for the dry season. As shown in Figure 7.3, the Social Impact Survey asked participants, 'Do you ever run out of water?' In 2014, all participants ran out of water during the dry season. However, in 2019, more than a third of the community reported having access to water year-round. Community members Toli Nancy Dan, Viran Dan and Tounefil Ser confirmed that this was due to purchasing or upgrading water tanks since 2014. 


\section{Q: Do you ever run out of water?}

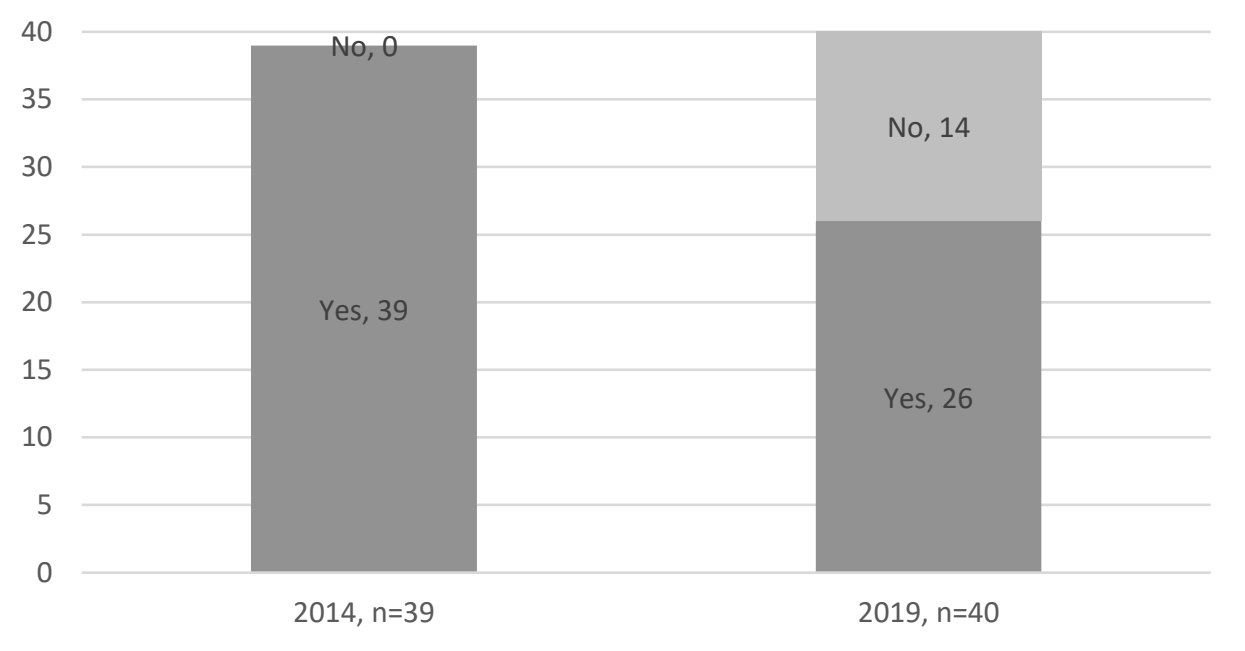

Figure 7.3 Ser clan access to water 2014 and 2019

The project also funds the employment of two local rangers, Kaltapang Fred and Kalros Ser, who protect the forest and partly funds a Khole project coordinator based in Port Vila.

\subsubsection{Transparency and distribution}

The community perceive positively of the project and its financial transparency. As shown in Figure 7.4, all 40 community members interviewed stated that they trusted the Loru project. When asked whether there was anything he wants to add at the end of the interview, John Moses expressed, "me likem Loru!" A sentiment that was echoed community-wide.

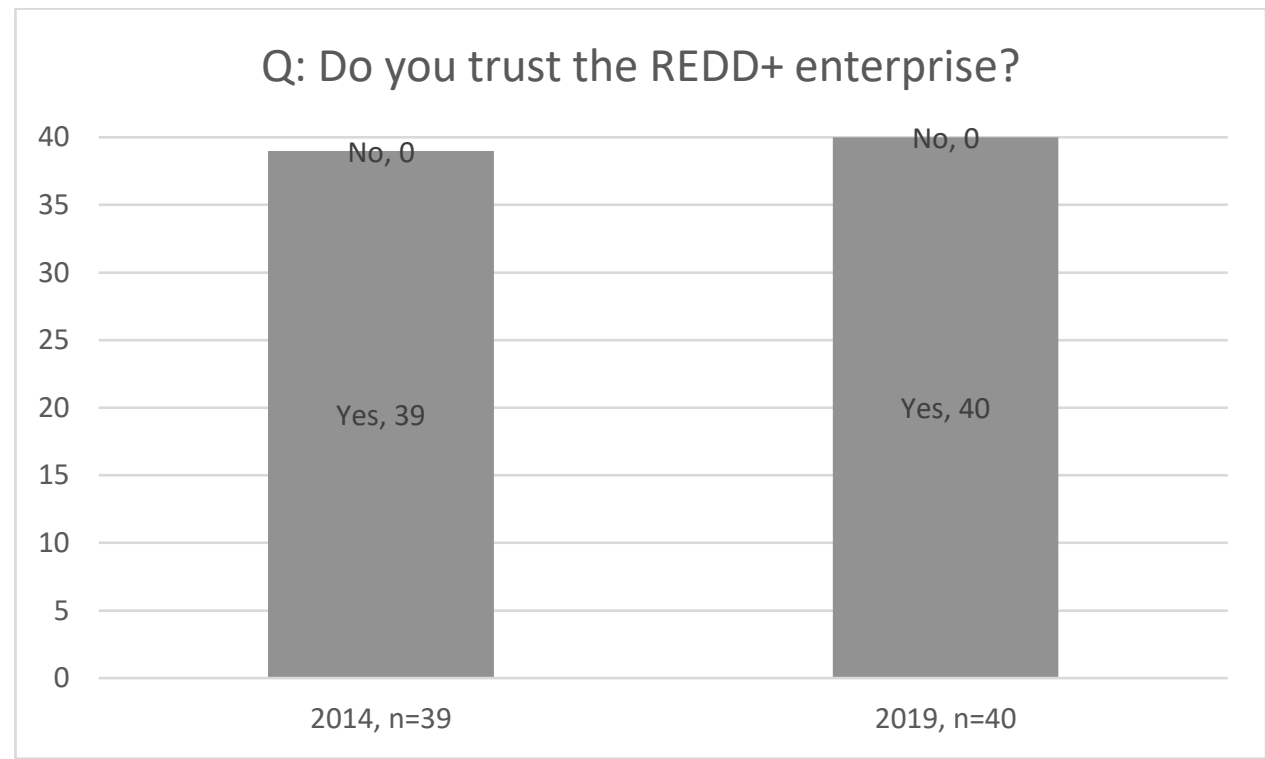

Figure 7.4 Ser clan trust of Loru project 2014 and 2019 
While the Social Impact Survey asked community members their income, the findings were not reliable so are not included. As expanded on in the Surveyor's Notes in Appendix C, community members do not track their income, income varies largely month-to-month, and individual income could not be easily separated from household income. Participants found it difficult to identify a figure when asked for their monthly income, often only choosing one rather arbitrarily when I suggested rough guesses (a serious limitation of monitoring and evaluation in development practice is that evaluators are often encouraged, as I was, to write a response even if it may be misrepresentative). Therefore, I do not feel I can trust this data and it was not possible to study the distribution of Loru income amongst community members.

Nevertheless, it can be concluded that the Loru project has resulted in at least a modest improvement of income distribution within the Ser community. Agroforestry serves as a distribution mechanism as every Ser clan member is allocated an agroforestry plot and are able to sell what they grow (Figure 7.5).

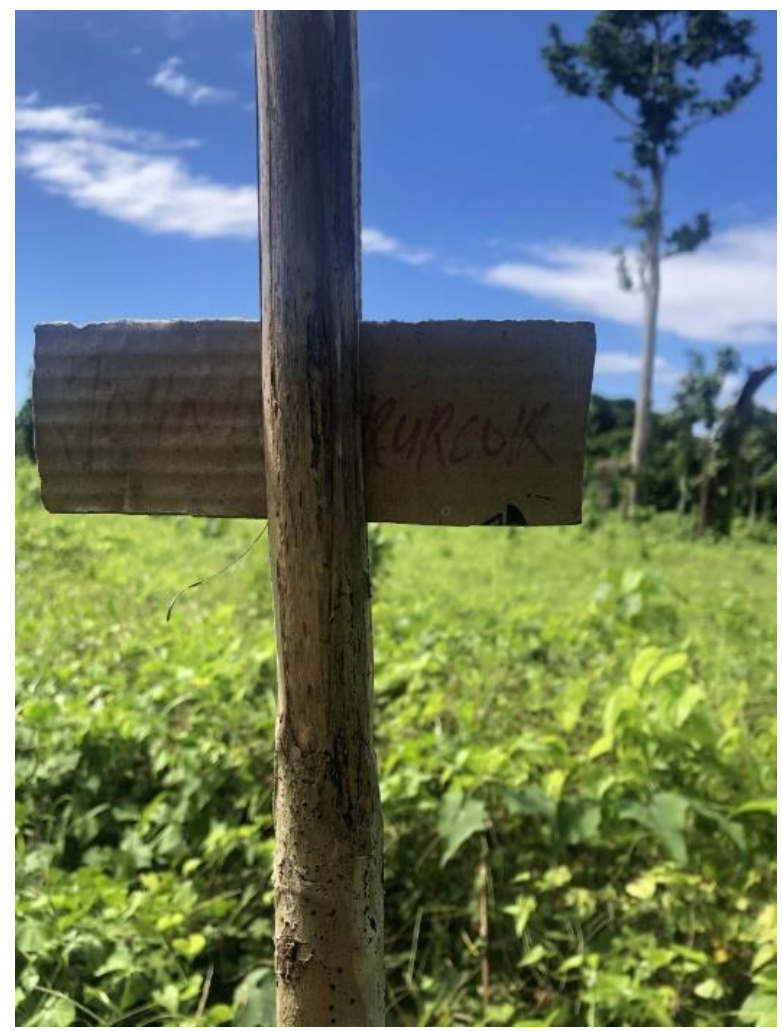

Figure 7.5 Sign marking John's agroforestry plot

Chief Skip is entitled to $40 \%$ of Community Benefit Funds. However, the amount he takes is at his discretion and it was not possible to conclude his actual takings as I only had 
access to one quarter's financial report. Nevertheless, the Quarter 32018 Bank Account Cash Flow and Closing Balance in Table 7.1 shows no expenditure out of the Community Benefit Funds for that quarter, meaning the Chief did not take any of the $40 \%$ of the VUV 107,000 which he was entitled to.

Furthermore, as shown in Figure 7.6, when asked whether community members could access financial records if they asked, 36 out of 40 community members reported that they would be able to look at the Finance Committees' reports which shows the Chief's cut. This suggests a high level of transparency.

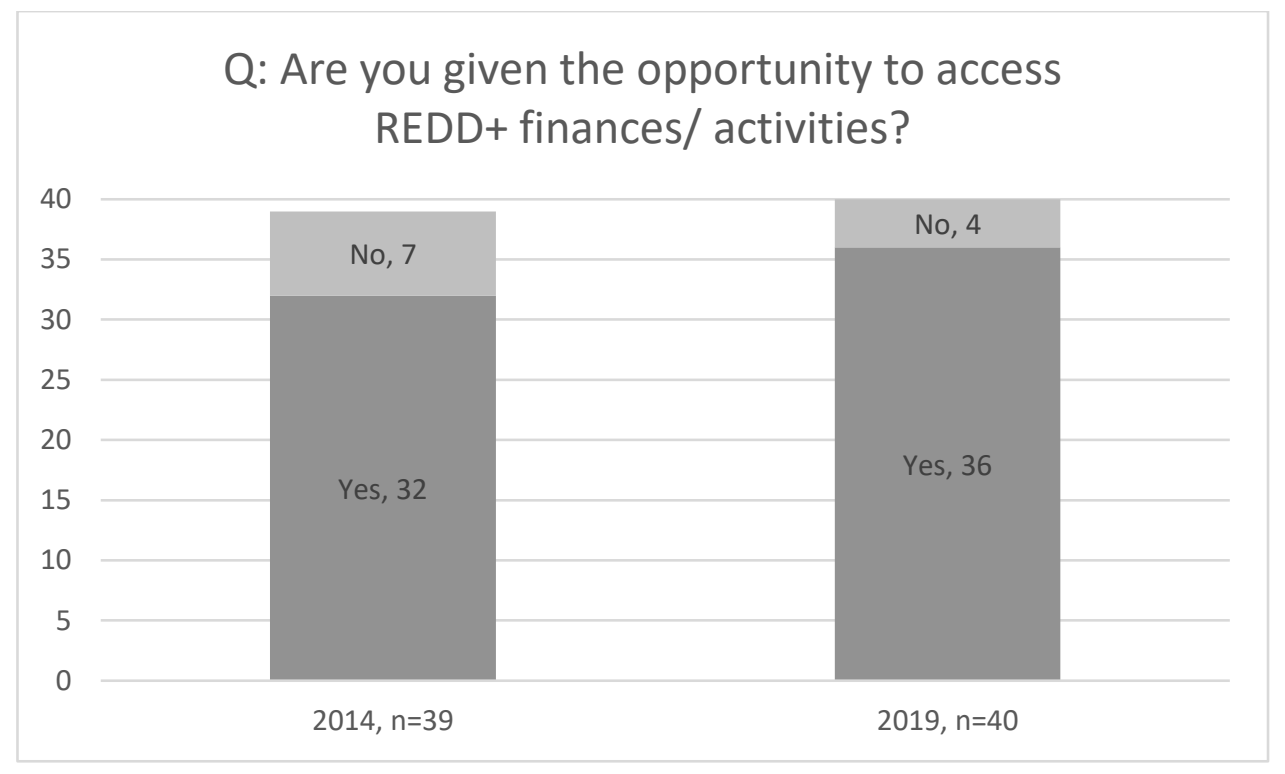

Figure 7.6 Ser clan access to Loru finance documents 2014 and 2019

Anjali Nelson acknowledges, "there's always a major risk that the powerful will take the money because there's not a huge amount of feedback mechanisms." However, she adds, "there's a general understanding that they all agreed that Loru was going to liftem up all men. That is was going to help everybody in the family." This demonstrates that while the limited feedback mechanisms do not protect against elite capture, Nelson perceives an egalitarian community attitude towards the benefits produced by the Loru project.

\subsubsection{Improved forest governance capacity}

LLV programmes and Loru activities have increased the Ser clan's knowledge of and skills in forest governance. Capacity building has been integrated into Loru at all stages of the project. LLV conducted several educational workshops on climate change and REDD+ prior to the project's commencement. This improved participants' understanding of the project and 
allowed the community to give their full, prior and informed consent. During fieldwork, the community displayed an awareness and understanding of the causes of climate change, including forestry's role in sequestration and mitigation, and the local impacts of logging and local biodiversity loss. Community ranger, Kaltapang Sam explained, "when we protect the area, it gives us what we call carbon dioxide... the area protectem birds and wildlife." This background knowledge informs the Ser clan's decision-making in forest governance.

Most notably, the community have built capacity in forest governance through managing the project. LLV oversee the management of Loru, but the day-to-day activities and decision-making occur at the community level through the Land Management Committee, Finance Committee and Board, all composed of Khole villagers. In Loru's Project Description, Ser-Thiac aims to "reduce the responsibilities and fees to the Project Coordinator [LLV] as they become more capable of managing the project" (A. Nelson et al., 2015 p. 45).

Additionally, LLV conduct specialist training for particular community members, especially those employed in the Loru project. LLV delivered bookkeeping and financial management training to the Loru Administrator, and forest monitoring training to Loru rangers (A. Nelson et al., 2015). Nelson recalled: “Definitely there's been a lot of capacity building for Lenny and Kaltapang, you know the rangers and the administrative staff." A current LLV project to build a biodiversity toolkit for Indigenous rangers involved training workshops on biodiversity in Port Vila for Khole rangers ("Biodiversity Monitoring Toolkit for Community Conservation Areas in Vanuatu," 2019). This demonstrates LLV's commitment to increasing the capacity of the Ser clan to have an active role in forest management. 
This content is unavailable. Please consult the figure list for further details.

Figure 7.7 REACTED- Participants of biodiversity training including Ser clan members in Khole village

Note: From Biodiversity Monitoring Toolkit for Community Conservation Areas in Vanuatu. (2019, 26/07/2019). Daily Post. https://dailypost.vu/news/biodiversity-monitoring-toolkit-for-community-conservation-areas-invanuatu/article 02858516-5954-546b-a895-05481b8bc17a.html?fbclid=IwAR3OsCiEi-

byepaYTbTZaFXn GkyLVM6QIOXm5roUnc8-KE1PnVdNLWVwFs

The benefits of capacity building extend beyond local forest governance for the community. Skills in bookkeeping and environmental monitoring are transferable and demanded in Vanuatu and along with the practical experience of Loru, provide valuable employment opportunities for the Ser clan (A. Nelson et al., 2015).

\subsubsection{Biodiversity}

The Ser clan displayed interest, awareness and concern for local biodiversity and are direct beneficiaries of its protection. The community relies on the forest for traditional medicines, food such as wild pigs, fish, nuts and fruit, and receive eco-tourism income through birdwatching tours. Healthy forests enhance air quality and provide food for wild pigs which are used for traditional mana (status) ceremonies where male villagers slaughter pigs for older family members to increase their mana.

In particular, the community were concerned about the endangered coconut crab that is a prized food source. When asked why conserving the forest is important, community member, Anna Fred singled out the coconut crab: "We're lucky in Loru because children know what is a coconut crab... we have a lot of birds, lot of fish in the sea, lot of crabs in the sea." 
This suggests the conservation of the Loru forest has resulted in greater biodiversity and ecological knowledge and increased the community's value of biodiversity.

\subsubsection{Climate change adaptation and resilience}

Vanuatu has been identified as vulnerable to climate change and is predicted to experience more frequent and severe cyclones (Granderson, 2017). Healthy forests play a direct role in protecting against storm and cyclone damage (Fritz \& Blount, 2007). The Loru project enhances the Ser clan's resilience to the local impacts of climate change by providing supplementary income sources and strengthening the traditional economy by transitioning away from producing copra.

Carbon credit revenue provides opportunities for economic development, as explained above. Diverse income sources allow communities to be resilient to the local impacts of climate change such as cyclone damage to copra plantations, housing and infrastructure (Nakashima et al., 2012).

The Loru project has supported the Ser clan to shift from a reliance on copra as its primary livelihood activity towards agroforestry. Whereas before, copra farming would have occupied most of the community's available time, the community now spends most of their time gardening a variety of food crops. Mixed organic gardening crops are more resilient to cyclone damage than monoculture plantations of coconut palms that can be destroyed and take longer to replant (Regenvanu, 2010). As told by Warakar Ser, "This generation they don't grow copra anymore... when you plant coconuts that's the end of that land. Maybe just do gardening then you can work on that piece of land for so many years." This indicates that the community's shift from copra harvesting to growing food crops is influenced by sustainability concerns.

Growing food crops reduces the community's need for cash and imported food. Crops can be traded locally for other goods and the excess sold for cash at the Luganville market. By contrast, copra is sold on the international market and exchanged for cash, but residents confirmed this is not a resilient income source (S. Warakar, personal communication, 1 July 2019). The copra price is so volatile that at the time of fieldwork, the purchase price was so low that no community members were harvesting copra (Figure 7.8). 


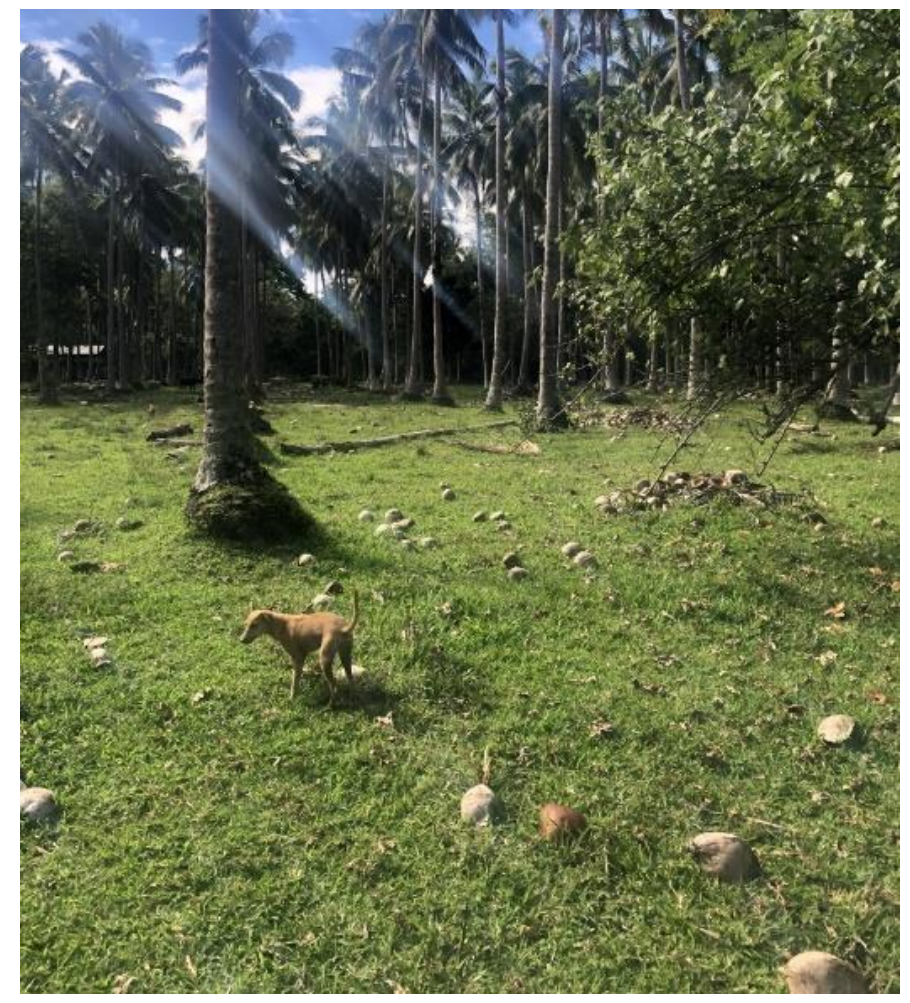

Figure 7.8 Unharvested coconuts left to rot on ground near in Loru forest

Horticultural gardening increases food security and climate change resilience. Higher quality, quantity and a wider variety of locally grown food becomes available, and community members are less dependent on less-nutritious imported food such as rice and biscuits. Imported goods are expected to increasingly fluctuate in availability and price as the impacts of climate change increase the cost of transport and extreme weather events worldwide (UNDP, 2019).

Additionally, shifting from copra to gardening strengthens the traditional cashless economy (Regenvanu, 2010). As community members rely less on producing and selling copra, they are more likely to interact with the cashless economy in other ways such as trading locally, reinforcing a long-term source of resilience in Vanuatu (Nakashima et al., 2012). The cashless economy strengthens traditional values of reciprocity and encourages self-sufficiency and local trade. This is already being demonstrated; community members reported sharing access to water tanks with family members during droughts and the Khole community are growing bamboo for building materials (S. Warakar, personal communication, 1 July 2019) which is more sustainable as a building material, and a traditional strategy to cyclone resilience (Nakashima et al., 2012). 
As Khole becomes less reliant on copra, villagers are less connected to the global economy and protected from volatility in price and supply. Imported food products are likely to become more expensive and less reliable with climate change as extreme weather raises the risk of damage to crops, and a higher price of fuel increases transport costs(UNDP, 2019).

\subsection{How does the social impact contribute to the sustainability of the Loru project?}

To answer the first sub-question, "how does this social impact affect the social, economic and environmental sustainability of the Loru Forest carbon project?' I conceptualise sustainability using an ecological economics framework. In ecological economics, sustainability refers to the ability to maintain and continue activity at the current level. 'Capital' refers to the means to generate this activity (Costanza, 1991) ${ }^{3}$. Capital is commonly grouped into three connected and co-dependent categories: financial capital, natural capital and social and human capital (Costanza et al., 2015; Purvis, Mao, \& Robinson, 2018). While many disciplines conceive of sustainable development in these three pillars, Ecological economics distinctly hierarchises the pillars in concentric circles as below which "understands economies as embedded in cultures and societies, which are embedded in the geosphere" (Costanza et al., 2015, p. 130).

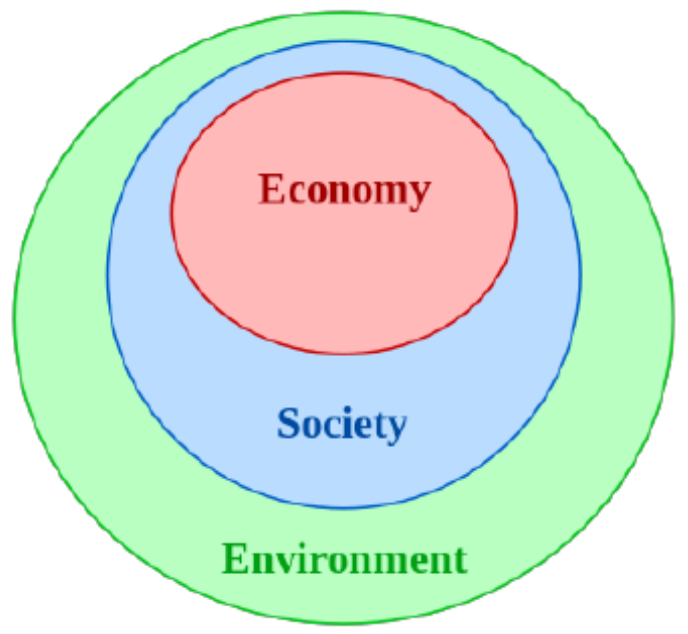

Figure 7.9 Ecological Economics three concentric circles of sustainability.

Note: Adapted from Purvis, B., Mao, Y., \& Robinson, D. (2018). Three pillars of sustainability: in search of conceptual origins. http://eprints.whiterose.ac.uk/136715/7/Purvis2018 Article ThreePillarsOfSustainabilityln.pdf

\footnotetext{
${ }^{3}$ For a discussion of sustainable development using the principles of Ecological Economics see (Costanza, 1991; Daly, 2011)
} 
Costanza et al. (2015, pp. 129-130) refer to natural capital as: "The natural environment and its biodiversity... needed to provide ecosystem goods and services." The 'society' circle includes social and human capital where social capital is: "The web of interpersonal connections, social networks, cultural heritage, traditional knowledge, and trust, and the institutional arrangements, rules, norms, and values that facilitate human interactions and cooperation between people," and human capital; "Human beings and their attributes, including physical and mental health, and other capacities that enable people to be productive members of society" (Costanza et al., 2015, p. 130). Economic capital refers to the economic resources used to support natural and social capital such as money, labour and machinery (Purvis et al., 2018). Economists frequently define other 'capitals' such as built capital. However, for simplicity, I will not distinguish built capital from financial capital as buildings can be easily bought with money (i.e. are commensurable) in a way relationships and soil health cannot.

The below section discusses how the Loru project supports or compromises these three capitals and thus, the ability of the project to continue its activity-its sustainability. The three spheres of sustainability are connected, co-dependent and interact in complex ways. Capitals can be complementary or supplementary; trade-offs may exist between different capitals, or growth in one capital may facilitate growth in another (Costanza et al., 2015).

\subsubsection{Social sustainability}

For a forest carbon farming project like Loru, to achieve social sustainability means protecting social and human capital: the livelihoods, social networks and wellbeing of the Ser clan. Sean Weaver expresses the importance of investing in social and human capital through explaining that forest carbon projects must have a 'community development angle':

[Projects] will fail if the project doesn't have a very strong community development angle to it and because... in places like Vanuatu, if people don't like what you're doing you'll get shut down really quickly, and really respect for proper processes for consultation and consent are so important, things just never get off the ground otherwise.

Weaver suggests that forest carbon projects which compromise livelihoods will fail. Consultation and consent processes ensure that communities have a forum to design and 
implement forest carbon projects in a way which enhances social and human capital and 'shut down' projects that threaten livelihoods.

Sean Weaver expressed that the financial advice provided to the Ser clan encourages them to invest the carbon revenue in infrastructure which enhances human capital, "We should invest mostly in social infrastructure like piped water, something durable that's going to benefit the whole community... So, provide financing advice to enable benefits." This demonstrates that the Loru project has been implemented to enhance the Ser clan's livelihoods.

As explained in the previous section, the Loru project enhances human capital through its positive impact on the Ser clan's livelihoods and forest governance capacity. The project's social capital includes the institutional network of the Loru project, and the relationships and trust between the Ser clan, LL and Nakau.

Community elder and previous employee of LLV, Warakar Ser, explained the importance of relationships for the success of the Loru project:

one of those things that interested us to participate more is because Serge [Warakar's son and LLV employee] is in this project and also a member of the family so that's how we communicate. It's important to how communication just flow from Live and Learn down to the community, so you feel free to talk. Because he's a member of the community and a landowner, he owns come part of it.

This indicates that the community's acceptance of the project is in part due to the connection of Serge. Warakar suggests that this is because communication can flow easily between the community and LL. Serge's connection to LL and the Ser clan is a vital piece of social capital which contributes to the sustainability of the Loru project. The Loru project's social sustainability stems from fostering the trust and connections which the Loru project relies on to operate.

\subsubsection{Economic sustainability}

The Loru project's generates economic capital from selling carbon offset credits to Ekos who on-sell to the international voluntary carbon market. This becomes economically sustainable when the sale of credits generates a large enough profit to fund project activities. LL and Nakau are not-for-profit and the establishment of the Loru project was partly grant- 
funded. However, the project is now self-sufficient. This offers advantages compared to social development projects reliant on grants.

Anjali Nelson argues that projects which produce economic capital (income) can better generate social and environmental impacts long term.

we work at the juncture of business and community development... it's very worthwhile if you can get it off the ground; then your chances of long-term sustainability are so much greater than they would be if you were just doing community development.

The manifestation of increasing climate change is the greatest threat to natural capital, in Loru and worldwide. Sean Weaver argues that forest carbon projects must produce income to reach a scale that meaningfully stabilises the climate:

We've got a climate emergency to deal with... we just want to maximise our beneficial impact. So it's useful to have an element of an economic mindset to steer those decisions... to get access to scale you've got to finance [forest carbon farming projects] at scale and you can never grant-fund anything at scale because there's simply not enough grants.

This suggests that as grant-funding is limited, forest carbon projects must generate income. To scale up forest carbon, economic resources must be invested efficiently so the project can produce a profit and attract further investment.

Weaver alludes to trade-offs between social, environmental and economic capital:

You've got to try and find that sweet spot of investing enough in the social side that you cover off the social dimension well, free prior informed consent, transparent governance, transparent business management, all of that. And you've got to have enough of that for it to work but if you have too much of that it gets inefficient. Whereas if it's purely grant-funded... it might get things done but it won't get it done efficiently and it won't be able to get to scale. Because the point is, the world's hugely buggered, and we need to fix it not just in one nice location, we've got to go wide, we've got to go up to scale.

This suggests that over-investing in social capital limits projects' environmental impact.

\subsubsection{Environmental sustainability}

The income generated by the Loru project has supported ecosystem services that occur at a local level such as biodiversity, water quality, air quality, food and traditional 
medicine. Carbon credit income funds the reforestation of the degraded forest in Zone $\mathrm{C}$ of the project site (S. Warakar, personal communication, 1 July 2019). The agroforestry replenishes the soil, resulting in a healthier forest as well as providing a food source.

Community members, Warakar Ser and Kaltapang Sam shared how the carbon credit revenue has supported forest reforestation:

The conservation is still there but no active programmes like nowadays. We just keep the forest how it is and no activity. But when the REDD+ came they just build up to this day. -Warakar Ser

It changed [from a grant-funded conservation project to a forest carbon project]. Many plantem trees so I think we have changed from conservation to REDD+. -Kaltapang Sam

Warakar and Kaltapang suggest that although the grant-funded conservation programme, Vanuatu Protected Areas Initiative, protected the Loru forest, the financial capital generated through carbon offset credit revenue funds has enhanced the natural capital of the forest: 'plantem trees,' 'active programmes' -fostering environmental sustainability.

\subsection{Chapter conclusion}

To answer my first research question, the Loru carbon project is producing a positive social impact for the Ser clan. It is enabling a transition from copra to other sustainable livelihood activities by providing income and economic opportunities such as agroforestry. Without this capital, it is possible the forest would have been logged; however, with the carbon income, the forest is protected and expanded. The local ownership and trusted relationships with project actors are essential in achieving the positive social impact of the project. The social impact is delivered in a sustainable way, due to the community's robust social capital and the economic sustainability of the project, enabling the environmental sustainability of the Loru forest, and - at a modest scale-contributes to global environmental sustainability by helping to mitigate climate change. 


\section{Chapter 8 Localising forest carbon in Loru}

In this chapter, I discuss how the Loru project has been driven by the local context and community in its design and implementation. First, I explain how local practices, aspirations and ecologies have been central to the project's goals and management. Next, I present findings which suggest that the community's sense of ownership of forest resources have been enhanced by the project. Lastly, I describe how the Loru project has met free, prior and informed consent (FPIC) under the United Nations Declaration on Indigenous Peoples (UNDRIP). A meaningful consent process suggests the community are involved in project decision-making.

\subsection{Integrating the local context}

Indigenous communities have diverse cultures, practices and ideologies that affect how a forest carbon project will operate. Projects which understand the local context can integrate local people's practices, knowledge and goals into the project's design and implementation. The Loru project has integrated the Ser clan's histories, ecological knowledge, practices and development aspirations. The Loru project has successfully navigated kastom land ownership of the Loru forest site and opted to legally register the land to the Ser clan and Chief Skip.

\subsubsection{Community development aspirations}

The development aspirations of the Ser clan informed the design and implementation of the Loru project. LLV conducted workshops with the community in 2010 and 2011 (A. Nelson et al., 2015) to identify their aspirations which informed the project's development priorities. These development priorities influenced the capacity building programme and investment of the carbon credit revenue (A. Nelson et al., 2015).

Anjali Nelson, who conducted the development aspiration workshops, shared that the workshops identified the community's desire for cash to pay for school fees, year-round access to water and domestic technologies

Two things really stood out to me. Education, again education linked to copra. A lot of people were stuck in livelihoods that they didn't want to do, things that didn't inspire them. Copra was not inspiring the community. It was not work that they wanted to do, and it was not what they wanted to do with their land. But they felt forced to do it and pursue it in order to pay for school fees... I felt that giving them an opportunity for a livelihood outside of copra was one of the main community benefits. 
Nelson continued:

...the other one which is again linked to that was that the women feeling very very clearly, saying to me very very clearly a couple of times, life needed to be easier. So, running a house, making a house easier to run day-by-day was just such a big thing for these women. So that was another kind of long-term hope for me out of the project in terms of a community development outcome was access to water, access to domestic technologies that they desperately wanted that would make their lives easier.

The community hope to transition away from coconut harvesting. Selling copra (the dried meat of the coconut fruit, which coconut oil is extracted from) is the main source of income for the community. The community's future aspirations centred around finding an alternative livelihood such as agroforestry and reducing dependency on copra.

Serge Warakar of the Ser clan explained that the community will only harvest copra when they need to pay for secondary school fees, alluding to the community's dependency on copra.

Copra is something like people need income for school fee and other needs then that's why people start to cut copra, but gardening is something ongoing everyday... because when [the children are] in secondary [school], there's copra. Copra is the one meeting all the costs. [Selling food at the] market will maybe just support. In primary school, market could cover all costs.

The community seem to value cash for its instrumental value rather than intrinsically or as a status symbol. Cash is valued as a means to pay for goods and services such as domestic technologies and school fees. Community members with extra income such as the Chief or those with jobs in Luganville or Port Vila seemed to dress, eat and live as modestly as the rest of the village (see Figure 8.1). 


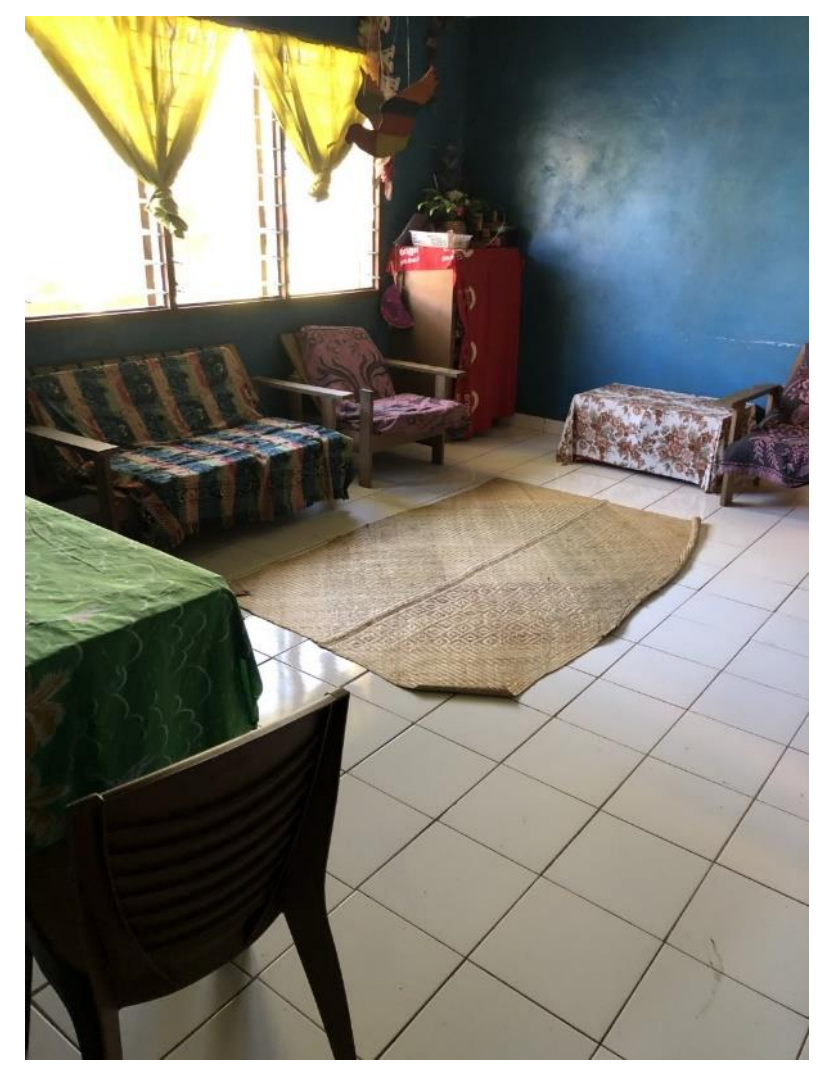

Figure 8.1 Typical dwelling in Khole village

Community members adjust their income according to their current needs rather than maximising income to gain status. For example, men harvest and sell copra only when they need additional income for secondary school fees, which are more expensive than primary school fees. This might explain why the community have opted to invest in agroforestry rather than receive individual dividends. The financial structure of the Loru project gives the community the freedom to allocate funding based on community preferences.

This suggests that the project's focus on agroforestry, as discussed in the previous chapter, reflects and integrates the Ser clan's goals and values. Rather than just provide income, the project has integrated the development aspirations of the community, supporting a transition from copra harvesting to a preferred livelihood based on agroforestry.

\subsubsection{Local histories}

The Ser clan have a legacy of environmental stewardship. The local focus of the Loru project gives the community the agency to structure and implement the project in line with their local identity, shaped by their history. 
The community are incredibly proud of their ancestor, Chief Kaleb placing a traditional tabu to protect the forest. The Loru project formalises the rules and boundaries of the conservation site but the conservation remains locally-driven with reference to the area's history. The tabu is mentioned in Loru Project documents (A. Nelson et al., 2015) and the community commonly referenced this history when interviewed about the Loru project. Two community members recall the tabu:

The chief, Chief Kaleb already put a local tabu. And the British guys, those volunteers just come and build upon what is already done by the chief here. -Warakar Ser

Local tabu just when they protect the area you have to inform the community about that this place is protected in a customary kind of law. That's why people started ok this place protected. -Serge Warakar

For multiple interviewees, when asked about when they first heard about the Loru project, they shared the area's local history, going back to the establishment of Chief Kaleb's tabu. This suggests that the project has continued the community's conservation narrative rather than undermining or replacing it with an externally-imposed conceptualisation of forest conservation (i.e. one based upon maximising carbon storage).

Anjali Nelson commented on how the family's local history of environmental stewardship is reflected through the Loru project. She explains how the Loru project enabled the community to continue this legacy:

All communities I've engaged do have a sense of environmental legacy... but I don't know whether you see the same level of commitment in other communities as you have in Loru where they were so proud of the story of old grandfather Chief Kaleb stopping the Malaysian loggers that, that was already their story, they were already environmental champions that wanted to see how they could maintain that and protect that going into the future... They already wanted that to be their legacy, they were just struggling to see how they would avoid the future pressures if they didn't legally protect it.

This suggests that the project's focus on the local histories and values has enhanced conservation and engaged the community. 


\subsubsection{Local practices}

The boundaries of the conservation site are marked by namele leaves, used to indicate traditional tabu sites. Serge Warakar explained the role of the leaf: "yeah we have namele leaf, it's traditionally used to indicate this place is a tabu place." Integrating this local practice has increased the environmental effectiveness of the project. As Warakar Ser explained, "When you place the leaf around certain area, people respect that." This indicates that conservation sites marked by the namele leaf have legitimacy and the rules are understood and respected by neighbouring villages.

The Loru project's approach to biodiversity recognises the customary value of the endangered coconut crab (see Figure 8.2 ). The coconut crab is valued by ni-Vanuatu and particularly by the Ser clan (Pacific Beat, 2013). It is featured on the ten vatu coin and exchanged in traditional status-exchange ceremonies (Marango, 2017). Protecting the coconut crab motivated late Chief Kaleb to place the customary tabu. Chief Kaleb's grandson, Serge Warakar shared, "At one time, the chief, Chief Kaleb went fishing and he saw some crabs, coconut crabs. The undersized ones, some people just killed them and then roast them... so that's when it happened, he put the tabu." This expresses the cultural significance of the coconut crab for the Ser clan, and its link to the conservation of the Loru forest. Protecting the coconut crab has been integrated as a key biodiversity goal for the Loru project and is included in the biodiversity management plan (A. Nelson et al., 2015). 


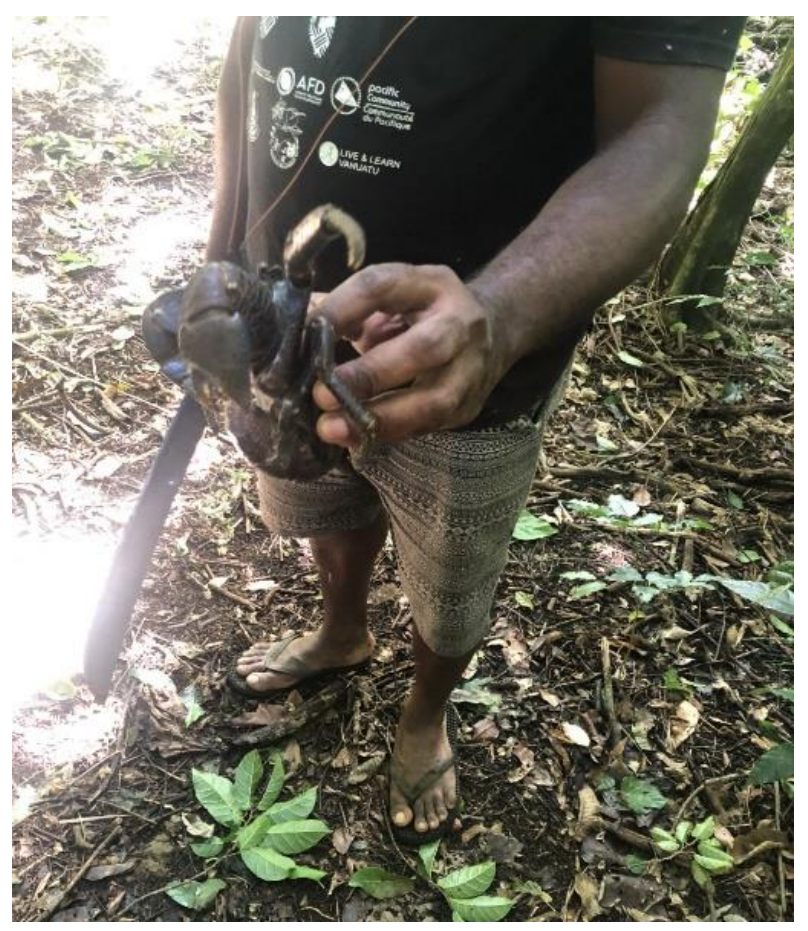

Figure 8.2 Serge Warakar shows me a young Coconut Crab during a walk of Loru forest

Agroforestry has been practised widely in Vanuatu, commonly by planting food crops amongst native trees (Addinsall et al., 2016). As noted by Addinsall et al. (2016) and Regenvanu (2010), agroforestry strengthens traditional resilience strategies. By integrating local farming knowledge and agroforestry, the Loru project strengthens local capacity and community engagement. Warakar Ser shared how the agroforestry plots have led to intergenerational engagement with the Loru project, "our first agroforest plot there is done by my children when they were still children. So that's why they're still happy and interested in the forest. Still have interest to participate." This demonstrates that agroforestry has led to community engagement with the Loru project. 


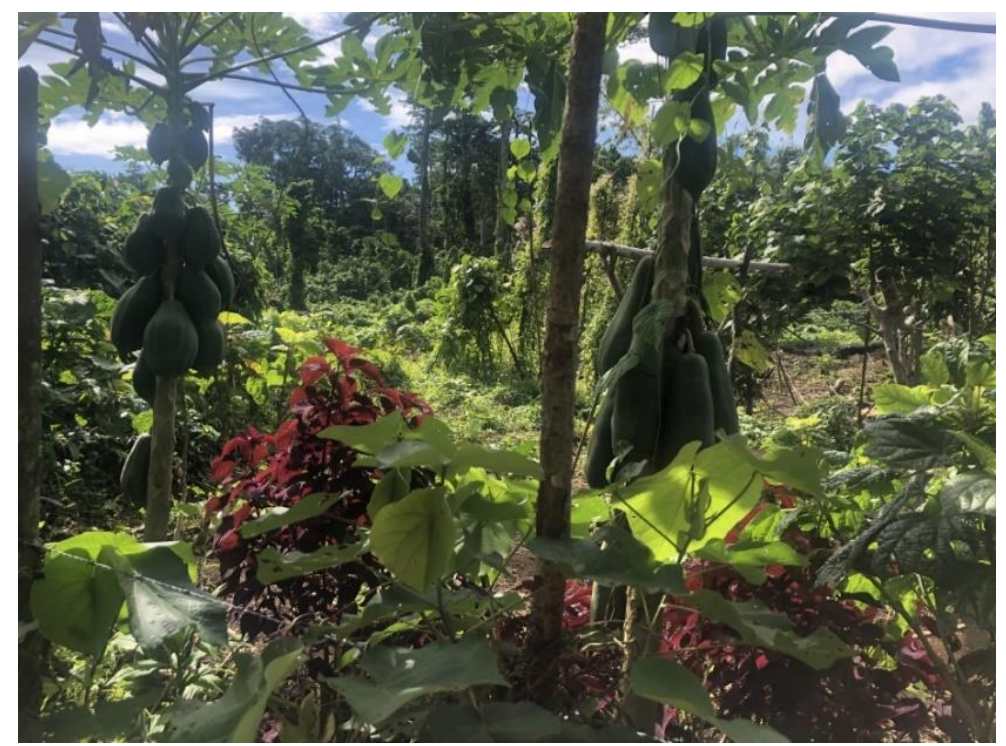

Figure 8.3 Agroforestry plots with Papaya trees

Being a local practice, agroforestry fits into existing structures and institutions. For example, women's markets in island capitals provide the community with a traditional forum to sell additional food crops.

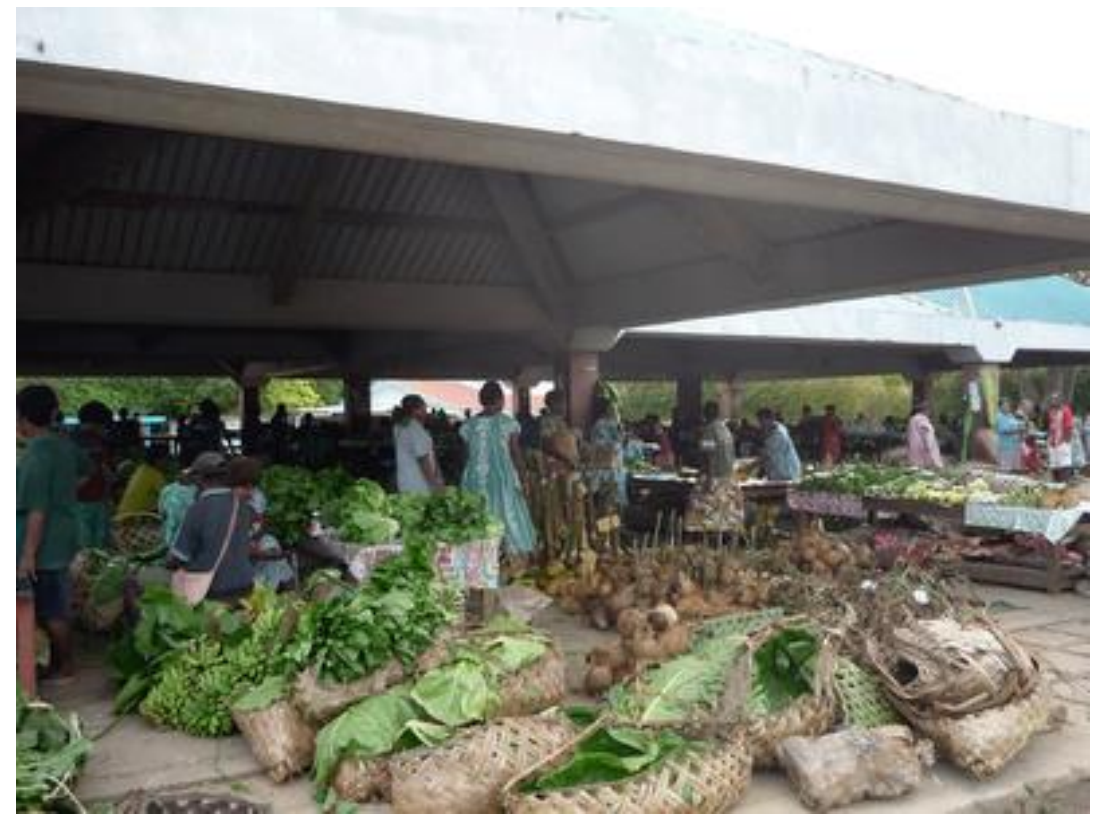

Figure 8.4 Luganville market

The success of agroforestry demonstrates the value of incorporating local practices and preferences. As chapter seven explains, LLV provided support to the Ser clan to pursue several economic diversification opportunities in the Loru project area. Of all economic opportunities, agroforestry, with the clearest link to traditional local practices was most successfully adopted. 


\subsubsection{Customary land ownership}

Forested land is often under insecure and communal land tenure arrangements (White \& Martin, 2002). However, World Bank reports characterise secure land tenure should be prerequisite to REDD+ to determine who are legally entitled to payments (Chomitz, 2006; Godden \& Tehan, 2016). However, forest carbon projects that define legal landowners can exclude landless members of the community, exacerbate land disputes and interfere with Indigenous perceptions of place (Sunderlin, Larson, et al., 2014). Therefore, scholars argue that land tenure must be applied in a context-specific way which does not undermine customary approaches to land (Ceddia et al., 2015; De La Fuente \& Hajjar, 2013).

For ni-Vanuatu peoples, belonging to local land, 'ples,' is deeply ingrained in communal identity (Smith, 2017). As expanded on in chapter four, Vanuatu land is owned by chiefs and inheritance is patrilineal (Smith, 2017). It is enshrined in ni-Vanuatu kastom and in Vanuatu's Constitution that all ni-Vanuatu have access to land for their livelihoods (Napua, 2017). Land is considered the domain of kastom, and formal state governance has a limited role in determining land rights (McDonnell, 2013; Napua, 2017). Much of Vanuatu's land is informally shared by neighbouring communities with overlapping kastom claims. However, due to the notion of universal rights of access, this largely operates without the need to legally determine boundaries and register land ownership. Nevertheless, land disputes are common in Vanuatu (Napua, 2017). As community member, Klarence Dan commented, "in some places land disputes... land disputes or family disputes for that particular area."

As discussed in chapter three, the potential of carbon income incentivises land grabbing and create or exemplify land disputes (Smith, 2017). Serge Warakar commented on how land developments had contributed to disputes, "there are plenty [of land disputes]. In the last 20 years, you can't come across many dispute. Now when the development started coming, people started many disputes."

Sean Weaver, founder of Nakau and Ekos, added that even after a project's establishment, landowners from different clans may have competing interests that make project implementation difficult and lead to conflict. 
When you're getting to a few thousand hectares you've got a different human geography of landowners living in different locations and coming together and they've got competing interests, they're from different clans, different hapū and there might be jealousies.

Unlike much of the land in Vanuatu, the Loru site is only held by one extended family, the Ser clan, led by Chief Stephen Ser. The clear land tenure and lack of border disputes led to LLV and the community to decide to legally register the land through the Ministry of Lands and Natural Resources (A. Nelson et al., 2015).

Loru's clear land tenure was a key reason the site was selected as Nakau's pilot forest carbon project. Warakar Ser, village elder and previous employee of LLV recounted the difficulty in establishing a forest carbon project in areas with multiple landowners, "We met with those communities, landowners. But... some of those lands have 10 or 15 or 20 landowners in a particular area so [Anjali Nelson] thought maybe it's too hard to place a project with too many landowners."

The Loru project operates land tenure in a way which respects ni-Vanuatu ideologies and norms. Chiefly title to land is respected; Chief Stephen Skip is recognised as the landowner of the project area and maintains a decision-making role in land-related matters.

Under ni-Vanuatu kastom, Chief Skip has a responsibility to ensure that all community members have access to enough land to grow food and live off. The community exercised this norm by sharing project benefits with an 'adopted' member of the family with no kastom land claim. As Anjali Nelson explains, "they're generally a very communitarian-minded people... There's this guy... He's not related at all, he was kind of adopted by them... and he's been included as a beneficiary of the project. That was under everybody's agreement."

This suggests that the legal registration of land did not interfere with customary communitarian approaches to land distribution. The Ser clan could determine how benefits were shared amongst the community according to community values.

\subsection{Community ownership}

The integration of local practices suggest that the community has been able to exercise ownership and agency over the Loru project. Moreover, the project is designed to enhance customary ownership of the Loru forest. The family business, Ser-Thiac, are the project owners and legally own the land and carbon rights (A. Nelson et al., 2015). The project's 
institutional framework is designed to maximise local forest governance by allocating local forest rights and supporting forest governance capacity.

Anjali Nelson contrasts the project's commitment to community ownership to a logging project:

We found that with new projects that people assume it's going to be run like a logging project or something else where you sign a piece of paper and somebody else does all the work... That sense of ownership: you are the centre of this project, you're not just a peripheral beneficiary who has given away the rights to your resources, you are running this.

The Ser family have a rich link with the Loru forest, embedded in their identity. Oral histories can track land use back several generations, such as community members explaining the tabu discussed above. To maintain Indigenous peoples' right to self-determine as stipulated by the UNDRIP, it is essential the project does not compromise the community's ability to govern and use customary land. Ser clan member and employee of LL, Serge Warakar describes the community's customary ownership: "if we own the area and we make a decision over the area then the community follows and the chief of [another] community has no right to make any decision about our land."

The project has strengthened rather than undermined the community's connection to the land. This has been achieved in several reinforcing ways.

Firstly, the land and associated carbon rights are legally registered to the community. The family business, Ser-Thiac, was formed to legally own the Loru forest carbon rights, locally manage the project and invest in economic development. Anjali Nelson explained that the community maintain the carbon rights, "Unlike other carbon projects where an external entity will come in and purchase the carbon rights... or buy the land and buy the resources, we try to maintain it so the landowners keep hold of that right."

Secondly, LLV provided education on the preservation of the forest; initially to seek informed consent, but which has continued as capacity building. Warakar Ser, a community elder and previous employee of LLV explained that this education has effectively increased the community's sense of ownership of the forest:

When the families came to know the importance of the protected area, in the long run, they still have some big respect for those, and at the end of the day, they feel part of it. They feel 
part of the forest, this generation here, because when they were still children we taught them many things about the forest, so when they grown up, like the ownership of the forest.

This suggests that project activities have enhanced the community's forest management knowledge, fostering a sense of ownership of customary land and commitment to its conservation.

Thirdly, the structure of the programme and roles of LLV and Nakau are designed to maximise the ability for the community to self-determine. Anjali Nelson explained that the structure of the project operates through three agreements between Ser-Thiac, Nakau and LL (see Figure 8.5). As the landowners and carbon rights holders, the family business Ser-Thiac owns and manages the project. Ser-Thiac has a Service Delivery Agreement with and pay a service delivery fee to LL. Nelson describes LL as "an intermediary, like a capacity building organisation... their ongoing role is supporting people on the ground." Ser-Thiac has signed a PES agreement with Nakau to on-sell carbon credits to resellers. Nakau and LL have a licence agreement, and Nakau is partly owned by LL.

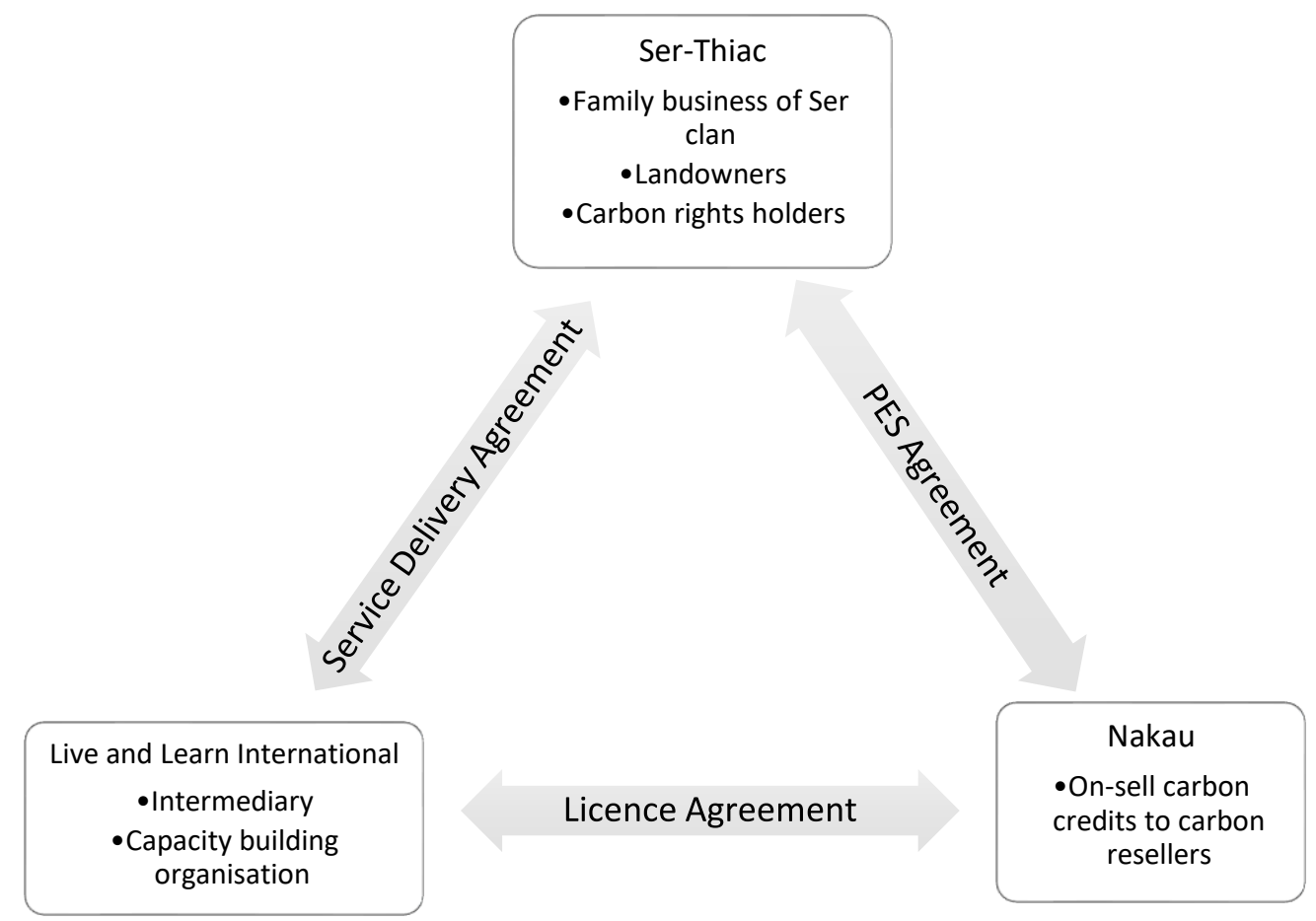

Figure 8.5 Institutional structure of the Loru project

Nakau aims to maximise community ownership of their projects. Anjali Nelson shared that in future, communities can work directly with Nakau, without using an NGO as an intermediary project coordinator: "In future, if a landowning community presented with the 
capacity to establish, write its own PD [project description] and manage itself from the start then you may not have any need for a project coordinator entity."

The Nakau Methodology requires the Project Description to identify the project owner capacity and outsource tasks to the project coordinator accordingly. The Loru Project Description identified the project owner capacity of Ser-Thiac as low (A. Nelson et al., 2015). This is based on characteristics such as little or no experience managing a group project, many participants with low levels of education and a difficult operating environment such as remoteness, poverty and poor infrastructure access (A. Nelson et al., 2015).

Based on this project owner capacity assessment, the Nakau Methodology recommends outsourcing the following services to LLV as the project coordinator: project development, sub-contract management, monitoring and reporting, and facilitating sale and purchase agreements (A. Nelson et al., 2015). The methodology recommends LLV and SerThiac co-manage the employment of local staff and project implementation (A. Nelson et al., 2015).

Notably, the Nakau Methodology (A. Nelson et al., 2015, p. 43) states:

In providing services for the project, the Project Coordinator must maintain a commitment to the participatory processes... In this respect, outsourcing of technical and administrative capabilities must not reduce the level of Project Owner power with respect to participation in decision-making.

The design and implementation of the project is organised by community committees. The Formation Committee determined the project design, and the Finance and Land Management Committees implement the project. Anjali Nelson describes the role of the Formation Committee:

The Nakau Methodology requires that you set up a Formation Committee for the project, that help you then set up that business structure or that governance structure. But it doesn't define what that structure needs to be. That depends on the community and what's right for them.

This demonstrates the key role of the Formation Committee in determining the project's design, suggesting meaningful community ownership of the project. 
The Land Management Committee and Finance Committee implement the project activities. Ex-Chairman of the Finance Committee, Klarence Dan explains, "we have two separate committees, the Finance Committee and Land Management Committee. We think in five years, make plans... and then approve and carry [out] that thing."

The Ser-Thiac Board is comprised of six community leaders including Chief Skip. The Board approve plans made by the committees. This is a transparency mechanism and integrates customary decision-making structures by providing a role for traditional leaders.

Importantly, the intention is that Ser-Thiac take on greater management of the Loru project. The Project Description (A. Nelson et al., 2015, p. 43) states,

Live and Learn Vanuatu is already undertaking a process of capacity building and skills transfer with the Ser-Thiac employees. The PES Agreement explains that each year, during the Project Management Workshops, the Project Owner group may reduce the responsibilities and fees to the Project Coordinator as they become more capable of managing the project. The roles and responsibilities of the Project Coordinator and Project Owner will be examined annually at each Project Management Workshop and at the conclusion of each monitoring period at the Project Monitoring Workshop. These points in the project provide the opportunity to change the roles and responsibilities of each Actor, with the intention to transfer greater responsibility to the Project Owner through time.

This demonstrates the intention and mechanisms in the project methodology to increase the Ser clan's roles and ownership of the project.

The capacity building provided by LLV intends to develop the business and environmental management skills necessary to manage the Loru project. Anjali Nelson described the business training run by LLV in 2014:

We did a lot of business training thinking critically about, having an idea, thinking critically about it, and what you need to think about if you're going to make it successful... I think all of 2014 was spent with the community saying, that if you could be any kind of businessperson what would you be? Or any type of farmer, what would you be? Let's crunch those numbers and look at that. 
This highlights how LLV thought holistically about the skills and capacities that would help the Ser clan self- manage the Loru project, providing business skills on top of forest management training.

Finally, project activities proactively involve every member of the Ser clan. Each adult is allocated an agroforestry plot and children are involved in community-wide tree-planting, scheduled during school holidays (S. Warakar, personal communication, 1 July 2019). The project operates as a membership model, all adults are members and children are invited to join once they reach a certain age (A. Nelson et al., 2015). All 40 community interviewees identified themselves as Loru members. One member from each family is involved in decisionmaking as part a committee of the Board. As Klarence Dan expressed, "each family, one is represented."

\subsection{Free, prior and informed consent}

Nakau adapted the consent process to the Ser community to effectively meet the principles of free, prior and informed consent (FPIC). To strengthen consent, Nakau has sought to understand the local characteristics of the community relevant to the consent process and integrate these characteristics such as traditional decision-making forums.

In a post-colonial context, it is critically important a project operating on Indigenous land meets the principles of FPIC to ensure Indigenous peoples are not exploited and have the agency to self-determine (Godden \& Tehan, 2016). The Nakau Methodology establishes a robust framework for reporting on the FPIC process. Nakau's interpretation of FPIC is based upon the UNDRIP and meets the FPIC requirements of the Plan Vivo Standard. The Nakau Methodology paraphrase the UNDRIP (UNDRIP through A. Nelson et al., 2015):

Free means no force, bullying or pressure. Prior means (Indigenous peoples) have been consulted before the activity begins. Informed means (Indigenous peoples) are given all of the available information and informed when that information changes or when there is new information. If people don't understand this information, then they have not been informed. Consent means (Indigenous peoples) must be consulted and participate and open process that ensures: All parties are equal, neither having more power or strength, Indigenous group decision-making processes are allowed to operate, Indigenous peoples right to choose how they want to live is respected.

The Plan Vivo standard (Plan Vivo, 2013, p. 22) states: 
Participants must enter into PES agreements voluntarily according to the principle of free, prior and informed consent, where sufficient information, in an appropriate format and language, is available to potential participants to enable them to make informed decisions about whether or not to enter into a PES Agreement.

Moreover, the Nakau Methodology sets its own standards for FPIC beyond UNDRIP and Plan Vivo requirements. The Nakau Methodology requires projects follow and report on FPIC processes at multiple decision-making points of the project's design, development and implementation (A. Nelson et al., 2015). The Loru project description sought FPIC at four points: (1) registering a legally constituted project owner entity to act on behalf of land/ resource user right holders, (2) agreement with the terms and conditions of project PES Agreement and Programme Agreement, (3) agreement to the Nakau Management Plan, and (4) agreement to submit the Project Description (A. Nelson et al., 2015).

In her interview, Anjali Nelson expanded on the Nakau Methodology's rigorous reporting requirements for FPIC consultation:

At each key point in the Nakau methodology, a write-up has to be done by the project coordinator entity saying, this was the consultation process that took place in, let's say, describing what the business structure was going to be, or the governance structure is going to be for the community in the project, this is why those decisions were made. And then that gets signed off by the Formation Committee themselves saying, yes this is what occurred. So, you can prove that you're not saying you've done consultation that you haven't done.

This demonstrates that the Nakau Methodology requires the ongoing consent of the community, enforcing reporting requirements to ensure this process is transparent.

\subsubsection{Free consent}

Free consent exists when the consenting party can freely give, withhold and withdraw consent with no pressure or fear of unfair consequences by other actors. Free consent can be difficult to determine, but an important indicator of fair consent is community members feel able to withhold or withdraw consent, even when they are perceived by others as the likely beneficiaries. This suggests that the community possess somewhat equal power with other actors to feel comfortable denying consent. 
This power dynamic was demonstrated in the Loru project when the Ser clan rejected economic opportunities such as producing nuts and growing tree seedlings. From the perspective of the project facilitators, this represented an opportunity for increased income for the community and the project facilitators expected the schemes to be adopted. However, after installing a nut processing plant, the community have opted to not continue processing and selling nuts and are not selling tree seedlings grown in the nursery.

Anjali Nelson, who was involved in establishing the tree nursery shared that the initiative was not adopted by the Ser family:

Everyone goes to the DoF but there is quite a lot of projects that want tree seedlings, a lot of people want sandalwood seedlings... We tried that, there was plenty of product, but trying to encourage to try and put a signpost on the main road for the seedlings or take the seedlings to the local market to sell, for some reason there was some gap. I've never worked out why that didn't go through.

This demonstrates that the community hold enough power to feel comfortable rejecting an initiative from the project facilitator without consequence. This suggested power balance gives confidence to the Ser clan's ability to provide free consent.

\subsubsection{Prior consent}

Prior consent occurs when the consenting party have been effectively consulted before any decisions are made. LLV committed to a rigorous consultation process and conducted over one and a half years of consultations and education before any formal decisions (A. Nelson et al., 2015).

Anjali Nelson stressed her belief in the importance of a lengthy consultation process in ensuring the community's consent:

Even if it's going to be a beneficial project, you know it's going to be beneficial, I would say anything less than two to three years of constant engagement and it's pretty unlikely that you really have their free, prior and informed consent. I wouldn't feel I could trust that otherwise.

This demonstrates LLV's commitment to prior consent based upon years of consultation. Anjali Nelson further explained how a rushed and dishonest consultation process can exclude and exploit customary landowners. She points to an example of a Vanuatu island which was 
leased to a cruise ship company and how Nakau aspires to conduct the FPIC to a higher standard.

There are so many examples of it in Vanuatu at the moment, totally outside of Nakau. There's an offshore island of Port Vila at the moment that has just been sold off to a cruise ship company... But the decision-making for that had three signatures for the final agreement. There's no way that there's only three landowners, there's no way that everyone was effectively consulted... There are always going to be people on the ground on islands who want things to happen quickly and say 'don't worry about that l'll sign'... so being able to fact check everything and always going through the right process, long slow process.

This explains how private elites can exploit local communities by not seeking community-wide consent. This has the potential to lead to poor local outcomes, such as displacing and undercompensating ni-Vanuatu peoples.

LLV has extensive experience in rural Vanuatu and prepared the Extension and Outreach Consultancy Report for Vanuatu's national REDD+ programme (A. Nelson et al., 2013). LLV has worked in Khole village for decades and two of the Ser clan work or previously worked for LLV on the Loru project. This allowed the Loru project to effectively consider the community's specific characteristics in the consultation process. The project balances traditional decision-making structures led by elders with community-wide consultation. Initial consultations were with community elders and the chief, who then led consultations with the family. Serge Warakar recalled his experiences with the consultation, "[the chief] consult with the families, all the families agree that yeah we can probably protect this area."

LLV conducted further consultations that included youth, women and neighbouring communities affected by the ban to hunt in the Loru forest site (A. Nelson et al., 2015). Warakar Ser shared; "We had consultations with other communities around the conservation area. The landowners especially, we had talks with them." This demonstrates that the Loru project consulted all community stakeholders prior to the project starting, giving communities a voice in the project's implementation. Sean Weaver stressed the importance of inclusive, community-wide consent: "If we're going to enable the community as a whole to be represented by the decisions made, they have to show us that they've got the mandate from across the community." 


\subsubsection{Informed consent}

Informed consent means the consenting parties have the necessary information and understanding to make an informed decision. In the context of Loru, informed consent required an understanding of concepts such as climate change and PES-foreign concepts for many Indigenous peoples. Indigenous peoples are often located in remote areas, with limited literacy and access to formal education. Their knowledge is therefore richly place-embedded. The neoliberal notion that local ecosystem services can be measured, valued and sold to a foreign buyer is fundamentally at odds with Indigenous conceptions of place (Sandbrook et al., 2010). To appropriately ensure that Indigenous communities understand forest carbon and can consent, it may take several years of information-sharing and relationship-building. This process is time-consuming and expensive, with no guarantee that it will eventuate into free consent. As discussed in chapter three, literature has thus criticised REDD+ projects for the unsuitability of PES to forest communities.

Nevertheless, the Loru project dedicated time and resources to ensure the Ser community's informed and ongoing consent. LLV implemented an extensive education programme for the Ser clan, starting in 2012. Along with providing information, the education programme was intended to give the Ser clan the knowledge and skills to effectively manage the Loru project themselves.

The first two years of the workshops focused on climate change, REDD+ and land use planning. Warakar Ser shared:

when the project first came here, the coordinator at the time had workshops in the nakamal [traditional kava and meeting house]. So the community came over, [Anjali Nelson] ran one or two workshops there. So [the community] got some basic understanding on climate change and REDD+.

Throughout the workshops, LLV monitored and assessed the Ser clan's knowledge. The assessments of knowledge included identifying opportunity costs and project impacts on food security. LLV produced management plans in an understandable format and language (A. Nelson et al., 2015). This ensured that the community understood concepts and could give informed consent. 
Serge Warakar shared that the workshops enabled community members to determine whether the project would benefit them:

Only a few family members actually know how, one day it will be benefit for me? This project, the REDD project. And many family members they have no idea, is REDD good project for us? But many of us though we continue to do trainings and workshops with them, and we invite everyone to be part of everything along the process, so we involve everyone.

This highlights the difficulty for community members to make consent decisions before they have enough information to understand potential long-term impacts. Nevertheless, Serge suggests that the information-sharing process was community-led and involved training and workshops aimed at informing the whole community.

\subsection{Chapter conclusion}

This chapter answered my second research question. The research suggests the project is legitimately community-owned. The community's practices, values and knowledge play a central role in the design and implementation of the project. The integration of community context assisted the project to be accepted by the community and meet the requirements of FPIC. This means ensuring the project is designed so it works with against community needs. Context-specific factors such as land rights are integrated, contributing to the long-term success of the Loru project. 


\section{Chapter 9 Loru and the future of forest carbon}

This chapter discusses and concludes my research. I firstly summarise my findings by returning to my research questions. Secondly, I describe the limitations of the research. Next, I discuss the findings in relation to the literature, asking how the project mitigates the risks of REDD+ on communities and instead results in positive social outcomes. Lastly, I consider the wider implications, discussing how this research might inform forest carbon policy and practice.

\subsection{Returning to the research questions}

Chapter seven answers my first research question, 'What has been the social impact of the Loru Forest Carbon Project on the local Indigenous community, the Ser clan?' I have found that the Loru project has contributed to social benefits by providing economic opportunities and increasing local forest governance capacity. This has supported the community's livelihood transition from copra harvesting to the preferred and more sustainable option of agroforestry, enhancing local biodiversity and climate change resilience.

Turning to the sub-question, 'How does this social impact affect the social, economic and environmental sustainability of the Loru Forest carbon project?' I find the social outputs of the project have been essential in generating economic and environmental sustainability. The social impact ensures the community's ongoing support of the project. Social investment in skill-building has built local capacity, improving the community's ability to locally-manage the project and conduct conservation activities. This ensures the community have the support, skills and resources to conserve the environmental sustainability of the forest.

The research suggests that the PES mechanism of the project, the sale of carbon offset credits, has allowed the project to be self-sustaining (and economically sustainable) by providing an ongoing income. This enhances the social and environmental sustainability as profits are invested into conservation and livelihood opportunities for the community. Further, the social and environmental co-benefits of the Loru project allow Ekos to sell the carbon offset credits at a premium. The project contributes modestly to global environmental sustainability through the climate stabilisation effect of avoided deforestation.

My second research question asks, 'How does the community exercise ownership over the Loru Forest Carbon project?' In the eighth chapter I explain that the integration of local 
priorities, practices and values suggests the community have agency over the project's implementation. Secondly, I conclude the project enhances the Ser clan's sense of ownership with the land and forest. The project supports community ownership by securing land rights, supporting forest-based livelihoods and allocating forest governance rights to the community.

The second sub-question asks, 'How has the Loru Forest Carbon project met the principles of free, prior and informed consent?' Consent is the minimum threshold for ensuring that the community have the agency to influence decisions. I conclude that the Ser clan appear to exercise free consent, for example by declining economic opportunities. I describe the lengthy education and consultation process that provided the community with the time and information to give prior and informed consent.

\subsection{Limitations}

The downside of selecting an unusual, community-owned case study is that findings cannot be generalised to REDD+ projects. Further research on community-owned forest carbon projects would need to be conducted to determine any generalisability of this study. Nevertheless, the findings of this research are consistent with findings in CFM literature (Hayes \& Persha, 2010; Pagdee et al., 2006), by emphasising the importance of local forest governance.

Building upon the limitations discussed in section 6.3, this research was limited in scope, based on one month's fieldwork and one case study in a single location. For example, while relevant, I did not have the time or scope to examine the intracommunity equity and gender distribution of community outcomes. These dynamics are often sensitive and hidden, and one month of fieldwork did not generate enough understanding to analyse robustly. However, research in these areas would enhance the understanding of the distribution of the social impact discussed in the research.

\subsection{Responding to the critiques of REDD+}

The scholarly critique of REDD+ discussed in chapter three centres on four major concerns. Firstly, that the uneven bargaining power of forest communities allows elites to capture project benefits. Secondly, the institutional structure of REDD+ funding and low capacity of REDD+ eligible governments risks reducing local forest governance. Thirdly, a PES mechanism undermines forest conservation and is inappropriate for Indigenous communities. And fourthly, that the unreliable funding of REDD+ can exacerbate poverty and 
exclude the poor. This section will discuss how the Loru project has mitigated each of these risks.

The first thing to note is REDD+ is intended for situations with a direct threat of deforestation or forest degradation. Therefore, critics should compare REDD+ outcomes to the potential outcomes of extractive industry developments, which are subject to many of the same risks.

\subsubsection{Elite capture}

As discussed in chapter three, REDD+ critics worry that forest carbon associated benefits (such as carbon payments) can easily be captured by elites due to the marginalisation of forest peoples (Barr \& Sayer, 2012; Corbera, 2012). This marginalisation, such as limited access to information, formal networks, education and infrastructure (Godden \& Tehan, 2016), means forest peoples have weak bargaining power compared to elite groups (McGregor, Eilenberg, \& Coutinho, 2015). A key concern is that REDD+ could lead to land alienation if forest peoples cannot represent their rights and interests (Sandbrook et al., 2010).

Nevertheless, this research finds that the Loru project has avoided elite capture of project benefits through the project's commitment to free, prior and informed consent and local capacity building. As expanded on in the previous chapter, the Loru project underwent a rigorous consultation and capacity building programme with the Ser clan and neighbouring communities. This ensured the community had a platform to represent their rights, and ability and power to negotiate.

Elite capture of forest resources is exacerbated in scenarios where local communities have weak land tenure (Astuti \& McGregor, 2017). The Loru project has helped secure the community's customary land claim. The Ser clan legally registered their land, also securing the carbon rights according to Vanuatu law (see chapter four). However, legal registration may not be a viable or appropriate option for all forest communities and can result in land alienation of marginalised communities members if borders are disputed, or landless forestdependent folks are excluded from decision-making (Bayrak \& Marafa, 2016).

Therefore, the lesson to be learned from the Loru project is that land tenure should be inclusive and locally adapted. The Loru forest was only legally registered after 
consultations with neighbouring groups and free, prior and informed consent was given by the Ser clan. By following appropriate processes that recognise forest peoples' rights, forest carbon farming has the potential to strengthen and formalise customary land tenure (Cronkleton et al., 2011).

In comparison to a business-as-usual scenario, the community are placed in a much better position to avoid elite capture (Allen, 2013). In neighbouring communities, multinational investors have leased ni-Vanuatu land for development, and the Ser clan face similar economic threats. This industrial development is less likely to follow FPIC processes, build community capacity and protect community rights.

\subsubsection{Centralisation of forest governance}

While scholars fear REDD+ could recentralise forest governance (Corbera, 2012; Sandbrook et al., 2010), the Loru project has strengthened local forest governance capacity. As explained in chapter three, the largest REDD+ donor, the FCPF, provides funding only to nation states. Additionally, the FCPF requires recipients to establish a national forest inventory, forest monitoring system, reference emission levels and national safeguard systems (Lujan et al., 2018). The intention is to build forest governance capacity at the national level. However, critics worry that this centralises forest governance, reducing the role of local communities.

The Loru project is funded by international sources, through multilateral grants from the European Union and Asian Development Bank, and sales of voluntary carbon offset credits in the New Zealand and European market. Nevertheless, the Loru project operates through a multi-scalar institutional network which maximises local forest governance. The Ser clan manage the forest locally and maintain legal ownership of the forestland and carbon rights. The family business of the Ser clan, Ser-Thiac, was established to coordinate the Loru project at a local level. Community committees organise conservation activities such as invasive vine clearing and reforestation. Community rangers and leaders monitor and enforce forest governance rules according to local practices such as bans on hunting. This operates within a network of intermediaries that include LL and Ekos who communicate between local and international actors. 
LLV has a long history and close connections with the Ser clan. Two Ser members are current or previous employees of LLV, and LLV has had a presence in Khole village for over ten years. LLV and the Nakau Programme also have close links. The Nakau Programme is coowned by LL, and key members of the Loru project, Robbie Henderson and Anjali Nelson, have worked for both organisations. These organisations act as intermediaries, moving between spaces to link the local community to multilateral donors. This allows forest governance to operate at a local level while gaining access to international funds.

Loru may be an extreme example of an interconnected institutional network which is difficult to replicate, especially at a larger scale. However, it highlights the importance of intermediaries for negotiating between geographies and scales. The growth in national forest governance capacity encouraged by the FCPF does not have to come at the expense of local forest governance. However, the role of intermediaries who negotiate between scales is critical (Dawson et al., 2018; McGregor et al., 2014). Therefore, REDD+ projects should engage with local NGOs and community groups and build local forest governance capacity.

\subsubsection{PES mechanism}

Results-based payments did not seem to be a motivating factor for the community participating in conservation activities. Previous research has found conflicting results. Pagdee et al. (2006) found anticipation of reward and linking payments with results were success factors. However other studies find intrinsic and non-monetary factors such as community culture have a greater effect on conservation outcomes (Beckford, Jacobs, Williams, \& Nahdee, 2010; Corbera, 2012; Sayer et al., 2017).

During fieldwork, when asked why it was important to protect the forest, no participant mentioned funding. And when discussing project funds, no community members mentioned that payments were tied to carbon storage. However, as expanded on in chapter eight, many participants discussed their family heritage of conservation, suggesting conservation culture in the Ser clan remains linked to family history.

Thus, the PES mechanism, tying payments to measurable ecosystem services, seemed to be an enabling factor rather than a motivating one. While the PES mechanism, through the sale of carbon offsets, allows the project to generate income and be self-sustaining, it is likely that the Ser clan would be as receptive to a grant-funded project. Nevertheless, the PES 
mechanism did not seem to interfere with the community's intrinsic motivation for conservation, the concern of Corbera (2012). Furthermore, as discussed in chapter seven, relying on grant-funding is less sustainable than an income-generating project.

\subsubsection{Poverty}

As concluded in chapter seven, the Loru project has enhanced the Ser clan's livelihoods by generating income and opportunities for diversification. The project included many propoor features in its design and implementation. For example, encouraging economic diversification beyond the project's 30-year carbon revenue generating period, allocating agroforestry plots to all community members, and setting targets for shared bank accounts which must be met before paying individual dividends.

As explained in chapter three, grant funding, especially with robust requirements such as the FCPF's, can be unreliable and exclude the poor who are less able to absorb income insecurity (Lujan et al., 2018). The Nakau Programme is able to better guarantee income through its links with the voluntary carbon offset markets in Europe and New Zealand (Weaver, 2015).

\subsection{Success factors}

Following from the previous section, I argue that the community capacity and institutional structure of the Loru project were key contributors to its social and environmental impact.

The Ser clan are hard-working, community-minded, proud of their heritage and passionate about conservation. Their dedication and hard work have been essential for the project's success and should not be overlooked. The values and contributions of communities are often deemphasised when analysing REDD+ projects being largely outside policymakers' and practitioners' control (Pagdee et al., 2006). However, this can wrongly give the impression that community culture and commitment does not impact project success. In fact, it is Ser clan members who work in the forest daily, planting trees, weeding and building fences. The Ser clan's committees regularly meet to write reports and allocate funds. Their pride in their community and conservation heritage fuel their passion and commitment to the Loru project.

The Nakau Programme's intermediaries support the Ser clan's dedication through training and connections. As discussed, the Ser clan received comprehensive skill-building in 
forest management and bookkeeping, and attended education workshops on climate change, forests and REDD+. This has allowed the Ser clan to effectively manage and implement project activities. The intermediaries link community and international networks, representing community interests to international actors and sourcing multilateral funding.

Forest carbon funding, whether through grants or carbon offset revenue, REDD+ or not, requires experience, knowledge and networks beyond the scope of most forest-dependent communities. Multilateral grants, such as those provided by the FCPF have proved complicated to apply for even by organisations with grant application experience such as NGOs and national governments (Lujan et al., 2018; Weaver, 2015). In the current landscape, voluntary carbon offset schemes are in their infancy and connecting to one requires networks and connections (Weaver, 2015). This makes intermediaries essential in connecting communities to forest carbon funding. Eligibility for funding requires carbon accounting and transparency systems such as forest monitoring, emission level measurement and auditing (Lujan et al., 2018). Intermediaries have a role in connecting external auditors and experts, or building local skills, so communities can perform some of these tasks themselves.

LLV is uniquely positioned as an organisation who specialise in environmental education and community capacity building, and one with strong links to the Ser clan. LLV provided high quality training and education workshops to the Ser clan due to their years of experience conducting environmental education in Vanuatu. Community consultations were strengthened through years of engagement and family members who could represent both sides of discussions. LL is closely connected to the carbon offset on-seller, co-owning the Nakau Programme.

It is no coincidence that Loru's institutional network and links between groups are so strong. Nakau is co-owned by Ekos and LLV because the groups understood the synergies of connecting a local capacity-building organisation with a carbon on-seller. The Loru site was chosen as a pilot, in part, because LLV has a long and close relationship with the community.

\subsection{The future of forest carbon}

The Loru project can point to success factors in generating positive community outcomes in the implementation of REDD+. In particular, this thesis recommends REDD+ 
policy which prioritises building local capacity through a bottom-heavy multi-scalar institutional network which supports local groups.

Under the status quo, much attention has been at national REDD+ coordination (Bayrak \& Marafa, 2016; Kronenberg et al., 2015). However, this present research argues that it is the actions of local actors and intermediaries which contributed to the positive social and environmental outcomes of the Loru project. In fact, the Loru project bypassed the Vanuatu government altogether. This suggests multilateral funders such as the FCPF could consider avenues for community groups to access REDD+ funding and support bottom-up initiatives which bypass national governments.

Nevertheless, national level coordination is useful to scale up REDD+ to a level which significantly protects the world's forests and acts as a carbon reservoir to mitigate climate change. National coordination allows projects to share resources and experience to achieve economies of scale and efficiently implement forest conservation at a larger scale.

Additionally, while the Loru project is funded by voluntary carbon offset revenue, this is a finite and comparatively small income source compared to the potential of governmentmandated carbon offset schemes (Weaver, 2015). The Nakau Programme sells its carbon offsets at a premium as voluntary buyers are less price sensitive, which can fund the social initiatives of its projects. National coordination could allow for governments to fund REDD+ by mandated carbon offsets to meet Paris obligations through domestic carbon policy or bilateral agreements (Lujan et al., 2018). Mandatory carbon offset credits are priced lower than Ekos' 'fair trade' carbon offset credits and projects would need to be run more efficiently.

However, scaling up and reducing the cost of forest carbon should not come at the expense of local communities. The Loru project shows the value of building local capacity and engaging with local institutions and NGOs. As REDD+ grows, costs can be saved through economies of scale and shared learning, rather than centralising forest governance. Hence, this thesis argues for a bottom-heavy multi-scalar institutional framework. Carbon accounting methodologies and funding can be shared at international and national levels to improve distribution and efficiency. However, the role of local actors such as NGOs and communities remain critical to implementing forest carbon in a just way. 
These recommendations align with the ideas of Collen et al. (2016) and Cronkleton et al. (2011) who argue bottom-up institutional development supported by multi-scaled governance is critical for effective and just REDD+ implementation.

\subsection{Conclusion}

This research investigated the impact of forest carbon farming on the Ser clan in Espiritu Santo, Vanuatu. The findings suggest the Loru project was able to generate positive social and environmental impacts as the community held ownership rights and had the agency to adapt the project to local values and practices. The research found that the Loru project supported a transition to a more sustainable livelihood, enhancing biodiversity and climate resilience, and increased local forest governance capacity. The Ser clan own the project and carbon rights, exercising ownership through legally registering land. The community influence the project's design and implementation, having given their full, prior and informed consent and are able to shape the project to local needs, values and practices.

Scholars have argued that forest carbon farming can reduce local forest governance, exacerbate poverty, be subject to elite capture of benefits, and undermine conservation through a results-based funding mechanism. However, this research suggests that the community ownership and institutional framework allowed the Loru project to mitigate these risks. As the first study of a community-owned forest carbon project, this is significant, suggesting that forest carbon policy should actively prioritise and support local forest governance and a multi-scalar institutional network. 


\section{References}

Addinsall, C., Glencross, K., Rihai, N., Kalomor, L., Palmer, G., Nichols, D., \& Smith, G. (2016). Enhancing agroforestry in Vanuatu: striking the balance between individual entrepreneurship and community development. Forests, Trees and Livelihoods, 25(1), 78-96. doi:10.1080/14728028.2015.1093434

Agrawal, A., \& Angelsen, A. (2009). Using community forest management to achieve REDD+ goals. In Realising REDD+: national strategy and policy options (Vol. 1, pp. 201-212).

Alforte, A., Angan, J., Dentith, J., Domondon, K., Munden, L., Murday, S., \& Pradela, L. (2014). Communities as Counterparties: Preliminary Review of Concessions and Conflict in Emerging and Frontier Market Concessions. Retrieved from https://rightsandresources.org/wp-content/uploads/Communities-asCounterparties-FINAL Oct-21.pdf

Allen, M. G. (2013). Melanesia's violent environments: Towards a political ecology of conflict in the western Pacific. Geoforum, 44, 152-161. doi:10.1016/j.geoforum.2012.09.015

Anderson, T., \& Lee, G. (2010). Understanding Melanesian customary land. In In defense of Melanasian customary land (pp. 2-4): AID WATCH.

Astuti, R., \& McGregor, A. (2015). Governing carbon, transforming forest politics: A case study of Indonesia's REDD+ Task Force. Asia Pacific Viewpoint, 56(1), 21-36. doi:10.1111/apv.12087

Astuti, R., \& McGregor, A. (2017). Indigenous land claims or green grabs? Inclusions and exclusions within forest carbon politics in Indonesia. The Journal of Peasant Studies, 44(2), 445-466. doi:10.1080/03066150.2016.1197908

Babon, A., \& Gowae, G. Y. (2013). The context of REDD+ in Papua New Guinea: drivers, agents, and institutions (Vol. 89): CIFOR.

Barr, C. M., \& Sayer, J. A. (2012). The political economy of reforestation and forest restoration in Asia- Pacific: Critical issues for REDD+. Biological Conservation, 154, 9-19. doi:10.1016/j.biocon.2012.03.020

Bayrak, M., \& Marafa, L. (2016). Ten Years of REDD+: A Critical Review of the Impact of REDD+ on Forest-Dependent Communities. 8, 620. doi:10.3390/su8070620

Beckford, C., Jacobs, C., Williams, N., \& Nahdee, R. (2010). Aboriginal Environmental Wisdom, Stewardship, and Sustainability: Lessons From the Walpole Island First Nations, Ontario, Canada. Environmental Education, 41(4), 239-248. doi:10.1080/00958961003676314

Bedford, S., Spriggs, M., \& Regenvanu, R. (1999). The Australian National Universtiy--Vanuatu cultural centre archaeology project, 1994-97: Aims and results. Oceania, 70(1), 16-24. doi:10.1002/j.1834-4461.1999.tb02986.x

Bhatta, A., Bigsby, H., \& Cullen, R. (2011). Alternative to Comprehensive Ecosystem Services Markets: The Contribution of Forest-Related Programs in New Zealand. IDEAS Working Paper Series from RePEC.

Bhattarai, M., \& Hammig, M. (2001). Institutions and the Environmental Kuznets Curve for Deforestation: A Crosscountry Analysis for Latin America, Africa and Asia. World Development, 29(6), 995-1010. doi:10.1016/S0305-750X(01)00019-5

Biodiversity Monitoring Toolkit for Community Conservation Areas in Vanuatu. (2019, 26/07/2019). Daily Post. Retrieved from https://dailypost.vu/news/biodiversitymonitoring-toolkit-for-community-conservation-areas-in-vanuatu/article 028585165954-546b-a895-05481b8bc17a.html?fbclid=IwAR3OsCiEibyepaYTbTZaFXn GkyLVM6QIOXm5roUnc8-KE1PnVdNLWVwFs 
Birrell, K., Godden, L., \& Tehan, M. (2012). Climate change and REDD+: Property as a prism for conceiving Indigenous peoples' engagement. Journal of Human Rights and the Environment, 3(2), 196- 216.

Bolton, L. (2003). Unfolding the Moon : Enacting Women's Kastom in Vanuatu. Honolulu: University of Hawaii Press.

Bonnin, C. (2010). Navigating fieldwork politics, practicalities and ethics in the upland borderlands of northern Vietnam. Asia Pacific Viewpoint, 51(2), 179-192. doi:10.1111/j.1467-8373.2010.01423.x

Bradacs, G., Heilmann, J., \& Weckerle, C. S. (2011). Medicinal plant use in Vanuatu: A comparative ethnobotanical study of three islands. Journal of Ethnopharmacology, 137(1), 434-448. doi:10.1016/j.jep.2011.05.050

Brugnach, M., Craps, M., \& Dewulf, A. (2017). Including indigenous peoples in climate change mitigation: addressing issues of scale, knowledge and power. An Interdisciplinary, International Journal Devoted to the Description, Causes and Implications of Climatic Change, 140(1), 19-32. doi:10.1007/s10584-014-1280-3

Büscher, B., Sullivan, S., Neves, K., Igoe, J., \& Brockington, D. (2012). Towards a Synthesized Critique of Neoliberal Biodiversity Conservation. Capitalism Nature Socialism, 23(2), 4-30. doi:10.1080/10455752.2012.674149

Campbell, A., Clark, S., Coad, L., Miles, L., Bolt, K., \& Roe, D. (2008). Protecting the future: Carbon, forests, protected areas and local livelihoods. Biodiversity, 9(3-4), 117-121. doi:10.1080/14888386.2008.9712916

Carino, J., Champagne, D., Collings, N., Cunningham, M., Dorough, D. S., Kipuri, N., \& Trask, M. (2009). State of the World's Indigenous Peoples. Retrieved from New York, United States:

Ceddia, M. G., Gunter, U., \& Corriveau-Bourque, A. (2015). Land tenure and agricultural expansion in Latin America: The role of Indigenous Peoples' and local communities' forest rights. Global Environmental Change, 35, 316-322. doi:10.1016/j.gloenvcha.2015.09.010

Chakravarty, S., Ghosh, S., Suresh, C., Dey, A., \& Shukla, G. (2012). Deforestation: causes, effects and control strategies. In Global perspectives on sustainable forest management: IntechOpen.

Chao, S. (2012). Forest peoples: numbers across the world: Forest Peoples Programme Moreton-in-Marsh.

Chomitz, K. (2006). At Loggerheads?: Agricultural Expansion, Poverty Reduction, and Environment in the Tropical Forests.

Collen, W., Krause, T., Mundaca, L., \& Nicholas, K. A. (2016). Building local institutions for national conservation programs lessons for developing Reducing Emissions from Deforestation and Forest Degradation (REDD+) programs. Ecology and Society, 21(2). doi:10.5751/ES-08156-210204

Corbera, E. (2012). Problematizing REDD+ as an experiment in payments for ecosystem services. Current Opinion in Environmental Sustainability, 4(6), 612-619. doi:10.1016/j.cosust.2012.09.010

Costanza, R. (1991). Ecological economics : the science and management of sustainability. New York: Columbia University Press.

Costanza, R., Cumberland, J. H., Daly, H., Goodland, R., Norgaard, R. B., Kubiszewski, I., \& Franco, C. (2015). An Introduction to Ecological Economics (Second edition. ed.). Raton, FL: CRC Press, Taylor \& Francis Group. 
Costanza, R., Daly, L., Fioramonti, L., Giovannini, E., Kubiszewski, I., Mortensen, L. F., . . . Wilkinson, R. (2016). Modelling and measuring sustainable wellbeing in connection with the UN Sustainable Development Goals. Ecological economics, 130, 350-355. doi:10.1016/j.ecolecon.2016.07.009

Cotula, L., \& Mayers, J. (2009). Tenure in REDD: Start-point or Afterthought? Retrieved from London, UK:

Cronkleton, P., Bray, D. B., \& Medina, G. (2011). Community forest management and the emergence of multi-scale governance institutions: Lessons for REDD+ development from Mexico, Brazil and Bolivia. Forests, 2(2), 451-473.

Crowley, T. (Ed.) (2003) A New Bislama Dictionary (2 ed.). Vanuatu: University of the South Pacific.

Daly, H. E. (2011). Ecological economics : principles and applications (2nd ed. ed.). Washington, DC: Island Press.

Dawson, N., Mason, M., Fisher, J., Mwayafu, D., Dhungana, H., Schroeder, H., \& Zeitoun, M. (2018). Norm Entrepreneurs Sidestep REDD+ in Pursuit of Just and Sustainable Forest Governance. Sustainability, 10(6), 1726. doi:10.3390/su10061726

De La Fuente, T., \& Hajjar, R. (2013). Do current forest carbon standards include adequate requirements to ensure indigenous peoples' rights in REDD projects?/Les standards actuels de carbone forestier incluent-ils des clauses adequates pour assurer les droits des autochtones dans les projets REDD?/Incluyen los actuales estandares de carbono forestal los requisitos necesarios para asegurar los derechos de los pueblos indigenas en los proyectos REDD? International Forestry Review, 15(4), 427. doi:10.1505/146554813809025676

Dehm, J. (2016). Indigenous Peoples and REDD Safeguards: Rights as Resistance or as Disciplinary Inclusion in the Green Economy? Journal of Human Rights and the Environment, 7(2), 170-217.

Ekos. (2017). Ekos- a regenerative marketplace for people and planet. Retrieved from www.ekos.org.nz

Ekos. (2019). Our projects. Retrieved from https://ekos.org.nz/our-projects

Fairhead, J., Leach, M., \& Scoones, I. (2012). Green Grabbing: a new appropriation of nature? The Journal of Peasant Studies, 39(2), 237-261. doi:10.1080/03066150.2012.671770

Ford, J., D., Cameron, L., Rubis, J., Maillet, M., Nakashima, D., Willox, A. C., \& Pearce, T. (2016). Including indigenous knowledge and experience in IPCC assessment reports. Nature Climate Change, 6(4), 349. doi:10.1038/nclimate2954

Forsyth, M., \& Batley, J. (2016). What the Political Corruption Scandal of 2015 Reveals about Checks and Balances in Vanuatu Governance. The Journal of Pacific History, 51(3), 255277. doi:10.1080/00223344.2016.1214247

François, A., Franjieh, M., Lacrampe, S., \& Schnell, S. (2015). The exceptional linguistic density of Vanuatu (Introduction to the volume). In A. François, M. Franjieh, S. Lacrampe, \& S. Schnell (Eds.), The Languages of Vanuatu: Unity and Diversity (pp. 1- 21). Canberra, Australia.

Fritz, H. M., \& Blount, C. (2007). Thematic Paper: Role of forests and trees in protecting coastal areas against cyclones. Retrieved from

Gautam, A. P., Shivakoti, G. P., \& Webb, E. L. (2004). Forest Cover Change, Physiography, Local Economy, and Institutions in a Mountain Watershed in Nepal. Environmental Management, 33(1), 48-61. doi:10.1007/s00267-003-0031-4 
Geary Nichol, M. (2014). Principles in practice? Ownership in monitoring and evaluation in Vanuatu. Victoria University of Wellington, New Zealand.

Godden, L. (2017). REDD+ in Melanesia. In K. A. Gover, L. C. Godden, M. A. Young, \& M. F. Tehan (Eds.), The Impact of Climate Change Mitigation on Indigenous and Forest Communities: International, National and Local Law Perspectives on REDD+ (pp. 203238). Cambridge: Cambridge University Press.

Godden, L., \& Tehan, M. (2016). REDD+: climate justice and indigenous and local community rights in an era of climate disruption. Journal of Energy \& Natural Resources Law, 114. doi:10.1080/02646811.2016.1121620

Granderson, A. A. (2017). The role of traditional knowledge in building adaptive capacity for climate change: Perspectives from Vanuatu. Weather, Climate, Society, 9(3), 545-561.

Griffiths, T. (2007). Seeing 'RED'? 'Avoided deforestation' and the rights of Indigenous Peoples and local communities. Retrieved from

http://www.forestpeoples.org/sites/fpp/files/publication/2010/01/avoideddeforest ationredjun07eng $0 . p d f$

Hall, R. (2008). REDD Myths: A Critical Review of Proposed Mechanisms to Reduce Emissions from Deforestation and Degradation in Developing Countries. Retrieved from https://elaw.org/system/files/15\%20foei\%20forest\%20full\%20eng\%20lr.pdf? ga=2. 2462576.1910253585.1579402323-1254900710.1579402323

Hart, M. A. (2010). Indigenous worldviews, knowledge, and research: The development of an indigenous research paradigm. Journal of Indigenous Voices in Social Work, 1(1), 1-16.

Harwell, E. (2003). Without remedy: Human rights abuse and Indonesia's pulp and paper industry: Human Rights Watch.

Hayes, T., \& Persha, L. (2010). Nesting local forestry initiatives: Revisiting community forest management in a REDD+ world. Forest Policy and Economics, 12(8), 545-553. doi:10.1016/j.forpol.2010.07.003

Heller, E., Christensen, J., Long, L., Mackenzie, C. A., Osano, P. M., Ricker, B., . . Turner, S. (2011). Dear Diary: Early Career Geographers Collectively Reflect on Their Qualitative Field Research Experiences. Journal of Geography in Higher Education, 35(1), 67-83. doi:10.1080/03098265.2010.486853

Hickey, F. R. (2007). Traditional marine resource management in Vanuatu: worldviews in transformation. Fishers' Knowledge in Fisheries Science and Management, 112.

Howson, P., \& Kindon, S. (2015). Analysing access to the local REDD+ benefits of Sungai Lamandau, Central Kalimantan, Indonesia. Asia Pacific Viewpoint, 56(1), 96-110. doi:10.1111/apv.12089

Additional Readiness Preparation Grant Agreement, (2018).

IPCC. (2018). Summary for Policymakers. Retrieved from https://www.ipcc.ch/sr15/chapter/spm/

Jolly, M. (1991). 'To save the girls for brighter and better lives' : Presbyterian mission $s$ and women in the south of Vanuatu : 1848-1870. Journal of Pacific history, 26(1), 27-48.

Jolly, M. (1996). Woman ikat raet long human raet o no? Women's rights, human rights and domestic violence in Vanuatu. Feminist Review(52), 169-190.

Jolly, M. (2014). Women of the place: kastom, colonialism and gender in Vanuatu: Routledge. Kashwan, P. (2015). Forest Policy, Institutions, and REDD+ in India, Tanzania, and Mexico. 15(3), 95-117. doi:10.1162/GLEP_a_00313 
Kiely, R. (1999). The Last Refuge of the Noble Savage? A Critical Assessment of PostDevelopment Theory. The European Journal of Development Research, 11(1), 30. doi:10.1080/09578819908426726

Kronenberg, J., Orligóra-Sankowska, E., \& Czembrowski, P. (2015). REDD+ and Institutions. Sustainability, 7(8), 10250-10263.

Lang, C. (2008, 9 December). Rights struck from draft text on REDD. Retrieved from https://redd-monitor.org/2008/12/09/rights-struck-from-draft-text-on-redd/

Lawlor, K., Madeira, E., Blockhus, J., \& Ganz, D. (2013). Community Participation and Benefits in REDD plus : A Review of Initial Outcomes and Lessons. Forests, 4(2), 296-318. doi:10.3390/f4020296

Lima, E., Merry, F., Nepstad, D., Amacher, G., Azevedo-Ramos, C., Lefebvre, P., \& Resque, F. (2006). Searching for sustainability: Forest policies, smallholders, and the transAmazon highway (vol 48, pg 26, 2006). Environment, 48(2), 36-36.

Live \& Learn. (2019). Our Vision \& Mission. Retrieved from http://www.livelearn.org/why/our-vision-mission

Live \& Learn Vanuatu (2019, 25 September). Finally Congratulations Ser-Thiac efforts and Committments recognized!! Amongst the 800 competitors of 2019 UN prestigious award Ser-Thiac is amongst the 22 Winners of this year's equator Prize. [Facebook]. Retrieved from https://www.facebook.com/livelearnvanuatu/photos/a.1892728930989338/236068 5090860384/

Lujan, B., Silva-Chávez, G., Braña-Varela, J., Meyer, C., Schaap, B., García-Espinosa, M., \& Krilasevic, E. (2018). Mapping forest finance: A landscape of available sources of finance for REDD+ and climate action in forests. Environmental Defense Fund, white paper. Retrieved from

MacClancy, J. (2002). To kill a bird with two stones. Port Vila: Vanuatu Cultural Centre.

Marango, T. (2017, 21 February). Law prohibits return of confiscated coconut crabs. Daily Post. Retrieved from https://dailypost.vu/news/law-prohibits-return-of-confiscatedcoconut-crabs/article c192a0e6-711b-5865-ba7b-60018ae4e1f5.html

Maraseni, T. N., Neupane, P. R., Lopez-Casero, F., \& Cadman, T. (2014). An assessment of the impacts of the REDD+ pilot project on community forests user groups (CFUGs) and their community forests in Nepal. Journal of Environmental Management, 136, 37-46. doi:10.1016/j.jenvman.2014.01.011

Marion Suiseeya, K. (2017). Contesting Justice in Global Forest Governance: The Promises and Pitfalls of REDD+. Conservation and Society, 15(2). doi:10.4103/cs.cs_15_104

McCarter, J., \& Gavin, M. (2014). Local Perceptions of Changes in Traditional Ecological Knowledge: A Case Study from Malekula Island, Vanuatu. Ambio, 43(3), 288-296. doi:10.1007/s13280-013-0431-5

McCauley, D., \& Heffron, R. (2018). Just transition: Integrating climate, energy and environmental justice. Energy Policy, 119, 1-7. doi:10.1016/j.enpol.2018.04.014

McDonnell, S. (2013). Exploring the cultural power of land law in Vanuatu: law as a performance that creates meaning and identities. Intersections, 33.

McGregor, A., Eilenberg, M., \& Coutinho, J. B. (2015). From global policy to local politics: The social dynamics of REDD+ in Asia Pacific. Asia Pacific Viewpoint, 56(1), 1-5. doi:10.1111/apv.12091 
McGregor, A., Weaver, S., Challies, E., Howson, P., Astuti, R., \& Haalboom, B. (2014). Practical critique: Bridging the gap between critical and practice- oriented REDD + research communities. Asia Pacific Viewpoint, 55(3), 277-291. doi:10.1111/apv.12064

Mele, L., Killmann, W., Glauner, R., \& Bartlett, C. (2013). Vanuatu National Forest Policy 20132023. Retrieved from https://www.nab.vu/vanuatu-national-forest-policy

Myers, N. (1993). Tropical Forests: The Main Deforestation Fronts. Environmental Conservation, 20(1), 9-16. doi:10.1017/S0376892900037176

Nakashima, D. J., Galloway McLean, K., Thulstrup, H. D., Ramos Castilo, A., \& Rubis, J. T. (2012). Weathering uncertainty: traditional knowledge for climate change assessment and adaptation. Retrieved from Paris:

Nakau. (2019). Loru Forest Project- Vanuatu. Retrieved from http://www.nakau.org/loru--vanuatu.html

Napua, A. (2017). Making the Invisible Seen: Putting Women's Rights on Vanuatu's Land Reform Agenda. In Kastom, property and ideology: Land transformations in Melanesia (pp. 305- 326). ACT, Australia: ANU Press.

National REDD+ Unit. (2017a). Addressing the drivers of deforestation and forest degradation. Retrieved

from

https://forestcarbonpartnership.org/system/files/documents/Policy\%20Brief\%20Dri vers\%20of\%20deforestations\%20-\%20GoV.pdf

National REDD+ Unit. (2017b). Strategy options for the national REDD+ strategy. Retrieved from Port Vila, Vanuatu: https://forestcarbonpartnership.org/system/files/documents/Policy\%20Brief\%20Str ategy\%200ptions\%20GoV.pdf

Nelson, A., Andre, G., Warakar, S., Weaver, S., \& Henderson, R. (2015). Loru Forest ProjectProject Description Part A: General Description. An avoided deforestation project at Loru, Santo, Vanuatu. Retrieved from http://www.nakau.org/uploads/5/2/2/5/52251233/loru pd part a d3.2a v1.0 201 51009b.pdf

Nelson, A., Thomas, A., \& Nickllum, M. (2013). Vanuatu Extension \& Outreach Consultancy Report. Retrieved from Port Vila: http://reddplus.vu/vanuatu-national-redd-program/

Nelson, P. N., Gabriel, J., Filer, C., Banabas, M., Sayer, J. A., Curry, G. N., . . Venter, O. (2014). Oil Palm and Deforestation in Papua New Guinea. Conservation Letters, 7(3), 188-195. doi:10.1111/conl.12058

Newton, P., Schaap, B., Fournier, M., Cornwall, M., Rosenbach, D. W., Deboer, J., . . Agrawal, A. (2015). Community forest management and REDD+. Forest Policy and Economics, 56, 27-37. doi:10.1016/j.forpol.2015.03.008

Nicholls, R. (2009). Research and Indigenous participation: critical reflexive methods. International Journal of Social Research Methodology, 12(2), 117-126. doi:10.1080/13645570902727698

Pacific Beat. (2013, 18 November). Efforts to conserve coconut crabs in Vanuatu under threat. $A B C$ News. Retrieved from https://www.abc.net.au/news/2013-11-18/an-coconutcrabs-conservation $/ 5098588$

Pagdee, A., Kim, Y.-S., \& Daugherty, P. J. (2006). What Makes Community Forest Management Successful: A Meta-Study From Community Forests Throughout the World. Society \& Natural Resources, 19(1), 33-52. doi:10.1080/08941920500323260 
Pahl-Wostl, C. (2009). A conceptual framework for analysing adaptive capacity and multi-level learning processes in resource governance regimes. Global Environmental Change, 19(3), 354-365. doi:10.1016/j.gloenvcha.2009.06.001

Payne, B. H. (2020). Community Development through Carbon: A Case Study of the First Indigenous-owned Forest Carbon Project in the Pacific. Paper presented at the Development Studies: Research, Debate \& Trajectories, Melbourne, Australia.

Peterson St-Laurent, G., Gélinas, N., \& Potvin, C. (2013). REDD+ and the agriculture frontier: Understanding colonists' utilization of the land. Land Use Policy, 31, 516-525.

Plan Vivo. (2013). The Plan Vivo Standard. Retrieved from https://www.planvivo.org/docs/Plan-Vivo-Standard.pdf

Purvis, B., Mao, Y., \& Robinson, D. (2018). Three pillars of sustainability: in search of conceptual origins. Retrieved from http://eprints.whiterose.ac.uk/136715/7/Purvis2018 Article ThreePillarsOfSustaina bilityln.pdf

Rammelt, C. F., \& Boes, J. (2013). Galtung meets Daly: A framework for addressing inequity in ecological economics. Ecological economics, 93(C), 269-277. doi:10.1016/j.ecolecon.2013.06.013

Rawlings, G. (2015). The geo-classifications of colonial statelessness: The anthropology of Kastom, land and citizenship in the decolonisation of Vanuatu. Aust. J. Anthropol., 26(2), 145-173. doi:10.1111/taja.12108

REDD+ Unit Department of Forests. (2017). Mid-Term Progress Report and Request for Additional Funding. Retrieved from Port Vila, Vanuatu: https://forestcarbonpartnership.org/system/files/documents/MidTerm\%20Progress\%20Report\%20for\%20REDD\%2B\%20with\%20additional\%20fundin g-Vanuatu-final.pdf

REDD+ Unit Department of Forests. (2019). Vanuatu Progress Report. Retrieved from https://forestcarbonpartnership.org/system/files/documents/FCPF Participants\%20 Progress\%20Report Vanuatu 2019.pdf

Regenvanu, R. (2010). The traditional economy as source of resilience in Vanuatu. Retrieved from Sydney, Australia:

Repetto, R. (1990). Deforestation in the tropics. Scientific American(4), 36-42.

Rey, D., Roberts, J., Korwin, S., Rivera, L., \& Ribet, U. (2013). A guide to understanding and implementing the UNFCCC REDD+ safeguards. Retrieved from London, United Kingdom:

Richmond, N., \& Sovacool, B. K. (2012). Bolstering resilience in the coconut kingdom: Improving adaptive capacity to climate change in Vanuatu. Bolstering resilience in the coconut kingdom: Improving adaptive capacity to climate change in Vanuatu, 50, 843848.

RNZ. (2018, 25 September). 8000 Ni-Vanuatuans working in Australia and New Zealand. RNZ. Retrieved from https://www.rnz.co.nz/international/pacific-news/367224/8000-nivanuatuans-working-in-australia-and-new-zealand

Rogelj, J., Elzen, M. D., Höhne, N., Fransen, T., Fekete, H., Winkler, H., . . Meinshausen, M. (2016). Paris Agreement climate proposals need a boost to keep warming well below $2{ }^{\circ} \mathrm{C}$. Nature, 534(7609), 631. doi:10.1038/nature18307

Rozzi, R. (2012). Biocultural ethics: recovering the vital links between the inhabitants, their habits, and habitats.(Author abstract). Environmental Ethics, 34(1), 27. doi:10.5840/enviroethics20123414 
Rudel, T., \& Roper, J. (1997). The Paths to Rain Forest Destruction: Crossnational Patterns of Tropical Deforestation, 1975-90. World Development, 25(1), 53-65. doi:10.1016/S0305-750X(96)00086-1

Sandbrook, C., Nelson, F., Adams, W. M., \& Agrawal, A. (2010). Carbon, forests and the REDD paradox. Oryx, 44, 330-334. doi:10.1017/S0030605310000475

Sayer, J., Margules, C., \& Boedhihartono, A. (2017). Will Biodiversity Be Conserved in LocallyManaged Forests? Land, 6(1), 6. doi:10.3390/land6010006

Scheyvens, R. (2014). Development fieldwork : a practical guide (2nd edition / edited by Regina Scheyvens.. ed.): London SAGE Publications Ltd.

Scheyvens, R., \& Leslie, H. (2000). Gender, ethics and empowerment: Dilemmas of development fieldwork. Women's Studies International Forum, 23(1), 119-130. doi:10.1016/S0277-5395(99)00091-6

Shandra, J. M. (2007). Economic Dependency, Repression, and Deforestation: A Quantitative, Cross-National Analysis*. Sociological Inquiry, 77(4), 543-571. doi:10.1111/j.1475682X.2007.00209.x

Smith, R. (2017). From Colonial Intrusions to 'Intimate Exclusions': Contesting Legal Title and 'Chiefly Title' to Land in Epi, Vanuatu. In Kastom, property and ideology: Land transformations in Melanesia (pp. 327- 356). ACT, Australia: ANU Press.

SommerFilms (2008, 11 May). REDD "2nd MAY REVOLT" at the UNPFII (REDD, CDM) [YouTube]. Retrieved from https://www.youtube.com/watch?v=UtORVi7GybY

Spriggs, M. (1993). Quantifying women's oppression in prehistory: the Aneityum (Vanuatu) case. Paper presented at the Women in Archaeology: A Feminist Critique. .

Stocks, A., McMahan, B., \& Taber, P. (2007). Indigenous, Colonist, and Government Impacts on Nicaragua's Bosawas Reserve.(Author abstract)(Report). Conservation Biology, 21(6), 1495. doi:10.1111/j.1523-1739.2007.00793.x

Suaalii-Sauni, T., \& Fulu-Aiolupotea, S. M. (2014). Decolonising Pacific research, building Pacific research communities and developing Pacific research tools: The case of the talanoa and the faafaletui in S amoa. Asia Pacific Viewpoint, 55(3), 331-344. doi:10.1111/apv.12061

Sumner, A., \& Tribe, M. (2004). The nature of epistemology and methodology in development studies: what do we mean by 'rigour'. Paper presented at the Development Studies Association Annual Conference.

Sunderlin, W. D., Ekaputri, A. D., Sills, E. O., Duchelle, A. E., Kweka, D., Diprose, R., . . Enright, A. (2014). The challenge of establishing REDD+ on the ground: Insights from 23 subnational initiatives in six countries (Vol. 104): CIFOR.

Sunderlin, W. D., Larson, A. M., \& Cronkleton, P. (2009). Forest tenure rights and REDD. In Realising REDD (pp. 139).

Sunderlin, W. D., Larson, A. M., Duchelle, A. E., Resosudarmo, I. A. P., Huynh, T. B., Awono, A., \& Dokken, T. J. W. D. (2014). How are REDD+ proponents addressing tenure problems? Evidence from Brazil, Cameroon, Tanzania, Indonesia, and Vietnam. 55, 37-52.

Tehan, M. (2017). The impact of climate change mitigation on indigenous and forest communities : international, national and local law perspectives on REDD+. Cambridge: Cambridge University Press.

The REDD Desk. (2013). REDD in Vanuatu Readiness Overview. Retrieved from https://theredddesk.org/countries/vanuatu

Thu, P., Scott, S., \& Van Niel, K. (2007). Gendered access to customary land in East Timor. GeoJournal, 69(4), 239-255. doi:10.1007/s10708-007-9094-8 
Tuhiwai Smith, P. L. (2012). Decolonizing Methodologies : Research and Indigenous Peoples. London: London: Zed Books.

Tunufa'I, L. (2016). Pacific Research: Rethinking the Talanoa 'Methodology'. New Zealand Sociology, 31(7), 227-239.

Tynan, L. (2020). Relationality: stories of a relational ethos in practice. Paper presented at the Development Studies: Research, Debates and Trajectories Conference, Melbourne, Australia.

UN-REDD. (2008). Framework Document. Retrieved from https://www.unredd.net/documents/foundation-documents-88/programmegovernance-2008-2015/4-un-redd-programme-framework-document-20-june-20084.html?path=foundation-documents-88/programme-governance-2008-2015

UNDP. (2019). Vanuatu Climate Change Adaptation. Retrieved from https://www.adaptationundp.org/explore/melanesia/vanuatu

Vaioleti, T. (2014). Talanoa: differentiating the Talanoa research methodology from phenomenology, narrative, Kaupapa Maori and feminist methodologies. Te Reo, 5657, 191.

Van Fossen, A. (2015). Law and political economy in Vanuatu's tax haven. Pacific Islands Monthly, 1, 157- 178.

van Kooten, G. C., Nijnik, M., \& Bradford, K. (2019). Can carbon accounting promote economic development in forest-dependent, indigenous communities? Forest Policy and Economics, 100, 68-74. doi:10.1016/j.forpol.2018.10.012

Vanuatu Constitution. Ch. 12. Retrieved from

Venuti, S. (2014). REDD+ in Papua New Guinea and the protection of the REDD+ safeguard to ensure the full and effective participation of indigenous peoples and local communities. Asia Pacific Journal of Environmental Law, 17, 131-153.

Viji, I., Napat, J., Phillips, B., Nelson, A., Hecht, B., Statz, J., . . Weaver, S. (2013). Readiness Preparation Proposal (R-PP) Vanuatu. Retrieved from Port Vila, Vanuatu:

VNSO. (2017). Post Pam Mini Census Report. Retrieved from https://vnso.gov.vu/index.php/component/advlisting/?view=download\&fileld $=4542$

VPAI. (2002). Loru Rainforest Protected Area. Retrieved from http://www.positiveearth.org/vpai/loru protected area.htm

Wa Thiong'o, N. (1992). Decolonising the mind: The politics of language in African literature: East African Publishers.

Wallbott, L., \& Florian-Rivero, E. M. (2018). Forests, rights and development in Costa Rica: a Political Ecology perspective on indigenous peoples' engagement in REDD+. Conflict, Security \& Development, 18(6), 493-519. doi:10.1080/14678802.2018.1532643

Warren-Rhodes, K., Schwarz, A.-M., Boyle, L. N., Albert, J., Agalo, S. S., Warren, R., . . Duke, N. (2011). Mangrove ecosystem services and the potential for carbon revenue programmes in Solomon Islands. Envir. Conserv., 38(4), 485-496. doi:10.1017/S0376892911000373

Warrick, O. (2009). Ethics and methods in research for communitybased adaptation: reflections from rural Vanuatu. Participatory learning and action, 60(1), 76-87.

Watson, J. E., Evans, T., Venter, O., Williams, B., Tulloch, A., Stewart, C., . . Salazar, A. (2018). The exceptional value of intact forest ecosystems. Nature ecology evolution, 2(4), 599.

Weaver, S. (2011). Draft Fiji REDD+ Carbon Financing Guidelines. Retrieved from Takaka, New Zealand: http://www.carbonpartnership.co.nz/redd.html 
Weaver, S. (2015). Practitioner perspective on REDD: Commercial challenges in project-based rainforest protection financing in the Asia Pacific region. Asia Pacific Viewpoint, 56(1), 140-152. doi:10.1111/apv.12090

White, A., \& Martin, A. (2002). Who owns the world's forests. Retrieved from Washington, D.C.:

Whyte, K. (2013). Justice forward: Tribes, climate adaptation and responsibility. An Interdisciplinary, International Journal Devoted to the Description, Causes and Implications of Climatic Change, 120(3), 517-530. doi:10.1007/s10584-013-0743-2 


\section{List of Interviews}

Listed in the order interviews were conducted

Structured

1. Toli Nancy Dan 29 June 2019

2. Viran Dan 29 June 2019

3. Tounefil Ser 29 June 2019

4. Kal Ser, 29 June 2019

5. Janice Fred 29 June 2019

6. Diana Kepsen 29 June 2019

7. Rachel Ser 29 June 2019

8. Kaltapang Sam 29 June 2019

9. Jenny Sam 29 June 2019

10. Samuel Dan 29 June 2019

11. Nelly Beter 29 June 2019

12. Rhonda Ser 29 June 2019

13. Roseneth Moses 29 June 2019

14. Rose Moses 29 June 2019

15. Serah Moses 29 June 2019

16. Tommy Moses 29 June 2019

17. Annia Moses 30 June 2019

18. Leimanu Bauivatole 30 June 2019

19. Lina Moses 30 June 2019

20. John Moses 30 June 2019

21. Junny Moses 30 June 2019

22. Tony Moses 30 June 2019

23. Kalem Moses 30 June 2019

24. Anna Fred 30 June 2019

25. Tamara Fred 30 June 2019

26. Laura Ser 30 June 2019

27. Losaline Fred 30 June 2019

28. Rosito Moses 30 June 2019

29. Lency Sam 30 June 2019

30. Fiona Ser 30 June 2019

31. Helen Dan 30 June 2019

32. Orpah Moses 30 June 2019

33. Oli Fred 30 June 2019

34. Leisaly Fred 30 June 2019

35. Kaltapang Fred 30 June 2019

36. Calros Ser 30 June 2019

37. Lasario Ser $\quad 30$ June 2019

38. Clarence Dan 30 June 2019

Semi-Structured

39. Serge Warakar and Warakar Ser 30 June 2019

40. Anjali Nelson 15 August 2019

41. Sean Weaver 16 August 2019 


\section{Appendices}

Appendix A Social Impact Survey Summary Statistics

\begin{tabular}{|c|c|c|c|c|c|c|c|c|c|c|c|c|c|}
\hline Question & Unit & $\begin{array}{l}\text { Female } \\
\text { Baseline }\end{array}$ & $\begin{array}{l}\text { Female } \\
2019\end{array}$ & Change & $\begin{array}{l}\text { Male } \\
\text { Baseline }\end{array}$ & $\begin{array}{l}\text { Male } \\
2019\end{array}$ & Change & $\begin{array}{l}\text { Youth } \\
\text { Baseline }\end{array}$ & $\begin{array}{l}\text { Youth } \\
2019\end{array}$ & Change & $\begin{array}{l}\text { Populatio } \\
\text { n } \\
\text { Baseline }\end{array}$ & $\begin{array}{l}\text { Populatio } \\
\text { n } 2019\end{array}$ & Change \\
\hline How often do you buy food & Times/ week & 4.99 & 5.06 & $2 \%$ & 4.28 & 3.88 & $-9 \%$ & 3.58 & 3.33 & $-7 \%$ & 4.64 & 4.59 & $-1 \%$ \\
\hline How big is your garden? & Hectare & 0.75 & 0.39 & $-49 \%$ & 0.66 & 0.38 & $-43 \%$ & 0.38 & 0.33 & $-13 \%$ & 0.71 & 0.38 & $-46 \%$ \\
\hline $\begin{array}{l}\text { How often do you eat from } \\
\text { your garden? }\end{array}$ & Times/week & 5.25 & 5.92 & $13 \%$ & 5.74 & 5.81 & $1 \%$ & 4.85 & 5.33 & $10 \%$ & 5.49 & 5.88 & $7 \%$ \\
\hline $\begin{array}{l}\text { How often do you eat food } \\
\text { from the forest? }\end{array}$ & Times/month & 2.80 & 8.36 & $199 \%$ & 2.00 & 2.33 & $17 \%$ & 3.23 & 2.17 & $-33 \%$ & 2.41 & 5.95 & $146 \%$ \\
\hline $\begin{array}{l}\text { How much do you make } \\
\text { selling food? }\end{array}$ & Vatu/ month & 10,636 & 8917 & $-16 \%$ & 0 & 9938 & \#DIV/0! & 6875 & 9000 & $31 \%$ & 7313 & 9325 & $28 \%$ \\
\hline Do you ever run out of food? & $\%$ yes & $0 \%$ & $4 \%$ & $100 \%$ & $0 \%$ & $0 \%$ & $0 \%$ & $0 \%$ & $0 \%$ & $0 \%$ & $0 \%$ & $3 \%$ & \#DIV/0! \\
\hline Do you ever run out of water? & $\%$ yes & $100 \%$ & $58 \%$ & $-42 \%$ & $100 \%$ & $75 \%$ & $-25 \%$ & $100 \%$ & $83 \%$ & $-17 \%$ & $100 \%$ & $65 \%$ & $-35 \%$ \\
\hline $\begin{array}{l}\text { For how many days do you } \\
\text { run out of water? }\end{array}$ & Days/year & & 32.00 & & & 35.33 & & & 50.60 & & & 33.54 & \\
\hline $\begin{array}{l}\text { What is your monthly } \\
\text { income? }\end{array}$ & Vatu/ month & 17,750 & 24,479 & $38 \%$ & 11,591 & 23,844 & $106 \%$ & 4,569 & 16,833 & $268 \%$ & 14,750 & 24,225 & $64.24 \%$ \\
\hline $\begin{array}{l}\text { Do you have the opportunity } \\
\text { to access REDD+ finances? }\end{array}$ & $\%$ yes & $75 \%$ & $96 \%$ & $28 \%$ & $89 \%$ & $81 \%$ & $-9 \%$ & $85 \%$ & $67 \%$ & $-21 \%$ & $82 \%$ & $90 \%$ & $10 \%$ \\
\hline $\begin{array}{l}\text { Do you trust the REDD+ } \\
\text { enterprise? }\end{array}$ & $\%$ yes & $100 \%$ & $100 \%$ & $0 \%$ & $100 \%$ & $100 \%$ & $0 \%$ & $100 \%$ & $100 \%$ & $0 \%$ & $100 \%$ & $100 \%$ & $0.00 \%$ \\
\hline Hamas yu drink kava? & Times/ week & 0.00 & 0.01 & \#DIV/0! & 0.53 & 0.86 & $63 \%$ & 0.00 & 0.50 & \#DIV/0! & 0.26 & 0.33 & $29 \%$ \\
\hline Hamas yu smoke cigarette? & Times/ week & 0.00 & 0 & $0 \%$ & 1.05 & 1.79 & $70 \%$ & 0.00 & 1.67 & \#DIV/0! & 0.51 & 0.68 & $312 \%$ \\
\hline Hamas yu drink alcohol? & Times/ week & 0.00 & 0 & $0 \%$ & 0.08 & 0.16 & $100 \%$ & 0.00 & 0.29 & \#DIV/0! & 0.04 & 0.06 & $0.05 \%$ \\
\hline $\begin{array}{l}\text { How many times do you leave } \\
\text { Khole village? }\end{array}$ & Times/ week & 1.38 & 1.51 & $10 \%$ & 1.22 & 1.76 & $44 \%$ & 0.99 & 3.33 & $236 \%$ & 1.30 & 1.61 & $234 \%$ \\
\hline Hours cooking & $\begin{array}{l}\text { Average hours/ } \\
\text { day }\end{array}$ & 2.40 & 1.31 & $-45 \%$ & 0.26 & 0.97 & $267 \%$ & 1.00 & 0.37 & $-63 \%$ & 1.36 & 1.17 & $-14 \%$ \\
\hline Hours on household chores & $\begin{array}{l}\text { Average hours/ } \\
\text { day }\end{array}$ & 2.08 & 2.43 & $17 \%$ & 0.63 & 0.83 & $33 \%$ & 1.15 & 0.67 & $-42 \%$ & 1.32 & 1.80 & $36 . \%$ \\
\hline Hours gardening/ copra & $\begin{array}{l}\text { Average hours/ } \\
\text { day }\end{array}$ & 5.08 & 5.65 & $11 \%$ & 5.63 & 5.67 & $1 \%$ & 3.88 & 4.00 & $3 \%$ & 5.35 & 5.66 & $6 \%$ \\
\hline Hours resting & $\begin{array}{l}\text { Average hours/ } \\
\text { day }\end{array}$ & 2.05 & 2.04 & $0 \%$ & 5.42 & 2.87 & $-47 \%$ & 5.69 & 3.58 & $-37 \%$ & 3.69 & 2.37 & $-36 \%$ \\
\hline
\end{tabular}


MEMORANDUM

Phone

Email

\begin{tabular}{l|l}
\hline TO & Bridget Payne \\
\hline FROM & Dr Judith Loveridge, Convenor, Human Ethics Committee \\
\hline
\end{tabular}

\begin{tabular}{l|l}
\hline DATE & 9 May 2019 \\
\hline PAGES & 1 \\
\hline
\end{tabular}

\begin{tabular}{l|l}
\hline SUBJECT & $\begin{array}{l}\text { Ethics Approval } \\
\text { Number: } 27391\end{array}$ \\
& $\begin{array}{l}\text { Title: What is the trade-off between scale and justice for a } \\
\text { forest management project in the Pacific? An appreciative } \\
\text { inquiry into the community-owned REDD+ project in Loru, } \\
\text { Vanuatu }\end{array}$ \\
\hline
\end{tabular}

Thank you for your application for ethical approval, which has now been considered by the Human Ethics Committee.

Your application has been approved from the above date and this approval is valid for three years. If your data collection is not completed by this date you should apply to the Human Ethics Committee for an extension to this approval.

Best wishes with the research.

Kind regards,

\section{REDACTED}

Judith Loveridge

Convenor, Victoria University of Wellington Human Ethics Committee 


\section{Loru Social Impact Survey 2019}

Surveyor comments

Question-specific

- 24 hour clock

- This was difficult to get an accurate measure of as participants guessed much time they spent on each task. Might be better to ask them to recall a certain day (i.e. yesterday)

- Would be beneficial at the beginning to have a clear definition of what fell into each category i.e. does caring for children count as household chores, is attending church 'rest'

- Extra categories to add: working, separate gardening and working on copra. This could measure any increase in gardening or working

- Participants tended to work in copra more during certain seasons, and garden consistently throughout the year, so the time of year could affect results.

- Would be interesting to add a question about whether the participants had bought a new water tank as another measure of water security

- Asking whether participants sometimes had more water than they needed was a redundant question, as they always did during the wet season and the question was complicated to explain

- Household/ individual income was a hard concept to explain and define. Villagers earned income from a variety of sources that wasn't necessarily consistant, and it took a little while to understand and calculate monthly income. Men and women shared work on the garden, but mostly women sold the food at the market, so there isn't a clear division of individual income.

- Size of garden is a rough measure as participants did not know the size of their garden plots, and often had several small gardens

- It was difficult to ask if any children had been kept at home due to the cost of school fees as many children finish school at year 10 for a variety of reasons (e.g. to work). I should have asked more explicitly about children of school age (up to 18).

General comments

- Results get more accurate at later surveys as I had a better idea of what answers to expect and what may have been from misinterpreting my question. However this also could have meant I pushed participants to answer as I expected e.g. when Diana told me in previous years she'd run out of water but not this year I said something like "oh because you've bought a water tank" as she was staying with her mother who told me they'd just bought a tank. However, in a later conversation Diana told me she misunderstood and in her home they hadn't bought a water tank recently. 
- I felt participants were embarrassed to answer drug-use questions honestly e.g. they laughed when I asked if they drank kava and a few times they would tell me one answer and a family member would laugh and say a higher number. Participants didn't seem bothered by other questions such as how much they earned.

- There were usually other people around during the surveys. Rhonda and Serge helped me translate, and children and other family members were often around. This may have affected the answers with participants answering a certain way because others are listening or copying others' answers. Mothers were often looking after young children, which could distract from the interviews, and meant I tried to keep the surveys short.

- The survey was conducted during term time so there weren't as many young people around than the baseline survey (conducted during holidays). To survey 40 people I had to survey everyone in the village at the time so it was hard to meet additional demographic requirements.

- I was able to interview most of the 40 participants in three days. During the week the village are out at the gardens for most of the day. So I found it easier to interview on the weekend and a rainy day. 


\begin{tabular}{|c|c|c|}
\hline REPUPLIQUE DE VANUATU & REPUBLIC OF VANUATU \\
DEPARTMENT DES FORÊTS & & \\
& DEPARTMENT OF \\
SAC POSTAL PRIVÉ 9064 & Tel: $23171 / 5333460$ & FRIVATE MAIL BAG 9064 \\
PORT VILA & Fax: Int +67823856 & PORT VILA \\
VANUATU & & VANUATU \\
\hline
\end{tabular}

30 April 2019

\section{To Whom it Concerns}

On behalf of the Department of Forests Vanuatu I would like to extend an invitation to Ms Bridget Payne of Victoria University, Wellington to undertake a short research task as part of her Masters Degree.

Bridget will be visiting Vanuatu to undertake community and organisational consultations around the impact of Vanuatu's pilot REDD+ project, the Loru Carbon Project on the island of Espiritu Santo. Her findings will support our national efforts towards the development of a forest carbon program for Vanuatu.

Please contact me should you have any queries.

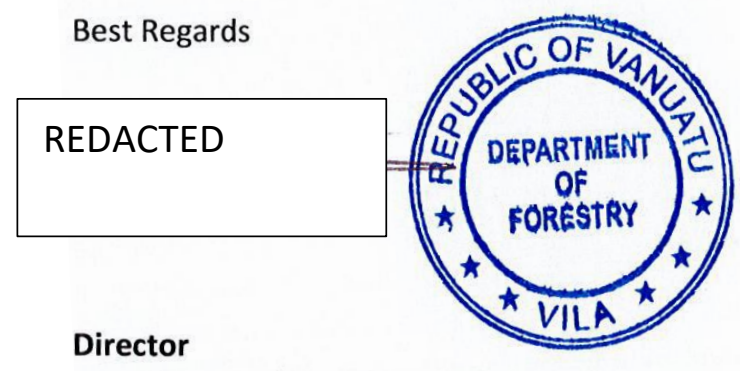

Department of Forests 


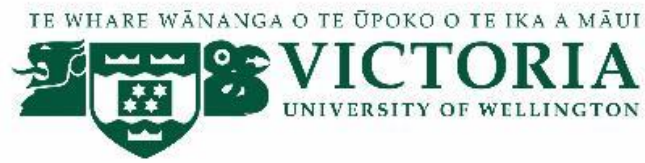

\section{Forest carbon \& community: A case study of the Loru project in Espiritu Santo, Vanuatu. INFORMATION SHEET FOR INTERVIEW PARTICIPANTS}

You are invited to take part in this research. Please read this information before deciding whether or not to take part. If you decide to participate, thank you. If you decide not to participate, thank you for considering this request.

\section{Who am I?}

My name is Bridget Payne and I am a Masters student in Development Studies at Victoria University of Wellington. This research project is work towards my thesis.

\section{What is the aim of the project?}

This project will study the Loru forest project. The research will look at how the project affects the lives of the local forest community, so future projects can better understand how they can be run to protect and improve the lives of the local community.

This research has been approved by the Victoria University of Wellington Human Ethics Committee (application reference number: 27391)

\section{How can you help?}

You have been invited to participate because you are a part of the Loru forest project. If you agree to take part I will interview you in your home. I will ask you questions about your involvement with Loru. The interview will take half an hour. I will audio record the interview with your permission and write it up later. You can choose to not answer any question or stop the interview at any time, without giving a reason. You can withdraw from the study by contacting me at any time before 1 September 2019. If you withdraw, the information you provided will be destroyed or returned to you.

\section{What will happen to the information you give?}

This research is not confidential, and you could be named in the final report.

Only my supervisors, the transcriber (who will be required to sign a confidentiality agreement) and I will read the notes or transcript of the interview. The interview transcripts, summaries and any recordings will be kept securely and destroyed on 3 March 2023. 


\section{What will the project produce?}

The information from my research will be used in my Masters report and academic publications or conferences.

\section{If you accept this invitation, what are your rights as a research participant?}

You do not have to accept this invitation if you don't want to. If you do decide to participate, you have the right to:

- $\quad$ choose not to answer any question;

- $\quad$ ask for the recorder to be turned off at any time during the interview;

- $\quad$ withdraw from the study before 1 September 2019;

- $\quad$ ask any questions about the study at any time;

- $\quad$ receive a copy of your interview recording;

- $\quad$ receive a copy of your interview transcript;

- $\quad$ read over and comment on a written summary of your interview;

- be able to read any reports of this research by emailing the researcher to request a copy.

If you have any questions or problems, who can you contact?

If you have any questions, either now or in the future, please feel free to contact either:

Student:

Name: Bridget Payne

University email address:

bridget.payne@vuw.ac.nz

\section{Supervisor:}

Name: Warwick Murray

Role: Professor

School: School of Geography, Environment and Earth Sciences

REDACTED

\section{Human Ethics Committee information}

If you have any concerns about the ethical conduct of the research you may contact the Victoria University HEC Convenor: Dr Judith Loveridge. Email hec@vuw.ac.nz or telephone +64REDACTED 
Forest carbon \& community: A case study of the Loru project in Espiritu Santo, Vanuatu.

\section{CONSENT TO INTERVIEW}

This consent form will be held for 5 years.

Researcher: Bridget Payne, School of Geography, Environment and Earth Sciences, Victoria University of Wellington.

I have read the Information Sheet and the project has been explained to me. My questions have been answered to my satisfaction. I understand that I can ask further questions at any time.

I agree to take part in an audio recorded interview.

understand that:

I may withdraw from this study at any point before 1 September 2019, and any information that I have provided will be returned to me or destroyed.

The identifiable information I have provided will be destroyed on 3 March 2023.

Any information I provide will be kept confidential to the researcher, research assistant, supervisor and the transcriber.

I understand that the results will be used for a Masters report and academic publications or presented to conferences.

I would like for my quotes in the report to use: My real name A pseudonym

I would like a copy of the recording of my interview: Yes No

I would like a copy of the transcript of my interview: Yes No

I would like a summary of my interview: $\quad$ Yes No

I would like to receive a copy of the final report and Yes No

have added my email address below.

Signature of participant:

Name of participant:

Date:

Contact details: 
Appendix G Ser-Thiac Reconciliation Report 1 July- 31 September 2018

\section{RECONCILIATION REPORT}

QUARTER: $31^{\text {st }}$ September 2018

\begin{tabular}{|c|c|}
\hline Operational Account & 190,000 ut \\
\hline Safety Account & $107,000^{N T}$ \\
\hline Community Benefit Account & $107,000^{\pi}$ \\
\hline
\end{tabular}

Expenditiure

\begin{tabular}{|c|c|}
\hline Operational Account & $258,920^{\mathrm{VT}}$ \\
\hline Safety Account & - \\
\hline Community Benefit Account & - \\
\hline Total Expenditures & $258,920^{\mathrm{NT}}$ \\
\hline
\end{tabular}

\begin{tabular}{|c|c|}
\hline Actual bank balance as at & $31^{\text {st }}$ of September2018 \\
\hline Operational Account & $54,434 \mathrm{VT}$ \\
\hline Safety Account & $1,003,183 \mathrm{VT}$ \\
\hline Community Benefit Account & $516,104 \mathrm{VT}$ \\
\hline Total Funds & $1,573,721 \mathrm{vm}$ \\
\hline
\end{tabular}

